\title{
International Union of Basic and Clinical Pharmacology. XCI. Structure, Function, and Pharmacology of Acid-Sensing Ion Channels and the Epithelial $\mathrm{Na}^{+}$Channel
}

\author{
Stephan Kellenberger and Laurent Schild \\ Département de Pharmacologie et de Toxicologie, Université de Lausanne, Lausanne, Switzerland
}

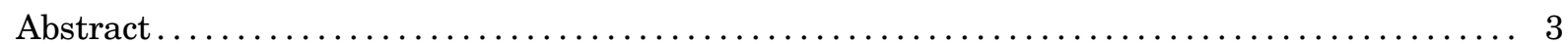

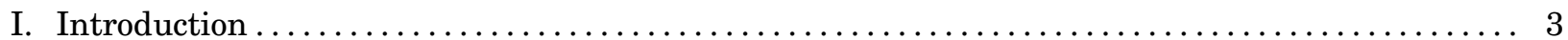

II. Phylogenetic and Sequence Comparison ................................... 3

III. Tissue Distribution, Cellular Functions, and Physiologic and Pathologic Roles............ 4

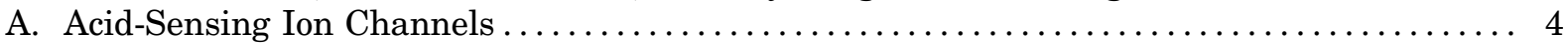

1. Tissue Distribution and Cellular Functions. .......................... 4

2. Physiologic and Pathologic Roles. ................................ 4

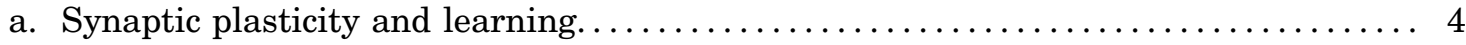

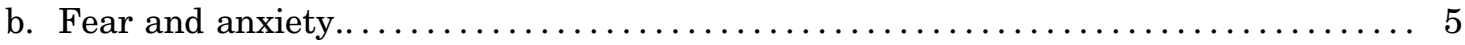

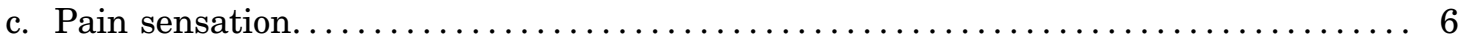

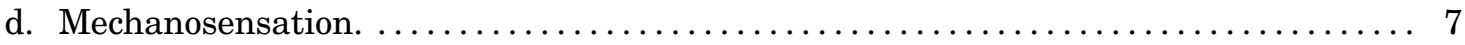

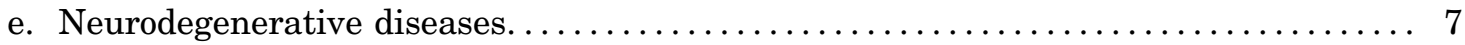

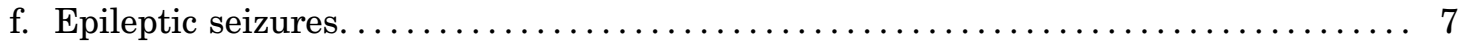

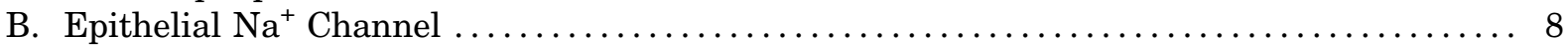

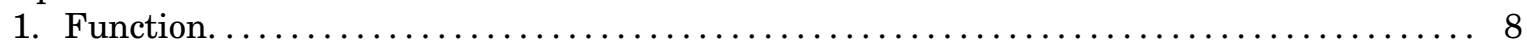

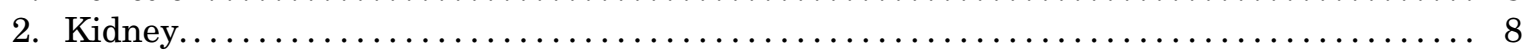

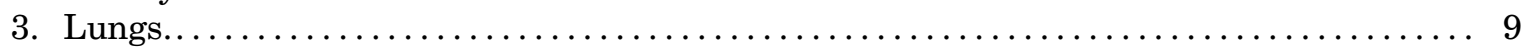

4. Gastrointestinal Tract.......................................... 9

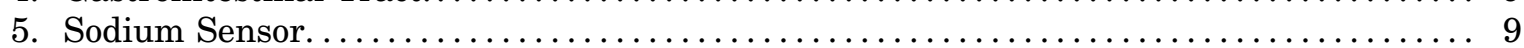

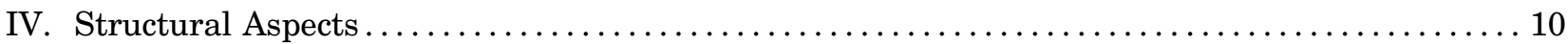

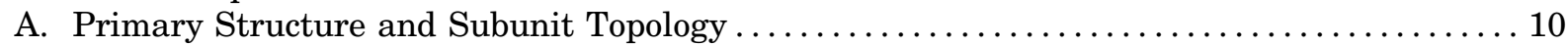

1. Subunit Organization of Epithelial $\mathrm{Na}^{+}$Channel and Acid-Sensing Ion Channels. . . . . 10

2. Origin and Experimental Conditions of Different Crystal Structures................ 10

3. Differences between the Open and the Desensitized Structure and between Different Published Structures. ......................................... 11

4. Difference and Similarities between the Acid-Sensing Ion Channels and Epithelial $\mathrm{Na}^{+}$Channel Subunit Organization. ............................. 11

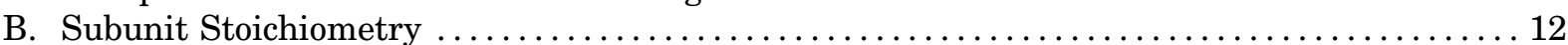

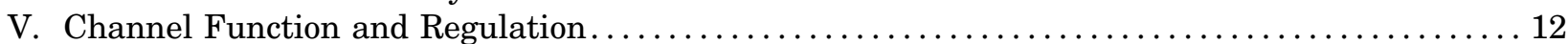

A. Acid-Sensing Ion Channels . . . . . . . . . . . . . . . . . . . . . . . . . . . . . . . . 12

1. Channel Gating and Ion Selectivity................................... 12

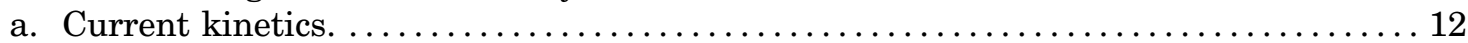

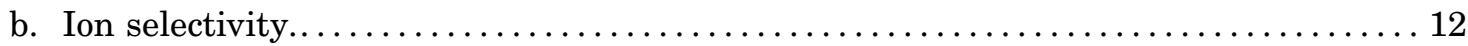

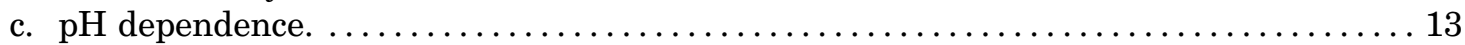

d. Coupling of activation and steady-state desensitization. $\ldots \ldots \ldots \ldots \ldots \ldots \ldots \ldots \ldots$

Research in the authors' laboratories was supported by Swiss National Science Foundation [Grants 310030_135378 (to L.S.) and 310030_135542 and 31003A_153419 (to S.K.)].

Address correspondence to: Stephan Kellenberger, Département de Pharmacologie et de Toxicologie, Rue du Bugnon 27, Université de Lausanne, CH-1005 Lausanne, Switzerland. E-mail: Stephan.Kellenberger@unil.ch dx.doi.org/10.1124/pr.114.009225. 


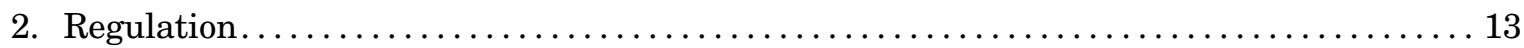

a. Regulation by protein-protein interactions................................ 14

b. Regulation by ions, small molecules, and proteins. ..................... 14

i. Calcium and Other Divalent or Polyvalent Cations...................... 14

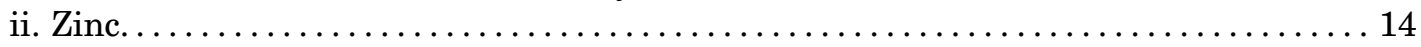

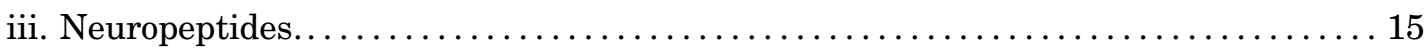

iv. Redox Reagents and Free Radicals..................................... 15

v. Arachidonic Acid. ............................................... 17

vi. G Protein-Coupled Receptors. ................................... 17

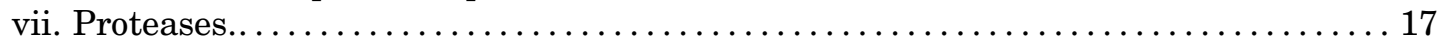

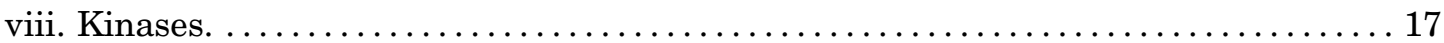

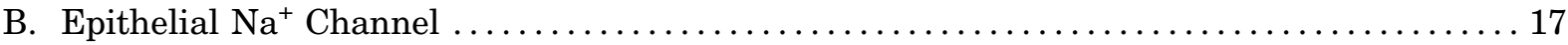

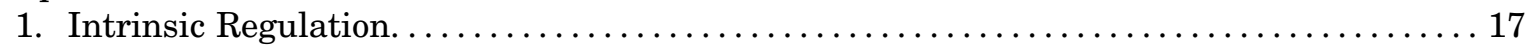

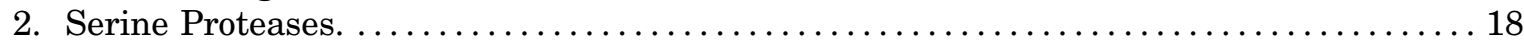

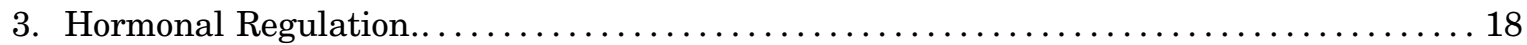

C. Structure-Function Relationship of Acid-Sensing Ion Channels and Epithelial $\mathrm{Na}^{+}$

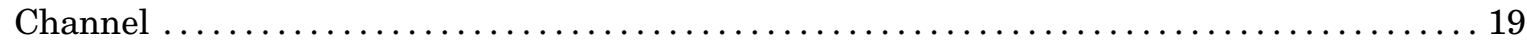

1. The Acidic Pocket and Other Proton-Sensing Sites of Acid-Sensing Ion Channels. ..... 19

2. The Finger-A Determinant of Subfamily-Specific Activation Mechanisms? ......... 19

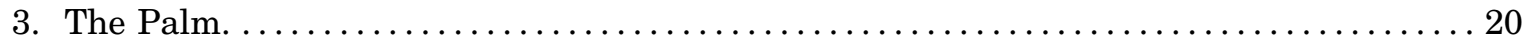

4. The $\beta$-Turn and the Extracellular Vestibule-at the Interface between the

Extracellular and Transmembrane Domains. ............................. 21

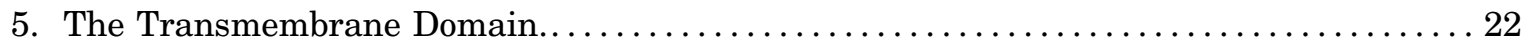

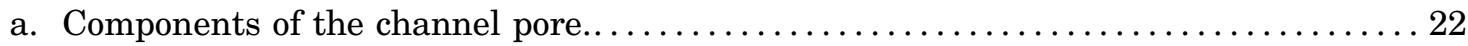

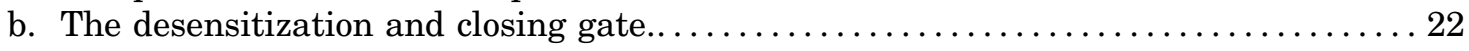

c. The degenerin residue and the amiloride binding site...................... 22

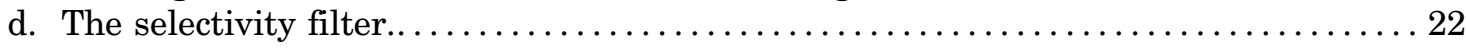

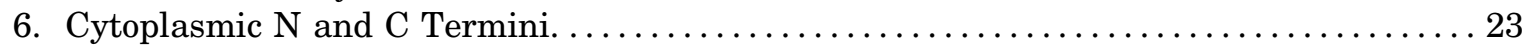

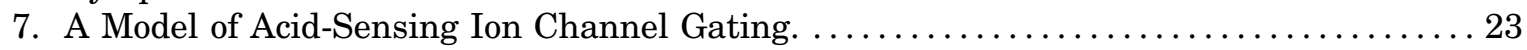

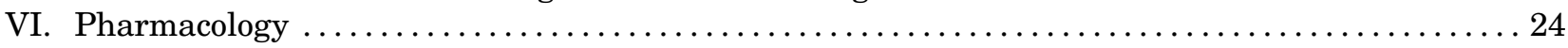

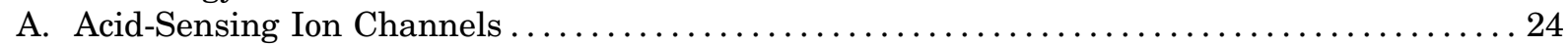

1. Small molecules............................................... 24

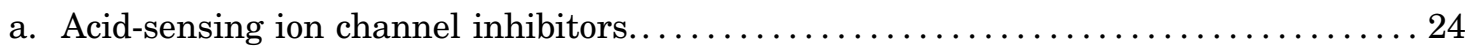

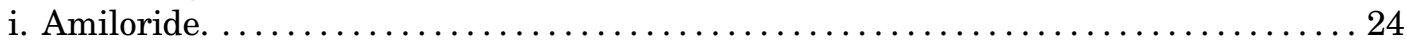

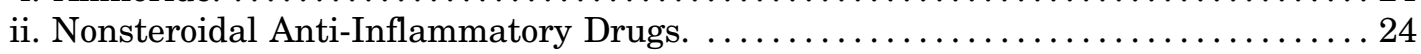

iii. Other Small-Molecule Inhibitors. . . . . . . . . . . . . . . . . . . . . . . . . . 25

b. The acid-sensing ion channel modulator 2-guanidine-4-methylquinazoline. ....... 25

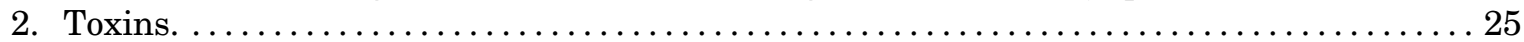

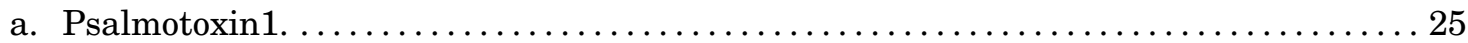

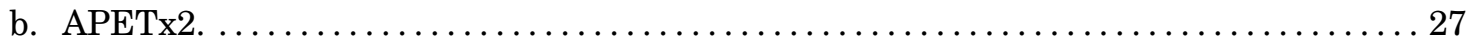

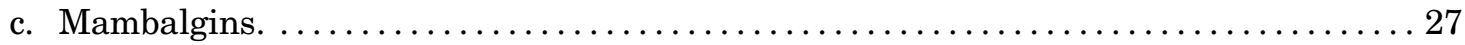

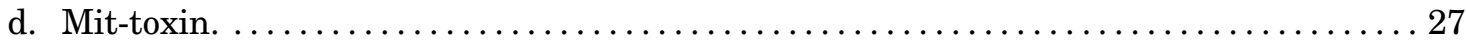

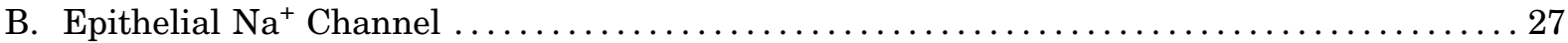

1. Direct Epithelial $\mathrm{Na}^{+}$Channel Antagonists. ........................... 27

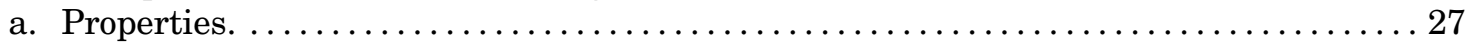

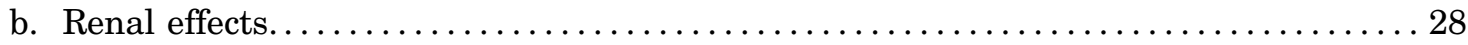

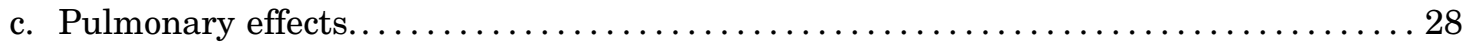

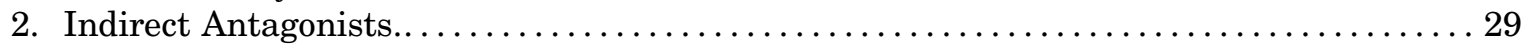

\begin{abstract}
ABBREVIATIONS: AA, arachidonic acid; ASDN, aldosterone-sensitive distal nephron; ASIC, acid-sensing ion channel; ASL, airway surface liquid; BASIC, bile acid-sensitive ion channel; BDNF, brain-derived neurotrophic factor; CAP, channel activating protease; cASIC1, chicken ASIC1; CCD, cortical collecting duct; CF, cystic fibrosis; CFTR, cystic fibrosis transmembrane conductance regulator; CNS, central nervous system; CNT, connecting tubule; DEG, degenerin; DRG, dorsal root ganglion; ENaC, epithelial Na ${ }^{+}$channel; ET-1, endothelin-1; GAS, GlyAla-Ser; GMQ, 2-guanidine-4-methylquinazoline; KO, knockout; LTP, long-term potentiation; MitTx, Mit-toxin; MS, multiple sclerosis; NAc, nucleus accumbens; NSAIDs, nonsteroidal anti-inflammatory drugs; PcTx1, Psalmotoxin1; PDB, protein data bank; $\mathrm{pH}_{50}$, $\mathrm{pH}$ of half-maximal activation; PHA-1, pseudohypoaldosteronism type 1; PICK1, protein interacting with C kinase; PKA, protein kinase A; PKC, protein kinase C, PNS, peripheral nervous system; S3969, $N$-(2-hydroxyethyl)-4-methyl-2-(4-methyl-1H-indol-3-ylthio)pentanamide; SSD, steady-state desensitization; TM, transmembrane segment; V2R, vasopressin receptor type 2; WIN55,212-2, (R)-(+)-[2,3-dihydro-5-methyl-3-(4-morpholinylmethyl)pyrrolo[1,2,3-de]-1,4-benzoxazin-6-yl]-1-naphthalenylmethanone.
\end{abstract}




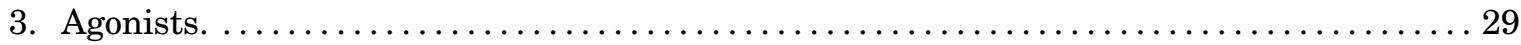

C. Bile Acid-Sensitive Ion Channel. . . . . . . . . . . . . . . . . . . . . . . . . . . . . . . . 29

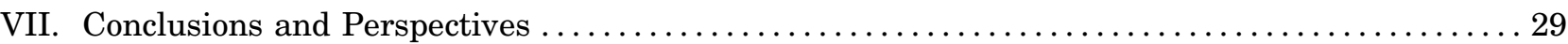

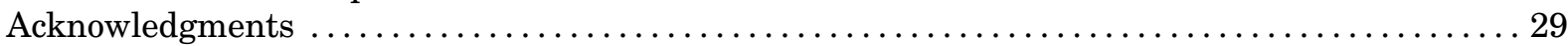

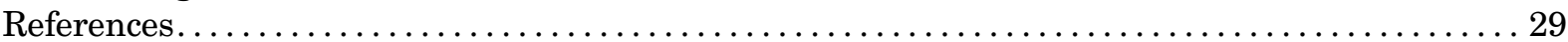

\begin{abstract}
The epithelial $\mathrm{Na}^{+}$channel $(\mathrm{ENaC})$ and the acid-sensing ion channels (ASICs) form subfamilies within the $\mathrm{ENaC} /$ degenerin family of $\mathrm{Na}^{+}$channels. ENaC mediates transepithelial $\mathrm{Na}^{+}$transport, thereby contributing to $\mathrm{Na}^{+}$homeostasis and the maintenance of blood pressure and the airway surface liquid level. ASICs are $\mathrm{H}^{+}$-activated channels found in central and peripheral neurons, where their activation induces neuronal depolarization. ASICs are involved in pain sensation, the expression of fear, and neurodegeneration after ischemia, making them potentially interesting drug targets. This review summarizes the biophysical properties, cellular
\end{abstract}

functions, and physiologic and pathologic roles of the ASIC and ENaC subfamilies. The analysis of the homologies between ENaC and ASICs and the relation between functional and structural information shows many parallels between these channels, suggesting that some mechanisms that control channel activity are shared between ASICs and ENaC. The available crystal structures and the discovery of animal toxins acting on ASICs provide a unique opportunity to address the molecular mechanisms of $\mathrm{ENaC}$ and ASIC function to identify novel strategies for the modulation of these channels by pharmacologic ligands.

\section{Introduction}

The epithelial $\mathrm{Na}^{+}$channel $(\mathrm{ENaC})$ and acid-sensing ion channels (ASICs) represent the mammalian subfamilies of the ENaC/degenerin (DEG) family of ion channels that was discovered at the beginning of the nineties. $\mathrm{ENaC}$ has a well established role in $\mathrm{Na}^{+}$ reabsorption in the distal nephron, in the distal colon, and in the control of the liquid film on airway epithelia. ENaC is inhibited by the drugs amiloride and triamterene that are clinically used as potassiumsparing diuretics. ASICs are neuronal channels that were discovered based on their primary structure homology to ENaC. Many of their physiologic and pathologic roles, which include pain sensation, synaptic plasticity, expression of fear, and neurodegeneration after ischemia, have been elucidated in genetically modified animal models during the last years and make them potentially interesting drug targets. Several animal toxins act on ASICs. Currently, there are however no ASIC drugs in clinical use. Crystal structures of ASICs, but not other ENaC/DEG family members, have been published. We review here the physiologic and pathologic roles of $\mathrm{ENaC}$ and ASICs, their structural organization, functional properties, and regulation. Functional and structural parallels and differences are discussed in the perspective of $\mathrm{ENaC}$ and ASICs as targets for pharmacological ligands. Other recent reviews cover relevant aspects of ASIC and $\mathrm{ENaC}$ function in more detail than this review: physiologic and pathologic roles of ASICs (Wemmie et al., 2013), regulation of ASIC function (Chu et al., 2011), physiology and regulation of $\mathrm{ENaC}$ (Palmer et al., 2012; Rossier, 2014), and ENaC's role in cystic fibrosis (Hobbs et al., 2013). Information on ASIC and ENaC properties and pharmacology can be found in the IUPHAR/BPS Guide to PHARMACOLOGY (www.guidetopharmacology. org/GRAC/FamilyDisplayForward?familyId=118; and
www.guidetopharmacology.org/GRAC/FamilyDisplayForward?familyId=122, respectively).

\section{Phylogenetic and Sequence Comparison}

The phylogenetic tree in Fig. 1 is based mainly on sequences of $\mathrm{ENaC}$ and ASICs. Because this review focuses on the mammalian $\mathrm{ENaC}$ and ASICs, the large Drosophila and Caenorhabditis elegans subfamilies each are represented by only one member, pickpocket and MEC-4, respectively. In addition, the peptidegated $\mathrm{FaNaC}$ of Helix aspersa is included. The four ENaC subunits are encoded by the genes SCNN1A-D, whereas the ASIC subunits are encoded by ACCN1-4. The mammalian hiNaC (human intestine $\mathrm{Na}^{+}$channel) and its rat/mouse ortholog BLINaC (brain-liver-intestine amiloride-sensitive $\mathrm{Na}^{+}$channel), whose names refer to their main sites of expression, have recently been renamed to BASIC for "bile acid-sensitive ion channel" after the discovery of their activation by bile acids (Wiemuth et al., 2012; Lefevre et al., 2014). BASIC has a slightly higher sequence homology to ASICs than to ENaC, is encoded by ACCN5, and also has been called ASIC5 despite the fact that it is not activated by protons and shares only $\sim 30 \%$ sequence homology with ASICs. ENaC and ASIC genes have in the meantime been cloned from many different species. For clarity we include in this phylogenetic tree mostly the human and rat sequences and, in addition, some fish ASIC sequences, which were used for functional studies, chicken ASIC1, from which the published crystal structures are derived, as well as Xenopus laevis $\mathrm{ENaC}$ sequences. ASIC genes have different splice variants, leading to currently at least 8 mammalian subunits, ASIC1a and -1b; ASIC2a and -2b; ASIC3a, -3b, and -3c (only in humans, in other organisms there is only one ASIC3), and ASIC4. Because of the cloning history, most ASICs originally had different names and were later renamed (Kellenberger 


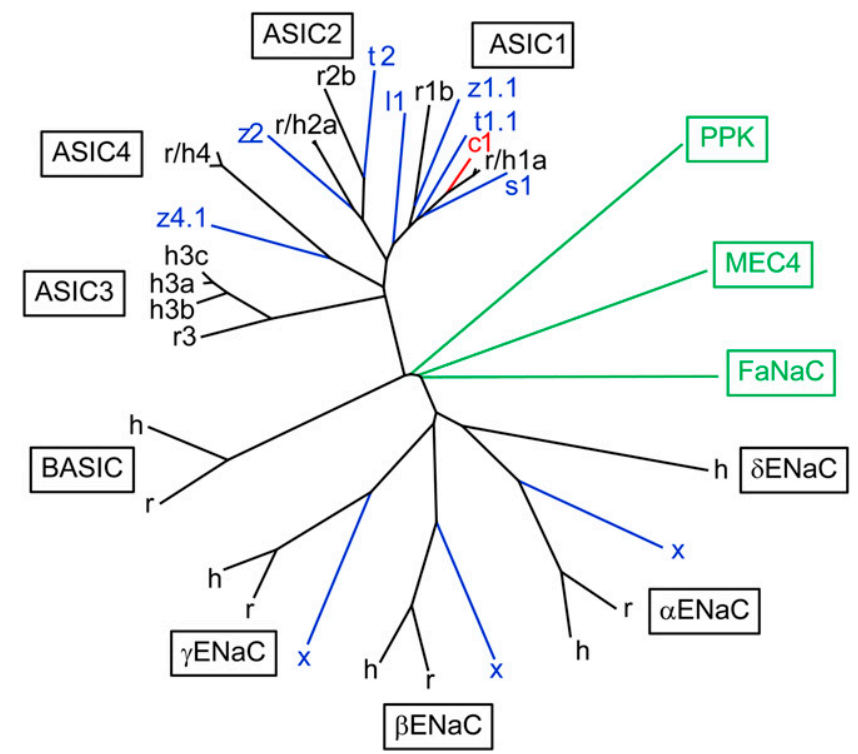

Fig. 1. Phylogenetic tree. Protein sequences of ENaC, ASICs, and members representing other ENaC/DEG subfamilies, Drosophila pickpocket (PPK), the C. elegans DEG MEC4, and the peptide-gated FaNaC of H. aspersa (shown in green) were aligned by using the ClustalW algorithm. In addition, the bile acid-sensing ion channel, BASIC (also known as hINaC or BLINaC) is shown. Mammalian ENaC, ASIC, and BASIC are shown in black, chicken ASIC in red, and other ENaC subunits and ASICs in blue. The species are indicated with single letters, c, chicken; h, human; l, lamprey; r, rat; s, shark; t, toad fish; $\mathrm{x}$, Xenopus; z, zebra fish.

and Schild, 2002; Alexander et al., 2013). Within the $\mathrm{ENaC}$ subfamily, the sequence identity is $\sim 30 \%$ for the different subunits, and within mammalian ASIC1-4, the sequence identity is $45-60 \%$. Within the ENaC subfamily, the two branches $\alpha-\delta$ and $\beta-\gamma$ can be distinguished. The homology between human and rat orthologs is close to $100 \%$ for ASIC1, -2 , and -4 ; $83 \%$ for ASIC3; and $~ 85 \%$ for $\mathrm{ENaC}$ subunits. Chicken ASIC1 shares $\sim 90 \%$ sequence identity with ASIC1a and $74 \%$ with ASIC1b. A recent study of the evolution of the ENaC/DEG genes based on genomic data indicated that ENaC/DEG genes exist in all sequenced genomes of metazoans, suggesting that they were already present in ancestors of Metazoa. $\mathrm{ENaC/DEG} \mathrm{genes} \mathrm{were} \mathrm{also} \mathrm{found} \mathrm{in} \mathrm{the} \mathrm{eukaryotic}$ microbe Naegleria gruberi (Studer et al., 2011). According to this study, ASIC1-4 and the four $\mathrm{ENaC}$ genes were generated by two rounds of whole genome duplication at the origin of vertebrates. In contrast, BASIC appears to be older than the origin of vertebrates (Studer et al., 2011). Interestingly, no mammalian orthologs of the C. elegans and Drosophila ENaC/DEG members and of the peptide-gated $\mathrm{FaNaC}$ of $H$. aspersa have been identified, possibly indicating that the different ENaC/DEG subfamilies diverged early in evolution.

\section{Tissue Distribution, Cellular Functions, and Physiologic and Pathologic Roles}

\section{A. Acid-Sensing Ion Channels}

1. Tissue Distribution and Cellular Functions. ASIC subunits are preferentially expressed in the nervous system. ASIC1a, ASIC2a, ASIC2b, and ASIC4 are found in both the central and peripheral nervous system, whereas ASIC1b and ASIC3 have been detected only in the peripheral nervous system (PNS), except for the human ASIC3 that also shows low levels of expression in the central nervous system (CNS) (Wemmie et al., 2006, 2013; Delaunay et al., 2012). In peripheral neurons, ASICs have been detected in cell bodies and sensory nerve terminals. In central neurons, ASIC1a is preferentially located at the cell body and dendrites and colocalizes with the postsynaptic marker PSD95 (Wemmie et al., 2002; Zha et al., 2006). Messenger RNA of the related mouse and rat BASIC was found mainly in brain, liver, and small intestine, and at lower levels in the kidney and the lung, whereas mRNA of human BASIC was detected only in the small intestine (Sakai et al., 1999; Schaefer et al., 2000). BASIC is highly expressed in bile ducts of the rat and is activated by bile acids (Wiemuth et al., 2012). By using a BASIC reporter mouse, it was shown that in mouse brain BASIC is mainly expressed in the cerebellum (Boiko et al., 2014).

Because ASICs are permeable to $\mathrm{Na}^{+}$, their activation leads to membrane depolarization, thus inducing action potentials in neurons (Deval et al., 2003; Vukicevic and Kellenberger, 2004; Poirot et al., 2006) (Fig. 2, A and B). ASICs, therefore, often have an activating effect on neurons. A strong ASIC-mediated depolarization, however, can inhibit an already actively signaling neuron (Vukicevic and Kellenberger, 2004). ASIC1a has a small permeability for $\mathrm{Ca}^{2+}$ in addition to its $\mathrm{Na}^{+}$permeability, and some of its cellular functions, as for example neurodegeneration after ischemic stroke (Xiong et al., 2004), are thought to depend on a $\mathrm{Ca}^{2+}$ entry into the cell (Waldmann et al., 1997b; Bassler et al., 2001).

The current view is that ASICs regulate neuronal activity in a $\mathrm{pH}$-dependent manner rather than being an essential component of action potential generation, such as voltage-gated $\mathrm{Na}$ channels.

2. Physiologic and Pathologic Roles.

a. Synaptic plasticity and learning. Disruption of the gene encoding ASIC1a in mice eliminates most of the acid-induced currents in central neurons. Consistent with the presence of ASIC1a in the postsynaptic membrane, long-term potentiation (LTP) was impaired in whole animal ASIC1a knockout mice (Wemmie et al., 2002). If the extracellular $\mathrm{Mg}^{2+}$ concentration was kept low in these experiments, LTP was normal in ASIC1a knockout animals, suggesting that the ASICmediated postsynaptic depolarization may increase NMDA receptor function by removing the $\mathrm{Mg}^{2+}$ block. Another study inhibited ASIC1a with Psalmotoxin1 (PcTx1) or used a nervous system-specific ASIC1 knockout approach based on the Cre/Lox system with the Nestin promoter, which leads to the loss of ASIC1 expression at approximately embryonic day 10.5 and, consequently, to the absence of ASIC1a mRNA and ASIC1a currents in brain neurons (Wu et al., 2013). In contrast to previous work with $\mathrm{ASIC} 1 \mathrm{a}^{-/-}$mice, 

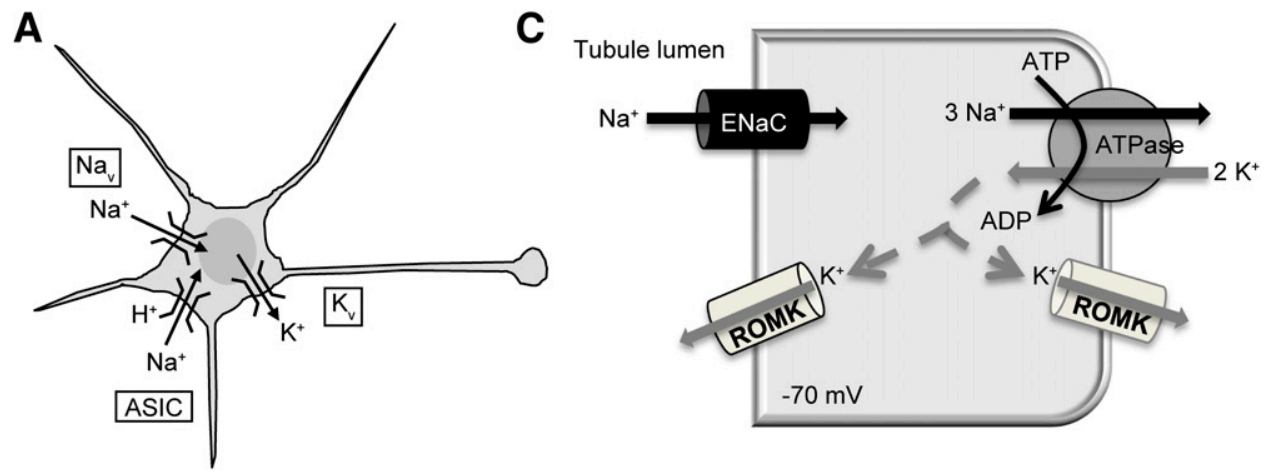

B

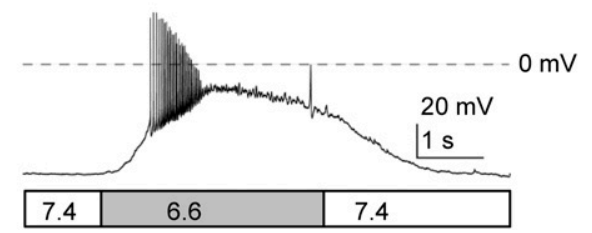

Fig. 2. Cellular functions. (A) Scheme illustrating the function of ASIC in a neuron. Activation of ASICs in the neuron by protons leads to $\mathrm{Na}^{+}$entry, inducing a depolarization that leads to the generation of action potentials by activating voltage-gated $\mathrm{Na}^{+}$and $\mathrm{K}^{+}$channels. (B) Current-clamp experiment from a hippocampal neuron in which activation of ASICs by acidification to $\mathrm{pH} 6.6$ induces a depolarization and a series of action potentials. (C) Scheme illustrating the vectorial transepithelial transport of $\mathrm{Na}^{+}$in a principal cell of the renal cortical collecting duct.

hippocampal LTP was normal in this study after pharmacologic blockade or knockout of ASIC1a. In an earlier study it was reported that block of ASICs by amiloride did not affect postsynaptic currents in cultured hippocampal neurons (Alvarez de la Rosa et al., 2003). The nervous system-specific ASIC1a knockout mice showed no deficit in spatial memory (Wu et al., 2013), in contrast to the whole-animal ASIC1a knockout mice in which a mild deficit in spatial memory and a decreased eye blink conditioning were observed (Wemmie et al., 2002). The opposite findings between these studies with different ASIC1a knockout mice may be due to the different knockout strategies resulting in deletion of ASIC1a at the very beginning (Wemmie et al., 2002) or during embryonic development (Wu et al., 2013) or to differences in animal strains or conditions of experiments, e.g., the absence of drugs in LTP measurements from whole-animal knockouts and the use of a $\mathrm{GABA}_{\mathrm{A}}$ receptor inhibitor in the corresponding experiments from nervous system-specific ASIC1a knockouts.

Two recent studies investigated the contribution of ASICs to synaptic plasticity in different areas of the mouse brain and showed that in nucleus accumbens (NAc) core neurons and lateral amygdala pyramidal neurons, a small fraction $(\sim 5 \%)$ of the evoked excitatory postsynaptic current amplitude is due to ASIC activation (Du et al., 2014; Kreple et al., 2014). Presynaptic stimulation transiently decreased the $\mathrm{pH}$ at spines and neighboring dendrites of lateral amygdala pyramidal neurons, consistent with proton release from synaptic vesicles ( $\mathrm{Du}$ et al., 2014). This study also showed that LTP in the lateral amygdala depended on the presence of ASICs and the increase in proton concentration.
The NAc is involved in addiction-related learning and behavior. Surprisingly, ASIC1a in the NAc was found to inhibit cocaine-induced synaptic plasticity and cocaine-conditioned behavior in rodents (Kreple et al., 2014). In a cocaine-conditioned place preference test, $\mathrm{ASIC1a}^{-/-}$mice showed greater preference for the cocaine-associated context than did wild-type control mice. Rats that overexpressed ASIC1a in the NAc after local injection of a viral vector, self-administered less cocaine than did control rats. Investigation of the cellular mechanisms underlying this effect of ASIC1a identified a small contribution of ASICs to the excitatory postsynaptic current, as mentioned above. However, the analysis also showed that loss of ASIC1a increased the dendritic spine density and the frequency of miniature EPSCs in the NAc, consistent with increased excitatory transmission. Glutamate receptors of the NAc are important for addiction-related behavior, and differences in the functional profile of glutamate receptors have been observed between NAc neurons of cocaine-naive and of cocaine-withdrawn animals. Interestingly, this study showed that NAc neurons of cocaine-naive $\mathrm{ASIC}_{\mathrm{a}} \mathrm{a}^{-1-}$ mice displayed the glutamate receptor profile of cocaine-withdrawn wild-type animals, suggesting therefore that ASICs, by influencing the glutamate receptor properties, may prevent cocaine-associated changes in the composition of NAc synapses (Kreple et al., 2014). Together, these studies suggest that ASICs contribute to synaptic plasticity and that, depending on the brain area, they either promote or inhibit plasticity.

b. Fear and anxiety. Because ASIC1a expression is particularly high in the amygdala, a possible role in fear-related behavior was investigated. This showed 
that whole-animal ASIC1a knockout mice displayed deficits in cue and context fear conditioning as well as in unconditioned fear behaviors (Wemmie et al., 2003, 2013; Coryell et al., 2007). The disruption of ASIC1a also produced antidepressant-like effects in several behavioral tests carried out with mice (Coryell et al., 2009). Overexpression of ASIC1a increased fearrelated behavior (Wemmie et al., 2004). It was shown that the amygdala senses acidic $\mathrm{pH}$ and thereby evokes fear behavior (Ziemann et al., 2009). It is known that an increase in $\mathrm{CO}_{2}$ levels induces fear behavior in humans and has the same effect in mice. Inhibition or disruption of ASIC1a function impaired $\mathrm{CO}_{2}$-induced fear behavior (Ziemann et al., 2009). Localized expression of ASIC1a in the amygdala of ASIC1a knockout mice rescued the fear phenotype, demonstrating that ASIC1a of the amygdala contributes importantly to fear behavior. As mentioned above, it was also shown that presynaptic stimulation lowers the amygdala $\mathrm{pH}$ and activates ASICs in lateral amygdala pyramidal neurons (Du et al., 2014). Intriguingly, a recent study with rats showed that activation of ASIC1a in the basolateral amygdala suppressed anxiety-like behavior (Pidoplichko et al., 2014). Activation of ASICs by injection of ammonium in the basolateral amygdala decreased the time spent in the center of the open field in the open field test, whereas inhibition of ASIC1a by PcTx1 had the opposite effect. Ammonium injection also prolonged the latency before the rats entered the dark compartment in the light/dark box test. ASIC currents were present in both principal cells and interneurons of the basolateral amygdala in the rat, and ASIC activation led to a higher increase in spontaneous inhibitory postsynaptic currents than EPSCs in principal cells, indicating that the inhibitory effects of ASICs on principal cell signaling prevailed (Pidoplichko et al., 2014). Because most results obtained with knockout mice were confirmed with pharmacologic approaches, the opposite results obtained in these studies cannot be due to a role of ASICs in development. It is therefore most likely that species differences are the cause of these contradictory results, thus that involvement of ASICs in the basolateral amygdala signaling may be different between mice and rats. Currently, behavioral data from rats on the role of ASICs in fear behavior is very limited and it will be necessary to extend such studies to cue and context fear conditioning and to $\mathrm{CO}_{2}$-induced fear to determine how different the role of ASICs in fear behavior is between mice and rats. In humans, single nucleotide polymorphisms in the noncoding region of the ASIC1a gene were found to be associated with panic disorder, amygdala volume, and fear-related reactions (Smoller et al., 2014). It would be interesting to identify the ASIC function that is changed in these variants.

c. Pain sensation. In a number of conditions involving pain, such as inflammation and ischemia, the tissue $\mathrm{pH}$ is lowered. The extracellular $\mathrm{pH}$ drops for example in cardiac ischemia to 6.7 (Cobbe and PooleWilson, 1980). ASICs in sensory neurons are therefore candidate receptors for acidification inducing pain. ASIC1a and ASIC2 are also expressed in painprocessing areas of the CNS where they may additionally contribute to pain sensation (Wemmie et al., 2013). Studies on human volunteers showed that local injection in the skin or iontophoresis of acidic solutions induced pain that was prevented by amiloride and displayed a $\mathrm{pH}$ of half-maximal effect of $\sim 6.5$, thus close to the $\mathrm{pH}$ of half-maximal activation $\left(\mathrm{pH}_{50}\right)$ of ASIC1a and ASIC3 (Ugawa et al., 2002; Jones et al., 2004). Several animal studies provided strong evidence for the role of peripheral ASIC3 and ASIC1 in pain sensation. Specific knockdown of ASIC3 with intrathecally administered siRNA in rats prevented inflammation-induced heat hyperalgesia or flinching after local injection of irritating substances (Deval et al., 2008). The synthetic compound 2-guanidine-4-methylquinazoline (GMQ) activates ASIC3 at physiologic $\mathrm{pH}$ and inhibits other ASICs (Yu et al., 2010; Alijevic and Kellenberger, 2012). Local injection of GMQ in the mouse paw induced pain behavior that depended on the presence of ASIC3, further confirming the importance of ASIC3 (Yu et al., 2010). A number of studies has demonstrated a contribution of ASIC3 to inflammation- and chronic acidificationrelated forms of pain (Sluka et al., 2009). Injection of the ASIC activator Mit-toxin (MitTx) of the Texas coral snake venom in the mouse paw induced pain behavior that was decreased by ASIC1a disruption (Bohlen et al., 2011). Recently, the ASIC-inhibitory toxin mambalgin-1 from black mamba venom was shown to reduce pain behavior after peripheral injection due to inhibition of ASIC1b (Diochot et al., 2012).

Intrathecal injection of mambalgin-1 diminished pain behaviors due to inhibition of ASICs containing the subunits ASIC1a and/or ASIC2a. Previous work had shown that the main functional ASICs in the spinal cord were ASIC1a homomers and ASIC1a/2a heteromers (Baron et al., 2008), and that ASIC RNAs in the spinal cord were upregulated by peripheral inflammation (Duan et al., 2007). Administration to the CNS of the spider toxin PcTx1, a specific inhibitor of ASIC1a, diminished pain behavior, further demonstrating the important role of central ASIC1a in pain sensation (Duan et al., 2007; Mazzuca et al., 2007). A recent study showed that ASIC1a in the spinal cord is the target of brain-derived neurotrophic factor (BDNF) (Duan et al., 2012). BDNF increased ASIC1a cell surface expression by inducing phosphorylation of the N-terminal residue Ser25 via the phosphoinositide 3-kinase-protein kinase B cascade. Intrathecal injection of BDNF induced mechanical hyperalgesia, which was prevented by ASIC1a disruption (Duan et al., 2012).

Migraine is associated with tissue acidification in the dura. Functional changes of several types of ion channels may contribute to an altered state of neuronal 
excitability of trigeminal afferent neurons innervating the dura (Yan and Dussor, 2014). The majority of rat dural afferents display ASIC currents, which are likely mediated by ASIC3-containing channels (Yan et al., 2011). Application of $\mathrm{pH} 5$ synthetic interstitial fluid to the dura of rats induced facial and hind paw allodynia. Facial allodynia is often associated with migraine (Yan et al., 2011). Amiloride has been reported to inhibit cortical spreading depression in rodents, and improved aura and headache severity in 4 of 7 patients of a small clinical trial (Holland et al., 2012).

Together, these studies provide clear indications for nociceptive roles of central and peripheral ASICs. Surprisingly, two studies showed that mice in which all ASIC currents were suppressed displayed increased pain behavior (Mogil et al., 2005; Kang et al., 2012). Mice overexpressing a dominant-negative mutant ASIC3 subunit were more sensitive than wild-type controls to mechanical pain and chemical/inflammatory pain and developed stronger mechanical hypersensitivity after inflammation (Mogil et al., 2005). Triple knockout mice, in which the ASIC1, ASIC2, and ASIC3 genes were simultaneously disrupted, showed an increased behavioral sensitivity to mechanical stimuli and an increased mechanosensitivity of A-mechanonociceptors (Kang et al., 2012). This indicates that the role of ASICs in nociception is still not fully understood despite many important findings.

d. Mechanosensation. Because related channels in C. elegans are involved in mechanosensation, a similar possible role of ASICs was investigated in mammals. Currently there is evidence of ASIC expression in primary sensory neurons and the afferents of mechanoreceptors, obtained either by retrograde tracing combined with functional analysis of isolated sensory neurons or by immunohistochemistry (reviewed in Chen and Wong, 2013). Disruption of the expression of different ASICs produced defects in mechanotransduction in tissues such as the skin, the stomach, the colon, the cochlea, and arterial baroreceptors (reviewed in Chen and Wong, 2013). These effects were most clearly demonstrated in the gastrointestinal tract and in arterial baroreceptors. Mechanotransduction in the gastrointestinal system is important for the control of gastric coordination and emptying, colonic motility, and the sensation of pain. Single-fiber recordings on an in vitro vagus-gastroesophageal or colon preparation showed in $\mathrm{ASIC} 1^{-/-}$mice enhanced, in $\mathrm{ASIC2}{ }^{-/-}$mice mixed, and in ASIC3 ${ }^{-/-}$mice decreased mechanosensitivity in visceral mechanoreceptors (Jones et al., 2005; Page et al., 2005). Analysis of the digestive function showed that that $\mathrm{ASIC}^{-1-}$ mice had an alteration in upper gastrointestinal functions manifested as a slower gastric emptying, whereas $\mathrm{ASIC}^{-1-}$ mice showed a decrease in the number of fecal pellets per day, indicating a changed lower bowel function (Page et al., 2005).
Aortic baroreceptor neurons in the nodose ganglia and their terminals express ASIC2. ASIC2 ${ }^{-l-}$ mice showed hypertension, increased sympathetic and decreased parasympathetic control of the circulation, and a decreased gain of the baroreflex (Lu et al., 2009). The impairment of the baroreflex in $\mathrm{ASIC} 2^{-1-}$ mice suggests that ASIC2 is a determinant of the sensitivity of arterial baroreceptor and contributes to the autonomic control of the circulation.

So far it has not been possible to demonstrate mechanosensitivity of recombinantly expressed ASICs or of ASICs expressed in dorsal root ganglion (DRG) neurons (Drew et al., 2004). Therefore it is possible that ASICs need to form complexes with other proteins to be able to act as mechanosensors.

e. Neurodegenerative diseases. Calcium entry into neurons is thought to be the most important cause of neuronal injury after ischemic stroke. Because ischemic stroke induces a tissue acidification and ASIC1a is partially permeable to $\mathrm{Ca}^{2+}$, a possible contribution of ASIC1a to this toxicity was investigated. Disruption of the ASIC1a gene or inhibition of ASIC1a by PcTx1containing spider venom reduced the infarct volume in an experimental stroke model by $>60 \%$, thus demonstrating an important contribution of ASIC1a to ischemic stroke-induced neurodegeneration (Xiong et al., 2004). Intracerebroventricular administration of PcTx1 up to 5 hours after transient middle cerebral artery occlusion reduced the infarct volume by $>50 \%$ (Pignataro et al., 2007). Subsequent studies showed a protective effect of ASIC gene disruption or inhibition of ASIC function in a number of neurodegenerative diseases, including multiple sclerosis (MS), Huntington's, and Parkinson's disease (reviewed in Wemmie et al., 2013). The disruption of the ASIC1a gene reduced the clinical deficit and axonal degeneration in experimental autoimmune encephalomyelitis (Friese et al., 2007). It was further shown that ASIC1a is upregulated in lesions from experimental autoimmune encephalomyelitis in mice and from MS patients (Vergo et al., 2011). Treatment with amiloride was neuroprotective in animal models and in human MS patients (Vergo et al., 2011; Arun et al., 2013). Interestingly, an association between the ASIC2 gene and MS has been shown in a remote human population in Sardinia (Bernardinelli et al., 2007).

f. Epileptic seizures. During epileptic seizures the brain $\mathrm{pH}$ is lowered, and it is known that acidosis can end seizures. Disruption of the ASIC1a gene increased the severity of seizures, and the opposite effect was observed with overexpression of ASIC1a (Ziemann et al., 2008). This study showed that ASIC1a expression is required for seizure termination by $\mathrm{CO}_{2}$ inhalation. Because inhibitory interneurons in hippocampus display higher ASIC current amplitudes than pyramidal neurons it is possible that the interneuron-mediated inhibition ended the seizures (Ziemann et al., 2008). Observations of seizure inhibition by high concentrations 
of amiloride (Ali et al., 2006; N'Gouemo, 2008; Luszczki et al., 2009) appear to contradict the role of ASIC1a in seizure termination. Because of its hydrophilic nature, amiloride is expected not to cross the blood-brain barrier, and it is currently not clear whether it reaches the brain or whether it exerts anti-seizure effects by other mechanisms. Amiloride is not specific for ASICs, and if it reaches the brain its effect on seizures may well be due to inhibition of the $\mathrm{Na}^{+} / \mathrm{H}^{+}$exchanger, which, by lowering the intracellular $\mathrm{pH}$, may decrease epileptic activity (Ali et al., 2006; Luszczki et al., 2009). Recently, a genetic study indicated an association between single nucleotide polymorphisms of ASIC1 and temporal lobe epilepsy (Lv et al., 2011). Whether these polymorphisms affected the expression and function of ASIC1a, however, were not investigated.

\section{B. Epithelial $\mathrm{Na}^{+}$Channel}

1. Function. According to the Koefoed-JohnsenUssing model of $\mathrm{Na}^{+}$absorbing epithelia, $\mathrm{Na}^{+}$enters the epithelial cell by facilitated diffusion across the apical membrane through a $\mathrm{Na}^{+}$-selective, amiloridesensitive channel (Koefoed-Johnsen and Ussing, 1958; Palmer and Andersen, 2008) (Fig. 2C). This $\mathrm{Na}^{+}$entry across the apical membrane occurs along a favorable electrochemical gradient. The epithelial $\mathrm{Na}^{+}$channel $\mathrm{ENaC}$ was first identified by patch-clamp in the apical membrane of the collecting ducts from rat kidney (Palmer and Frindt, 1986). This epithelial $\mathrm{Na}^{+}$channel is spontaneously open at the cell surface and is characterized by a small conductance ( $5 \mathrm{pS}$ at physiologic $\mathrm{Na}^{+}$concentrations), a half-saturation of ion conductance obtained at $70 \mathrm{mM} \mathrm{Na}{ }^{+}$, and a selectivity for $\mathrm{Na}^{+}$over $\mathrm{K}^{+}$ions of $>100$.

The primary structure of $\mathrm{ENaC}$ was solved by cloning of three homologous $\mathrm{ENaC}$ subunits, $\alpha, \beta$ and $\gamma$, that form the functional channel (Canessa et al., 1993, 1994b). Coexpression of the three $\alpha \beta \gamma \mathrm{ENaC}$ subunits is required for maximal expression of $\mathrm{ENaC}$-mediated $\mathrm{Na}^{+}$current (Firsov et al., 1996) and to reproduce the biophysical properties observed in the epithelial $\mathrm{Na}^{+}$ channel of the cortical collecting duct (CCD). The three $\mathrm{ENaC}$ subunits $\alpha, \beta$ and $\gamma$ are expressed and are detected at the protein level in the kidney, the lung, the colon, and in salivary glands. In skin, blood vessels, the eye, and heart, the presence of ENaC mRNAs was also reported (Mauro et al., 2002; Drummond et al., 2004; Krueger et al., 2012). The functional role of $\mathrm{ENaC}$ in these tissues is still a matter of debate, and no clear phenotype is associated with the loss of function of $\mathrm{ENaC}$ in these tissues in humans (Riepe, 2009).

In addition to the well characterized $\alpha \beta \gamma \mathrm{ENaC}$ subunits, a $\delta$ subunit has been identified by cloning from a human kidney cDNA library (Waldmann et al., 1995). The $\delta$ subunit shows highest transcriptional expression levels in the ovaries, testis, pancreas, and brain. In heterologous cell expression systems, the $\delta$ subunit can functionally substitute for the $\alpha$ subunit (Waldmann et al., 1995). The $\delta$ subunit has only been identified in humans, and nothing is known about its physiologic/ pathologic role.

2. Kidney. Most of the filtered $\mathrm{Na}^{+}(90 \%)$ is reabsorbed in the proximal tubule and the thick ascending limb of the nephron by antiporters or cotransporters, and only $3-5 \%$ of the filtered load of $\mathrm{Na}^{+}$is reabsorbed in the distal part. The ENaC subunit proteins are located at the apical membrane of principal cells lining the distal end of the distal convoluted tubule DCT2, the connecting tubule (CNT), and the collecting duct (Loffing et al., 2000a). This correlates with the presence of active $\mathrm{ENaC}$ channel detected by electrophysiologic techniques ex vivo in the CNT and CCD (Frindt and Palmer, 2004). The distal nephron segment is generally called the aldosterone-sensitive distal nephron (ASDN) because of the coexpression of $\mathrm{ENaC}$ channels with the mineralocorticoid receptor in this tubule segment (Malsure et al., 2014).

In the distal nephron and the renal collecting duct, $\mathrm{ENaC}$ is the only $\mathrm{Na}^{+}$-selective channel present at the apical membrane of the principal cells and constitutes the rate-limiting step for $\mathrm{Na}^{+}$reabsorption. The ENaCmediated $\mathrm{Na}^{+}$absorption is under tight hormonal control to precisely match the amount of $\mathrm{Na}^{+}$excreted in the urine to the daily $\mathrm{Na}^{+}$intake to maintain a $\mathrm{Na}^{+}$ balance. In principal cells, $\mathrm{ENaC}$ is coexpressed at the apical membrane with $\mathrm{K}^{+}$-selective channels named rat outer medulla $\mathrm{K}^{+}$(ROMK) channel (Palmer and Frindt, 2007) (Fig. 2C). ENaC and ROMK are electrically coupled, and when ENaC-mediated $\mathrm{Na}^{+}$absorption increases, the membrane depolarization provides an increase in electrical driving force for $\mathrm{K}^{+}$secretion across the apical membrane and an increase in renal excretion of $\mathrm{K}^{+}$.

The role of $\mathrm{ENaC}$ in the maintenance of $\mathrm{Na}^{+}$and $\mathrm{K}^{+}$ homeostasis is best illustrated by two genetic syndromes associated with mutations in the $\mathrm{ENaC}$ genes leading to either a loss or a gain of function of the channel. Pseudohypoaldosteronism type-1 (PHA-1) is a rare disease of mineralocorticoid resistance associating hyponatremia, severe hyperkalemia, and metabolic acidosis with high levels of plasma aldosterone. Two forms of PHA-1 have been identified: an autosomal dominant form with usually mild symptoms restricted to the kidney that is associated with heterozygous mutations in the NR3C2 gene encoding for the mineralocorticoid receptor (Chang et al., 1996; Geller et al., 1998), and the generalized PHA-1 form that is also called autosomal recessive PHA-1. This second form of PHA-1 is a multisystem disorder characterized by salt wasting from the kidney, the colon, the sweat glands, and a reduced capacity to reabsorb $\mathrm{Na}^{+}$in the airways, leading to rhinorrhea, pulmonary congestion, and recurrent pulmonary infections. Mutations have been identified in the SCNN1A, SCNN1B, and SCNN1G 
genes encoding the $\alpha, \beta$, and $\gamma \mathrm{ENaC}$ subunits, leading to loss of function of ENaC (Chang et al., 1996). The mirror image of PHA-1 is Liddle syndrome (or pseudoaldosteronism), an autosomal dominant form of salt-sensitive hypertension associated with low plasma aldosterone, low plasma renin activity, hypokalemia, and metabolic alkalosis. In the early sixties, G. W. Liddle reported a case of pseudoaldosteronism and described the syndrome as "a disorder in which the renal tubules transport ions with such abnormal facility that the end result simulates that of a mineralocorticoid excess" (Liddle and Coppage, 1963). Blood pressure in these patients could be normalized with amiloride and dietary salt restriction, but the mineralocorticoid receptor antagonist spironolactone was not effective. The genetic defects associated with this syndrome are mutations in the last exon of the SCNN1B and SCNN1G genes encoding the $\beta$ and $\gamma \mathrm{ENaC}$ subunits that delete a conserved proline-rich motif in the cytosolic $\mathrm{C}$ terminus (Shimkets et al., 1994). In vitro experiments could establish that the mutations associated with this syndrome are gain-of-function mutations, as postulated by G. W. Liddle, leading to an increase in the abundance and activity of $\mathrm{ENaC}$ at the cell surface (Schild et al., 1995; Firsov et al., 1996). The molecular mechanism leading to $\mathrm{ENaC}$ gain of function in Liddle syndrome is now well established. The proline-rich PPPxY motif in the $\mathrm{C}$ terminus of $\mathrm{ENaC}$ $\beta$ and $\gamma$ subunits that is mutated in this syndrome is involved in specific interactions with cytosolic proteins, such as the Nedd4-2 ubiquitin ligase, that tightly control the channel density at the cell surface (Rotin, 2000; Staub et al., 2000). The ENaC mutants lacking this prolinerich motif show a defect in channel internalization, leading to retention of active channels at the cell surface (Debonneville et al., 2001).

Genetic mouse models targeting $\mathrm{ENaC}$ genes have been generated, reproducing, completely or partially, the clinical features of these syndromes (Hummler et al., 1997; Pradervand et al., 2003). In addition, targeting the $\mathrm{ENaC}$ gene knockout (KO) to specific nephron segments revealed that the expression of $\mathrm{ENaC}$ in the collecting duct is not necessary for the maintenance of $\mathrm{Na}^{+}$and $\mathrm{K}^{+}$ balance, suggesting that $\mathrm{ENaC}$ in more proximal parts of the nephron such as the CNT likely plays the most important role in this process (Rubera et al., 2003; Christensen et al., 2010).

3. Lungs. Airway epithelial cells reabsorb and secrete fluid to maintain an appropriate airway surface liquid (ASL) level and mucociliary clearance. Liquid movements across the airway epithelium depend on transepithelial ion transport, and the coordination of ENaC-mediated $\mathrm{Na}^{+}$absorption with $\mathrm{Cl}^{-}$secretion is critical for the maintenance of ASL (Goralski et al., 2010). In the lung, ENaC subunits were detected at the mRNA level in the medium and small airways and in alveolar type II cells (Burch et al., 1995), $\alpha \mathrm{ENaC} \mathrm{KO}$ mice die shortly after birth, due at least in part to a massive lung edema at birth, leading to a respiratory distress syndrome (Hummler et al., 1996). In contrast, an increase in $\mathrm{Na}^{+}$absorption by $\mathrm{ENaC}$ overexpression in a genetic mouse model leads to a cystic fibrosis lung phenotype (Mall et al., 2010). In airway epithelia of cystic fibrosis patients, the loss of cystic fibrosis transmembrane conductance regulator (CFTR) activity is accompanied by an increased $\mathrm{ENaC}$ activity resulting in $\mathrm{Na}^{+}$hyperabsorption, suggesting that $\mathrm{ENaC}$ upregulation may contribute to the cystic fibrosis lung phenotype (Mall et al., 2010; Hobbs et al., 2013). A cystic fibrosis-like lung phenotype, however, has not been consistently observed in Liddle patients. The $\mathrm{ENaC}$ activity is coupled to CFTR function in human sweat ducts, where it increases with CFTR activity; in sweat ducts of cystic fibrosis patients, the loss of CFTR activity is accompanied by reduced $\mathrm{ENaC}$ activity (Reddy et al., 1999).

4. Gastrointestinal Tract. As in the kidney, most of the $\mathrm{Na}^{+}$in the lumen of the gut is reabsorbed by electroneutral transporters. An electrogenic $\mathrm{Na}^{+}$reabsorption mediated by $\mathrm{ENaC}$ is restricted to the colon and the rectum. $\mathrm{ENaC}$ in the distal colon is under mineralocorticoid and glucocorticoid control: both aldosterone and dexamethasone control the abundance of $\beta$ and $\gamma$ but not $\alpha$ mRNA transcripts (Epple et al., 2000; Fuller et al., 2000). Mice lacking the $\alpha \mathrm{ENaC}$ subunit in colonic superficial cells (SCNN1A-KO) are viable without perinatal lethality, in contrast to mice lacking $\alpha \mathrm{ENaC}$ in the kidney, but show salt loss and mineralocorticoid resistance, indicating that $\mathrm{Na}^{+}$absorption in the kidney can compensate for the absence of ENaC-mediated $\mathrm{Na}^{+}$ absorption in the colon (Malsure et al., 2014).

5. Sodium Sensor. Mammals perceive five different qualities of taste, bitter, sweet, umami, sour, and salty. Salt taste represents a warning signal to prevent consumption of hypersaline fluid or food and is also important to satisfy our salt appetite. The balance between these two antagonistic signals likely influences our daily sodium consumption, which is a major risk factor for developing hypertension. Different mechanisms are involved in salty taste sensation. One sodium-sensing system activated at high sodium concentrations $(500 \mathrm{mM})$ is not specific for $\mathrm{Na}^{+}$and responds to a variety of salts. Another sensing system is activated by lower concentrations of $\mathrm{Na}^{+}$and inhibited by amiloride, suggesting the contribution of $\mathrm{ENaC}$ in salt taste. In humans, $\alpha, \beta, \gamma$, and $\delta \mathrm{ENaC}$ subunits are expressed in taste bud cells (Stahler et al., 2008). In mice lacking $\alpha \mathrm{ENaC}$ in taste receptor cells, the highly sensitive response to $\mathrm{Na}^{+}$salt and the behavioral attraction to sodium salt were considerably reduced (Chandrashekar et al., 2010). These observations support an important physiologic role of $\mathrm{ENaC}$ in salt taste perception. Taste response to sodium is common among terrestrial vertebrates but is differentially sensitive to amiloride. In humans, for instance, the perception of saltiness to $\mathrm{NaCl}$ 
or LiCl remained essentially unchanged by amiloride at concentrations up to $100 \mu \mathrm{M}$ (see for review, Halpern, 1998). These observations are consistent with the contribution of different salt-sensing systems that may vary among vertebrates and possibly be dependent on factors such as the environment or the genetic background.

\section{Structural Aspects}

\section{A. Primary Structure and Subunit Topology}

1. Subunit Organization of Epithelial $\mathrm{Na}^{+}$Channel and Acid-Sensing Ion Channels. All DEG/ENaC family members share a common membrane topology. ASIC and ENaC subunits are composed of two transmembrane segments, intracellular $\mathrm{N}$ and $\mathrm{C}$ termini, and a large extracellular loop that represents more than half of the mass of the channel protein (Canessa et al., 1994a) (Fig. 3A). Protease digestion and glycosylation site analysis of $\mathrm{ENaC}$ showed the presence of a large extracellular loop, comprising $\sim 50 \mathrm{kDa}$, between the two transmembrane domains. It also indicated that the $\mathrm{N}$ and $\mathrm{C}$ termini are intracellular (Canessa et al., 1994a; Renard et al., 1994; Snyder et al., 1994). This subunit topology was confirmed in ASIC2a by analyzing engineered glycosylation sites and epitope accessibility to antibodies (Saugstad et al., 2004). The large extracellular domain has essential roles in the regulation and control of activity of ENaC and ASICs. It contains $\mathrm{H}^{+}$-sensing residues and is involved in the activation of ASICs. Its specific role in supporting $\mathrm{Na}^{+}$ ion flow through the $\mathrm{ENaC}$ pore, however, remains unclear. The membrane topology was confirmed by the three-dimensional structures of chicken ASIC1 (cASIC1), the only ENaC/DEG family member that has successfully been crystallized so far.

The different crystal structures of cASIC1 show a channel composed of three subunits arranged around a central ion pore (Fig. 3A). In these structures, the intracellular channel domains are either truncated or, when present, not resolved (Table 1). The domain arrangement of ASIC subunits has some resemblance with an upright forearm and a clenched hand. The forearm would correspond to the transmembrane part, the hand to the extracellular channel part, and the wrist would form the transmembrane-extracellular domain junction. Accordingly, the different extracellular domains have been labeled palm, knuckle, finger, $\beta$-ball, and thumb (Jasti et al., 2007) (Fig. 3, $\mathrm{A}$ and $\mathrm{B}$ ).

The transmembrane helices are connected to $\beta$ strands, forming the palm domain, that is arranged along the central vertical axis of the channel and constitutes the core of the extracellular domain (Jasti et al., 2007; Gonzales et al., 2009; Baconguis and Gouaux, 2012; Baconguis et al., 2014; Dawson et al., 2012). The knuckle and $\beta$-ball are located close to the central vertical axis at the upper end of the palm, while the finger and thumb are oriented toward the outside of the protein. The finger forms the upper external edge, whereas the thumb, a rigid structure formed by two $\alpha$ helices and stabilized by several disulfide bonds, is located below the finger and is connected by two loop structures to the lower part of the palm. One of these loops interacts with the top end of the first transmembrane segment via a structural element that has been named $\beta$-turn (Fig. 3A). The channel further contains four vestibules or cavities that are all aligned along the central vertical axis. From top to bottom these are the upper vestibule, the central vestibule, which is enclosed by the lower palm, the extracellular vestibule located just above the extracellular pore entry and finally the intracellular vestibule. Remarkably, the surfaces of the central and extracellular vestibules are electronegative, therefore attracting cations (Jasti et al., 2007; Gonzales et al., 2009).

2. Origin and Experimental Conditions of Different Crystal Structures. All currently published ASIC structures were obtained from the chicken ASIC1, which shares $\sim 90 \%$ sequence identity with human and rat ASIC1a. The conditions of the different ASIC
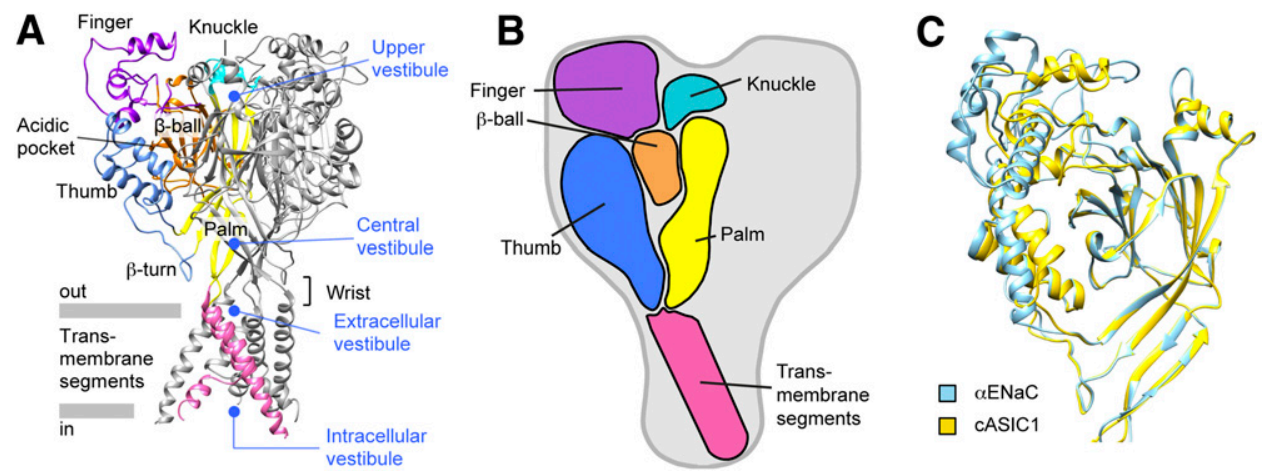

Fig. 3. ASIC structure and ENaC model. (A) The different subdomains transmembrane segments (pink), palm (yellow), thumb (blue), finger (purple), $\beta$-ball (orange), and knuckle (turquoise) are indicated in one of the three ASIC subunits in the crystal structure obtained in complex with MitTx (Baconguis et al., 2014). The acidic pocket and the $\beta$-turn, as well as the four vestibules are indicated. (B) Schematic view of one ASIC subunit with indication of the domains in the same colors as in (A). (C) Structural alignment of an $\alpha$ ENaC model (turquoise) (Kashlan et al., 2011) and the cASIC1 desensitized structure 2QTS (yellow) (Jasti et al., 2007). All structural images were made with Chimera (Pettersen et al., 2004). 
TABLE 1

ASIC structures

All crystal structures were obtained from chicken ASIC1. The structures 2QTS and 3HGC (4NYK) likely represent the desensitized state, whereas the other structures represent the open state. $2 \mathrm{QTS}, 3 \mathrm{~S} 3 \mathrm{~W}, 4 \mathrm{FZ} 0$, and $4 \mathrm{FZ} 1$ display a continuous TM2 segment, whereas in $4 \mathrm{NYK}$ (reinterpretation of $3 \mathrm{HGC}$ ) and $4 \mathrm{NTW}$ the TM2 is split in two parts by the selectivity filter GAS motif.

\begin{tabular}{|c|c|c|c|c|c|c|c|}
\hline PDB ID & Construct & $\begin{array}{l}\text { Complex } \\
\text { with }\end{array}$ & $\mathrm{pH}$ & Resolution & Symmetry & Function & Reference \\
\hline & & & & $\AA$ & & & \\
\hline 2QTS & $\begin{array}{l}\mathrm{N} \text { and } \mathrm{C} \text { terminus } \\
\text { truncated }\end{array}$ & - & 5.6 & 1.9 & $\begin{array}{l}\text { 3-fold, except } \\
\text { in TM part }\end{array}$ & Nonfunctional & Jasti et al., 2007 \\
\hline $3 \mathrm{HGC}^{a}(4 \mathrm{NYK})$ & C terminus truncated & - & 6.5 & 3.0 & 3 -fold & Functional & Gonzales et al., 2009 \\
\hline 3S3X & $\begin{array}{l}\mathrm{N} \text { and } \mathrm{C} \text { terminus } \\
\text { truncated }\end{array}$ & PcTx1 & 5.5 & 3.0 & $\begin{array}{l}\sim 3 \text {-fold, except } \\
\text { in TM part }\end{array}$ & Nonfunctional & Dawson et al., 2012 \\
\hline $4 \mathrm{FZ} 0$ & $\begin{array}{l}\text { Truncation of } 13 \\
\text { N-terminal and } 63 \\
\text { C-terminal residues }\end{array}$ & PcTx1 & 5.5 & 2.8 & $\begin{array}{l}\sim 3 \text {-fold, except } \\
\text { in TM part }\end{array}$ & $\begin{array}{l}\text { Functional, } \mathrm{Na}^{+} \text {-selective and } \\
\text { amiloride-inhibited at pH } 5.5\end{array}$ & $\begin{array}{l}\text { Baconguis and } \\
\text { Gouaux, } 2012\end{array}$ \\
\hline $4 \mathrm{FZ} 1$ & " & PcTx1 & 7.25 & 3.3 & 3 -fold & $\begin{array}{l}\text { Functional, nonselective, and } \\
\text { amiloride-resistant at pH } 7.25\end{array}$ & $\begin{array}{l}\text { Baconguis and } \\
\text { Gouaux, } 2012\end{array}$ \\
\hline $4 \mathrm{NTW}^{b}$ & “ & MitTx & 5.5 & 2.1 & 3 -fold & $\begin{array}{l}\text { Functional, } \mathrm{Na}^{+} \text {-selective, } \\
\text { amiloride-inhibited }\end{array}$ & Baconguis et al., 2014 \\
\hline
\end{tabular}

structures presently available are summarized in Table 1. The first published crystal ASIC structure and one of the PcTx1-cASIC1 structures were obtained from a truncated, nonfunctional construct (Jasti et al., 2007; Dawson et al., 2012). The other crystal structures were obtained from functional but still truncated constructs. ASICs exist in three functional states: closed, open, and desensitized. Two structures were obtained at acidic $\mathrm{pH}$ in the absence of gating modifiers (Protein Data Bank [PDB] ID 2QTS and 3HGC/4NYK) and their transmembrane region did not contain a continuous pore that would allow ion transport. Therefore, it was concluded that these structures likely represent the desensitized conformation of ASIC1 (Jasti et al., 2007; Gonzales et al., 2009). Recently, crystal structures of cASIC1 in complex with the gating modifiers PcTx1 or MitTx were published (Baconguis and Gouaux, 2012; Dawson et al., 2012; Baconguis et al., 2014). MitTx is an ASIC activator and PcTx1 had been known to be a gating modifier that shifts the $\mathrm{pH}$ dependence of activation and desensitization to more alkaline values, thereby inhibiting human and rat ASIC1a. However, PcTx1 opens cASIC1 at $\mathrm{pH} 7.4$ and rat ASIC1b at slightly acidic pH (see section VI) (Chen et al., 2005, 2006; Samways et al., 2009). Both functional cASIC1toxin complexes showed an incomplete desensitization at the $\mathrm{pH}$ used for crystallization. In contrast to the previous crystals, all toxin-bound cASIC1 structures contained a continuous open pore and therefore likely represent the channel in an open conformation. The cASIC1 crystal structures with the highest resolution were the first, putatively desensitized structure obtained at $1.9 \AA$ and the open cASIC1-MitTx structure, resolved at $2.1 \AA$ (Jasti et al., 2007; Baconguis et al., 2014). All structures showed generally a 3 -fold symmetry except for the transmembrane domain, which was asymmetric in the first desensitized structure (2QTS) and the two cASIC1PcTx1 structures obtained at $\mathrm{pH} 5.5$ (3X3X and 4FZ0).

\section{Differences between the Open and the Desensitized} Structure and between Different Published Structures. Comparison of the open PcTx1- and MitTx-complex structures with that of the desensitized state (PDB ID 4NYK) showed no difference in conformation of the knuckle and upper palm domains, suggesting that these domains may act as a scaffold for the movement of other channel domains. Compared with the desensitized conformation, the lower palm and wrist of the open conformations undergo a rotation that increases the distance between the thumb and the palm domain of adjacent subunits, thus widening the central vestibule. In open ASIC structures the extracellular vestibule becomes wider than it is in the desensitized structures, and the "desensitization gate" forming an $\sim 8 \AA$-thick occlusion in the upper half of the transmembrane part opens up (Baconguis and Gouaux, 2012; Grunder and Augustinowski, 2012; Baconguis et al., 2014).

The conformation of the ectodomain is the same in the two desensitized structures (2QTS, 3HGC) and is similar between the open structures. In the recent cASIC1-MitTx structure obtained at high resolution, the transmembrane (TM)2 segment is separated into two parts at the level of the selectivity filter sequence Gly-Ala-Ser, which adapts a horizontal, extended conformation. Reinterpretation of the desensitized structure 3HGC showed a similar break in helical structure. In contrast, the first desensitized structure (2QTS) and the cASIC1-PcTx1 complexes have continuous TM2 helices. It is currently not clear which of these pore structures is more realistic, although the cASIC1-MitTx structure may be favored because it has a higher resolution, shows a 3 -fold symmetry, and seems to be compatible with known ASIC functions.

4. Difference and Similarities between the AcidSensing Ion Channels and Epithelial $\mathrm{Na}^{+}$Channel Subunit Organization. In the extracellular domain, $\mathrm{ENaC}$ and ASIC1 show the highest sequence homology 
in the palm and the $\beta$-ball $(\sim 35 \%)$. Although the sequence homology is lower in the peripheral domains finger, thumb, and knuckle, there is evidence for structural homology in most of these domains (Kashlan et al., 2011; Kashlan and Kleyman, 2011) (Fig. 3C). The predicted secondary structure of the $\mathrm{ENaC}$ thumb matches the crystal ASIC structure (although the $\alpha 5$ helices do not align well), and the Cys residues forming the 5 disulfide bonds of the thumb are conserved. The predicted secondary structure of the knuckle matches the ASIC structure moderately well. ENaC and ASIC sequences share the lowest homology in the finger domain. In addition, $\mathrm{ENaC}$ contains an $\sim 80$-residue insertion in this domain. The low homology between $\mathrm{ENaC}$ and ASIC finger domains may be at the origin of the different activation mechanisms of these two channels. The transmembrane segments TM1 and TM2 share $\sim 20$ and 40\% homology, respectively, between ASIC and $\mathrm{ENaC}$. A model of $\alpha \mathrm{ENaC}$ has been constructed that, for the most part, is based on the cASIC1 structure 2QTS and in which the finger was modeled based on constraints derived from functional data and from secondary structure predictions (Kashlan et al., 2011) (Fig. 3C).

\section{B. Subunit Stoichiometry}

All published cASIC1 structures show the channel as a trimer (Jasti et al., 2007; Gonzales et al., 2009; Baconguis and Gouaux, 2012; Dawson et al., 2012; Baconguis et al., 2014). Recently, the counting of bleaching steps of fluorescently tagged mammalian ASIC1a and ASIC2a channels at the plasma membrane of Xenopus oocytes indicated that functional ASICs in a cellular environment are also trimers (Bartoi et al., 2014).

The subunit stoichiometry of the functional $\mathrm{ENaC}$ channel is still controversial. The total number of subunits that form the functional $\alpha \beta \gamma \mathrm{ENaC}$ complex as reported in the literature varies from 3 to 9 subunits (Firsov et al., 1998; Kosari et al., 1998; Eskandari et al., 1999; Dijkink et al., 2002; Anantharam and Palmer, 2007; Carnally et al., 2008). This likely reflects methodological problems in evaluating the subunit stoichiometry of a channel as well as uncertainties in the interpretation of the experimental data. However, before the crystallization of ASIC1, a general consensus based on functional and biochemical observations from different laboratories agreed on a tetrameric subunit oligomerization of ENaC involving two $\alpha$ subunits, and one $\beta$ and one $\gamma$ subunit. Data leading to this finding include the quantification of the relative abundance of $\mathrm{ENaC}$ subunits at the cell surface per functional channel, the dominant or recessive effects of mutations in a single subunit on channel block by ligands or on channel conductance, functional analysis of $\mathrm{ENaC}$ subunit concatemers, and biochemical determination of the molecular mass of the $\mathrm{ENaC}$ channel complex (Firsov et al., 1998; Kosari et al., 1998; Dijkink et al., 2002; Anantharam and Palmer, 2007).
After the release of the three-dimensional structure of ASIC1, the ENaC/DEG field seems to have settled that $\mathrm{ENaC}$ is a trimer, a dogma that still needs solid confirmation by experimental evidence.

\section{Channel Function and Regulation}

\section{A. Acid-Sensing Ion Channels}

1. Channel Gating and Ion Selectivity. For a long time, protons were the only known activators of ASICs. Recently it was shown, however, that the synthetic compound GMQ activates ASIC3 at $\mathrm{pH} 7.4$ (Yu et al., 2010). The spider toxin PcTx1 shifts ASIC pH dependencies, inhibiting ASIC1a under physiologic conditions and activating cASIC1 and rat ASIC1b at $\mathrm{pH}$ 7.4 and slightly acidic $\mathrm{pH}$, respectively (Chen et al., 2005, 2006; Samways et al., 2009; Baconguis and Gouaux, 2012). The recently identified MitTx activates ASICs by a currently unknown mechanism (Bohlen et al., 2011). GMQ and the toxins are further discussed below (section VI). Currently it seems that protons are the only physiologic activators of ASICs.

a. Current kinetics. Acid-induced opening of homomultimeric ASICs is under most conditions transient, because it is rapidly followed by desensitization (Waldmann et al., 1997b) (Fig. 4A). This can be described by a kinetic model containing a closed, an open, and a desensitized state (Fig. 4B). Time constants of channel opening kinetics of 10 milliseconds or less have been measured for ASIC1a, ASIC1b, and ASIC3 under very rapid solution change conditions at $\mathrm{pH} \leq 6$ (Bassler et al., 2001; Sutherland et al., 2001; Li et al., $2010 \mathrm{~b})$. In most of the published functional ASIC studies, the observed kinetics of channel opening are probably limited by the speed of the solution change. Desensitization is fastest in ASIC3 and slowest in ASIC2a (Fig. 4A; Table 2). ASIC3 activation by $\mathrm{pH} \sim 7$ and by $\mathrm{pH}<5$ induces a sustained current component in addition to the transient current (Waldmann et al., 1997a; Yagi et al., 2006). Sustained currents were also observed with ASIC heteromers (Lingueglia et al., 1997; Benson et al., 2002). They may mediate ASIC function in slow and long-lasting $\mathrm{pH}$ changes. Human ASIC3 is not only activated by extracellular acidification. Changes to a $\mathrm{pH}$ more alkaline than the physiologic values can induce a sustained ASIC3 current (Delaunay et al., 2012).

b. Ion selectivity. Transient ASIC currents are $\mathrm{Na}^{+}$ selective with a $\mathrm{Na}^{+} / \mathrm{K}^{+}$permeability ratio of $\sim 10$ (Table 2) (Kellenberger and Schild, 2002). Homomeric ASIC1a and heteromeric ASIC1a/2b have in addition a low permeability to $\mathrm{Ca}^{2+}\left(\mathrm{Na}^{+} / \mathrm{Ca}^{2+}\right.$ permeability ratio between 1.8 and 18.5, depending on study), which is likely important for some of their physiologic and pathologic roles (Waldmann et al., 1997b; Bassler et al., 2001; Samways et al., 2009; Sherwood et al., 2011). Although ASICs are also permeable to protons with an estimated $\mathrm{H}^{+} / \mathrm{Na}^{+}$permeability ratio of $<5$ for 
ASIC1a (Chen and Grunder, 2007), the contribution of $\mathrm{H}^{+}$to the ASIC current amplitude, under most conditions, is negligible because the $\mathrm{H}^{+}$concentration is orders of magnitude lower than the $\mathrm{Na}^{+}$concentration.

c. $p H$ dependence. From $\mathrm{pH}$-response curves of ASIC currents a $\mathrm{pH}_{50}$ can be determined (Fig. 4C, shown for ASIC1a). $\mathrm{pH}_{50}$ values of $\sim 6.5$ have been measured for ASIC1a and ASIC3, indicating that these channels are activated by acidification to values just below $\mathrm{pH}$ 7. ASIC1b has a $\mathrm{pH}_{50}$ of $\sim 6.1$, whereas ASIC2a, with a $\mathrm{pH}_{50}$ of $\sim 4.5$, requires much higher proton concentrations for activation (Table 2). If ASICs are exposed to a moderately acidic $\mathrm{pH}$ they can desensitize without apparent opening, thus passing directly from the closed to the desensitized state (Waldmann et al., 1997b). This process that is analogous to closedstate inactivation of voltage-gated $\mathrm{Na}^{+}$channels is called steady-state desensitization (SSD). The steep part of its $\mathrm{pH}$ dependence is found for ASIC1a, $-1 \mathrm{~b}$, and -3 at slightly more acidic $\mathrm{pH}$ than physiologic values (Fig. 4C; Table 2). Changes in this $\mathrm{pH}$ dependence or in the basal $\mathrm{pH}$ can therefore affect the availability of ASICs for opening. A small overlap of the activation and the SSD curves in ASIC3 is at the origin of the small sustained current at pH 7 (Yagi et al., 2006). ASIC activity is also modulated by intracellular $\mathrm{pH}$. It was shown that the amplitude of ASIC currents in mouse cortical neurons was decreased by intracellular acidification due to an alkaline shift of the $\mathrm{pH}$ dependence of SSD and an acidic shift of the $\mathrm{pH}$ dependence of activation (Wang et al., 2006).

d. Coupling of activation and steady-state desensitization. Mutations affecting the $\mathrm{pH}$ dependence of activation change in many cases the $\mathrm{pH}$ dependence of SSD as well (Sherwood and Askwith, 2008; Bargeton and Kellenberger, 2010; Liechti et al., 2010), indicating that activation and desensitization are structurally coupled. Further support for a coupling of these two transitions comes from the observations that changes in the extracellular $\mathrm{Ca}^{2+}$ concentration, as well as application of PcTx1 or cleavage by proteases shift the $\mathrm{pH}$ dependence of both activation and SSD in ASIC1a (Babini et al., 2002; Poirot et al., 2004; Chen et al., 2006).

2. Regulation. ASIC function is regulated by many different modulators such as $\mathrm{Ca}^{2+} \mathrm{Zn}^{2+}$, redox reagents, free radicals, arachidonic acid (AA), kinases, and proteases, which are likely physiologically relevant.
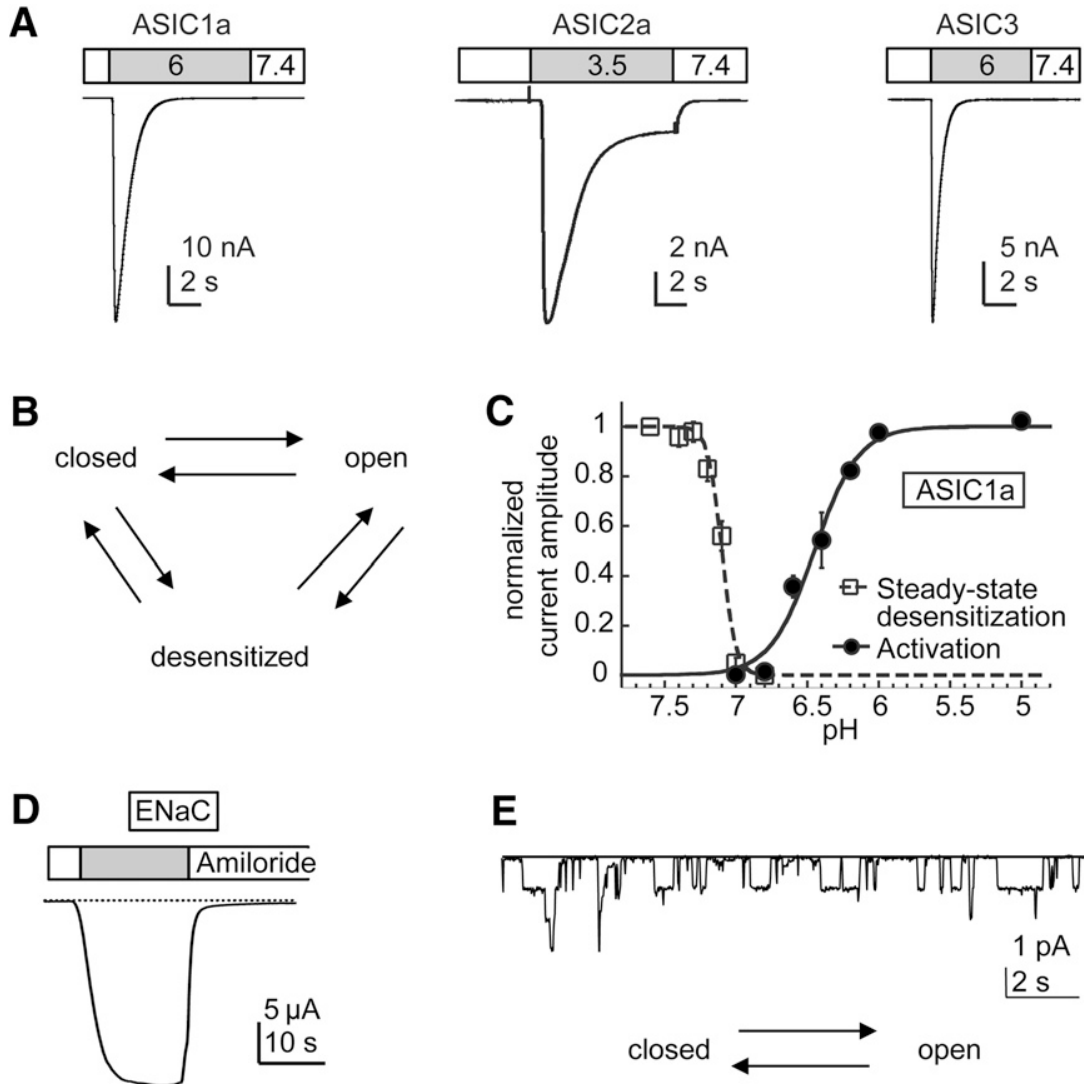

E

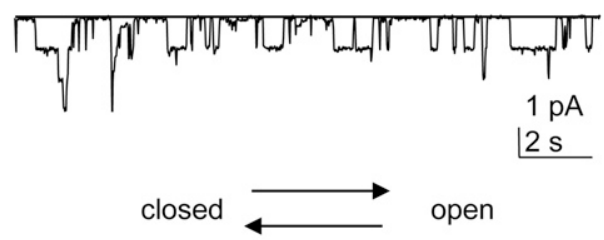

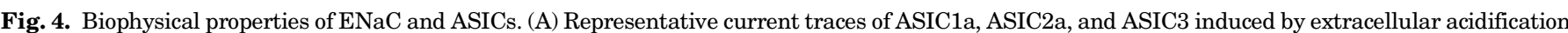

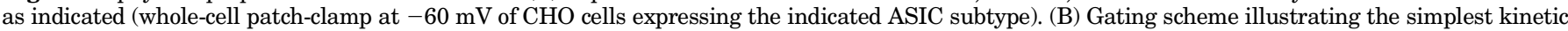

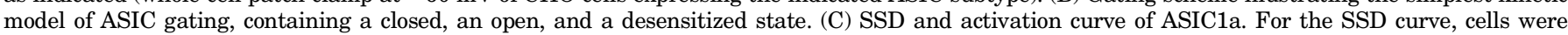

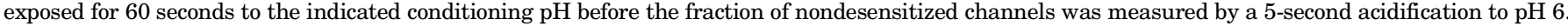

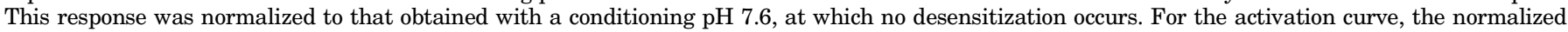

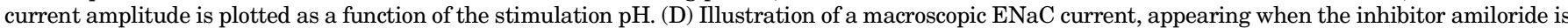

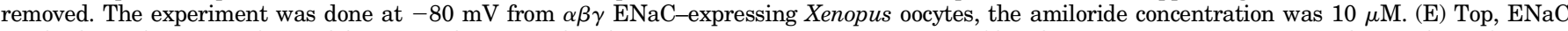
single-channel current, obtained from outside-out patches from Xenopus oocytes at $100 \mathrm{mM} \mathrm{LiCl}$ and $-130 \mathrm{mV}$. Bottom, gating scheme of ENaC. 
TABLE 2

ASIC and ENaC properties

Data are from many different studies and reviews (Sutherland et al., 2001; Hesselager et al., 2004; Poirot et al., 2004; Blanchard and Kellenberger, 2011; Alijevic and

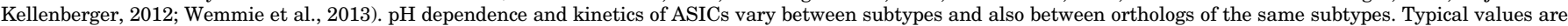
indicated here. For more information, see the relevant chapters.

\begin{tabular}{|c|c|c|c|c|c|c|}
\hline & $\begin{array}{l}\text { IC }_{50} \text { Amiloride } \\
\text { Inhibition }^{a}\end{array}$ & $\begin{array}{c}\mathrm{Na}^{+} / \mathrm{K}^{+} \\
\text {Permeability Ratio }\end{array}$ & $\begin{array}{c}\mathrm{pH}_{50} \\
\text { Activation }\end{array}$ & $\begin{array}{c}\mathrm{pHD}_{50} \text { Steady-State } \\
\text { Desensitization }\end{array}$ & $\begin{array}{l}\text { Desensitization Time Constant } \\
\quad \text { (at } \mathrm{pH} \text { Close to } \mathrm{pH}_{50} \text { ) }\end{array}$ & $\begin{array}{l}\text { Most Important } \\
\text { Sites of Expression }\end{array}$ \\
\hline & $\mu M$ & & & & $s$ & \\
\hline ASIC1a & 10 & $6-13$ & $6.2-6.6$ & $\sim 7.2$ & $\sim 0.4$ & CNS, PNS \\
\hline ASIC1b & 21 & $\sim 3$ & $5.9-6.3$ & $\sim 6.7$ & $\sim 0.9$ & PNS \\
\hline ASIC2a & 28 & $\sim 10$ & $4.0-4.9$ & $\sim 5.6$ & $\sim 1.4$ & CNS, PNS \\
\hline ASIC3 & $60-100$ & $\sim 12$ & $6.4-6.7$ & $\sim 7.1$ & $\sim 0.3$ & PNS \\
\hline $\mathrm{ENaC} \alpha \beta \gamma$ & 0.1 & $\geq 100$ & N.A. & N.A. & N.A. & Kidney, colon, lung \\
\hline
\end{tabular}

N.A., not applicable; $\mathrm{pHD}_{50}$, $\mathrm{pH}$ of half-maximal desensitization.

${ }^{a}$ For transient ASIC current component.

We discuss here the most important modulators of ASIC function and provide an overview in Tables 3 and 4. For a more exhaustive discussion of ASIC modulation see also Chu et al. (2011) and Wemmie et al. (2013).

a. Regulation by protein-protein interactions. As many other membrane proteins, ASICs interact with other proteins, some of which have been identified in the last years, as shown in Table 3 (Wemmie et al., 2006). ASICs were shown to interact mostly with scaffolding proteins and with other ion channels. PDZ binding domains at the cytoplasmic $\mathrm{C}$ terminus were involved in many of these interactions. In many cases, these interactions affect the cell surface expression or localization of ASICs, their regulation, or their gating. Currently, most of these interactions have been shown in cellular systems and their in vivo relevance is not known.

b. Regulation by ions, small molecules, and proteins.

i. Calcium and Other Divalent or Polyvalent Cations. The extracellular $\mathrm{Ca}^{2+}$ concentration affects ASIC $\mathrm{pH}$ dependence in a way that suggests a competition between $\mathrm{Ca}^{2+}$ and $\mathrm{H}^{+}$for a common binding site. It has been shown that increasing the extracellular $\mathrm{Ca}^{2+}$ concentration in the range of low micromolars to $10 \mathrm{mM}$ shifts the $\mathrm{pH}$ dependence of activation to more acidic values in ASIC1a and ASIC3 (Babini et al., 2002; Immke and McCleskey, 2003). A similar $\mathrm{Ca}^{2+}$-dependent shift has also been shown for the $\mathrm{pH}$ dependence of SSD in ASIC1a and ASIC1b, and other divalent or polyvalent cations $\left(\mathrm{Mg}^{2+}, \mathrm{Ba}^{2+}\right.$, spermine) had similar effects as $\mathrm{Ca}^{2+}$ (Babini et al., 2002). The spermine-induced increase in neuronal injury in animal stroke models might be due to such a mechanism (Duan et al., 2011). In addition to its effects on gating, extracellular $\mathrm{Ca}^{2+}$ also inhibits maximal currents by a pore block with an $\mathrm{IC}_{50}$ of the order of millimolars. The decrease of the unitary conductance by $\mathrm{Ca}^{2+}$ has been demonstrated in ASIC1a, ASIC2a, and ASIC3 (de Weille and Bassilana, 2001; Immke and McCleskey, 2003; Paukert et al., 2004; Zhang et al., 2006). Depending on the $\mathrm{pH}$ conditions, an increase in extracellular $\mathrm{Ca}^{2+}$ concentration can therefore either increase current amplitudes due to an acidic shift of the $\mathrm{SSD} \mathrm{pH}$ dependence or decrease them due to the shift of the activation $\mathrm{pH}$ dependence and the pore block (Waldmann et al., 1997b; Babini et al., 2002; Wu et al., 2004). The $\mathrm{Ca}^{2+}$ blocking site in ASIC1a is formed by E426 and D433 of the extracellular pore entry (Paukert et al., 2004) (cASIC1 numbering, Fig. 6B). Its localization in other ASICs is not known. The $\mathrm{Ca}^{2+}$ binding site mediating the shift in $\mathrm{pH}$ dependence has not been identified yet. The $\mathrm{Ca}^{2+}$ and $\mathrm{H}^{+}$dependence of ASIC3 currents is compatible with a mechanism of $\mathrm{H}^{+}$-induced opening of ASIC3 by relieving a constitutive pore block by $\mathrm{Ca}^{2+}$ (Immke and McCleskey, 2003). However, two articles strongly indicate that ASIC1a is not opened by this mechanism. After mutation of the residues forming the $\mathrm{Ca}^{2+}$ binding site in the ASIC1a pore, the mutant channels were not constitutively open but still activated by protons (Paukert et al., 2004). In toadfish ASIC1, lowering of the $\mathrm{Ca}^{2+}$ concentration progressively opened more channels and did not show properties associated with a pore block, such as, e.g., an increase in the mean open time (Zhang et al., 2006).

Anaerobic metabolism during ischemia can lead to extracellular lactate concentrations of $12-20 \mathrm{mM}$ (normally $\sim 1 \mathrm{mM}$ (Schurr, 2002). At these concentrations, lactate potentiated ASIC1a and ASIC3 currents, as well as ASIC currents of PNS and CNS neurons (Immke and McCleskey, 2001; Allen and Attwell, 2002). Lactate is a weak chelator of $\mathrm{Ca}^{2+}$ and other divalent cations. It appears that the induced reduction of free $\mathrm{Ca}^{2+}$ concentration is sufficient to increase the ASIC currents (Immke and McCleskey, 2001).

ii. Zinc. ASIC1a is inhibited by nanomolar concentrations of $\mathrm{Zn}^{2+}$, whereas micromolar concentrations are needed to inhibit ASIC1b and ASIC3 (Chu et al., 2004; Poirot et al., 2006; Jiang et al., 2010, 2011). The inhibition of ASIC1b and ASIC3 is pH-independent, whereas an acidic shift of the $\mathrm{pH}$ dependence of activation contributes to the $\mathrm{Zn}^{2+}$ inhibition of ASIC1a. Interestingly, $\mathrm{H}^{+}$-induced currents mediated by ASIC2containing channels are potentiated by $\mathrm{Zn}^{2+}$ due to an alkaline shift in the $\mathrm{pH}$ dependence of activation (Baron et al., 2001). Residues important for the effects of $\mathrm{Zn}^{2+}$ were identified in the finger of ASIC1a and ASIC1b and in the finger and thumb of ASIC2a (Baron et al., 2001; 
TABLE 3

ASIC protein interaction partners

\begin{tabular}{|c|c|c|c|c|c|}
\hline Interaction Partner & $\begin{array}{c}\text { ASIC } \\
\text { Subtypes } \\
\text { Concerned }\end{array}$ & $\begin{array}{l}\text { Site of } \\
\text { interaction } \\
\text { on ASIC }(\mathrm{C} \text { or } \\
\mathrm{N} \text { Terminus })^{a}\end{array}$ & Consequences & System & References \\
\hline $\begin{array}{l}\text { A kinase-anchoring protein } \\
\text { (AKAP) } 79 / 150 \text { and } \\
\text { calcineurin }\end{array}$ & $1 \mathrm{a}, 2 \mathrm{a}$ & $\begin{array}{l}\text { ASIC2a: } \\
\text { N \& C, } \\
\text { ASIC1a: C }\end{array}$ & $\begin{array}{l}\text { AKAP } 150 \text { binding increases } \\
\text { ASIC currents; calcineurin } \\
\text { decreases ASIC currents. }\end{array}$ & $\begin{array}{l}\text { Transfected cortical } \\
\text { neurons or } \\
\text { CHO cells }\end{array}$ & Chai et al., 2007 \\
\hline $\begin{array}{l}\text { Channel-interacting PDZ } \\
\text { domain protein (CIPP) }\end{array}$ & 3 & $\mathrm{C}, \mathrm{PDZ}$ & $\begin{array}{l}\text { Enhances peak current } \\
\text { amplitude of ASIC3 }\end{array}$ & $\begin{array}{l}\text { Transfected COS } \\
\text { cells }\end{array}$ & Anzai et al., 2002 \\
\hline PICK1 & $1 \mathrm{a}, 2 \mathrm{a}, 2 \mathrm{~b}$ & $\mathrm{C}, \mathrm{PDZ}$ & $\begin{array}{l}\text { Affects localization of ASIC1a } \\
\text { and allows ASIC2a current } \\
\text { increase by PKC. } \\
\text { Allows current increase of } \\
\text { ASIC2b/3 channels by } \\
\text { PICK1-dependent PKC } \\
\text { phosphorylation of ASIC3. }\end{array}$ & $\begin{array}{l}\text { Mainly recombinant } \\
\text { expression } \\
\text { systems }\end{array}$ & $\begin{array}{l}\text { Baron et al., 2002; Duggan } \\
\text { et al., 2002; Hruska- } \\
\text { Hageman et al., 2002; } \\
\text { Deval et al., } 2004\end{array}$ \\
\hline $\operatorname{Lin} 7 \mathrm{~B}$ & 3 & $\mathrm{C}, \mathrm{PDZ}$ & $\begin{array}{l}\text { Increases ASIC3 cell surface } \\
\text { expression and current } \\
\text { amplitude }\end{array}$ & $\begin{array}{l}\text { Transfected } \mathrm{CHO} \\
\text { cells }\end{array}$ & $\begin{array}{l}\text { Hruska-Hageman } \\
\text { et al., } 2004\end{array}$ \\
\hline $\begin{array}{l}\text { MAGI-1b (membrane- } \\
\text { associated guanylate } \\
\text { kinase) }\end{array}$ & 3 & $\mathrm{C}, \mathrm{PDZ}^{b}$ & $\begin{array}{l}\text { Increases ASIC3 current } \\
\text { amplitude }\end{array}$ & $\begin{array}{l}\text { Transfected } \mathrm{CHO} \\
\text { cells }\end{array}$ & $\begin{array}{l}\text { Hruska-Hageman } \\
\text { et al., } 2004\end{array}$ \\
\hline PIST & 3 & $\mathrm{C}, \mathrm{PDZ}^{b}$ & $\begin{array}{l}\text { Increases ASIC3 current } \\
\text { amplitude }\end{array}$ & $\begin{array}{l}\text { Transfected } \mathrm{CHO} \\
\text { cells }\end{array}$ & Hruska-Hageman et al., 2004 \\
\hline PSD95 & 3 & $\mathrm{C}$ & $\begin{array}{l}\text { Reduces ASIC3 cell surface } \\
\text { expression and current } \\
\text { amplitude }\end{array}$ & $\begin{array}{l}\text { Transfected } \mathrm{CHO} \\
\text { cells }\end{array}$ & $\begin{array}{l}\text { Hruska-Hageman } \\
\text { et al., 2004; Eshcol et al., } \\
\text { 2008; Zha et al., } 2009\end{array}$ \\
\hline Stomatin & $1,2,3$ & NR & $\begin{array}{l}\text { Inhibits ASIC3 current } \\
\text { amplitude and accelerates } \\
\text { ASIC2a desensitization }\end{array}$ & & Price et al., 2004 \\
\hline $\begin{array}{l}\text { Stomatin-like proteins } \\
\text { (STOML) }\end{array}$ & $1,2,3$ & NR & $\begin{array}{l}\text { ASIC- and STOML-subtype- } \\
\text { dependent, inhibition of } \\
\text { current amplitude and } \\
\text { acceleration of desensitization }\end{array}$ & $\begin{array}{l}\text { Transfected cells, } \\
\text { neurons }\end{array}$ & $\begin{array}{l}\text { Lapatsina et al., } 2012 ; \\
\text { Kozlenkov et al., } 2014\end{array}$ \\
\hline $\begin{array}{l}\mathrm{Na}^{+} / \mathrm{H}^{+} \text {exchanger regulatory } \\
\text { factor }(\mathrm{NHERF})\end{array}$ & 3 & $\mathrm{C}, \mathrm{PDZ}^{b}$ & $\begin{array}{l}\text { Increases ASIC current } \\
\text { amplitude }\end{array}$ & Various cell lines & Deval et al., 2006 \\
\hline Annexin II light chain p11.1 & $1 \mathrm{a}$ & $\mathrm{N}$ & $\begin{array}{l}\text { Increases cell surface } \\
\text { expression and current } \\
\text { amplitude }\end{array}$ & $\begin{array}{l}\text { DRG neurons and } \\
\text { transfected cells }\end{array}$ & Donier et al., 2005 \\
\hline$\alpha$-Actinin & $1 \mathrm{a}$ & $\mathrm{C}$ & $\begin{array}{l}\text { Effect on ASIC1a current } \\
\text { amplitude and properties, } \\
\text { depending on actinin subtype }\end{array}$ & $\begin{array}{l}\text { Cell lines and } \\
\text { neurons }\end{array}$ & Schnizler et al., 2009 \\
\hline $\begin{array}{l}\text { High-conductance } \mathrm{Ca}^{2+} \text { - and } \\
\text { voltage-activated } \mathrm{K}^{+}(\mathrm{BK}) \\
\text { channel }\end{array}$ & $1 \mathrm{a}$ & NR & Reciprocal current inhibition & $\begin{array}{l}\text { Transfected cells } \\
\text { and neurons }\end{array}$ & Petroff et al., 2008, 2012 \\
\hline P2X channels & 3 & NR & $\begin{array}{l}\text { ATP sensitizes ASIC3 for } \\
\text { activation by protons }\end{array}$ & $\begin{array}{l}\text { Neurons and } \\
\text { transfected cells }\end{array}$ & Birdsong et al., 2010 \\
\hline
\end{tabular}

NR, not resolved

a"PDZ" in this column indicates that the interacting protein binds to the ASIC PDZ binding domain.

${ }^{b}$ ASIC3 PDZ binding domain is different from that of ASIC1 and ASIC2. These proteins did not bind to ASIC1 or ASIC2.

Chu et al., 2004; Jiang et al., 2011). Lys134, which is critical for ASIC1a inhibition by $\mathrm{Zn}^{2+}$, is also involved in the redox regulation of ASIC1a (Chu et al., 2006; Cho and Askwith, 2007).

iii. Neuropeptides. The short peptide FMRFamide activated the ENaC/DEG family member FaNaC (Lingueglia et al., 1995). In ASICs, dynorphins and the shorter RFamide peptides shift the $\mathrm{pH}$ dependence of SSD to more acidic values. The RFamide peptides also slow the kinetics of desensitization and induce a sustained current in some ASICs (Askwith et al., 2000; Lingueglia et al., 2006; Sherwood and Askwith, 2009; Sherwood et al., 2012). FMRFamide and structurally related peptides are abundant in the invertebrate nervous system where they function as neurotransmitters and modulators. Related peptides are also found in mammals and exert most of their effects by binding to
$\mathrm{G}$ protein-coupled receptors. These peptides affect the function of ASIC1 and ASIC3, but not ASIC2. The $\mathrm{EC}_{50}$ of dynorphin A and the RFamide peptides for ASIC modulation are on the order of 10-50 $\mu \mathrm{M}$, whereas big dynorphin shifts the SSD of ASIC1a with an $\mathrm{EC}_{50}$ of $\sim 30 \mathrm{nM}$ (Lingueglia et al., 2006; Sherwood and Askwith, 2009). FMRFamide modulates the function of ASICs directly, although the exact binding site is still not known. Residues in the loop linking $\beta 9$ of the palm to $\alpha 4$ of the thumb are involved in the effects of RFamide peptides on ASIC1a, although they do not form their binding site (Sherwood and Askwith, 2008). A competition with PcTx1 may suggest that dynorphins bind to the acidic pocket (Sherwood et al., 2012).

iv. Redox Reagents and Free Radicals. ASIC modulation by reducing and oxidizing reagents, mostly studied with recombinant ASIC1a or in neurons, showed 
TABLE 4

ASIC modulators

Interacting proteins, toxins, and pharmacological agents are not included in this table. Only most directly-linked references are indicated. For more exhaustive indication of references see text.

\begin{tabular}{|c|c|c|c|c|}
\hline Class & Example & Effect & Site of Action & References \\
\hline \multirow[t]{3}{*}{ Divalent cations } & $\mathrm{Ca}^{2+}, \mathrm{Ba}^{2+}, \mathrm{Mg}^{2+}$ & $\begin{array}{l}\text { Acidic shift of } \mathrm{pH} \text { dependence } \\
\text { of activation and SSD } \\
\text { Pore block }\end{array}$ & $\begin{array}{l}\text { Not known for shift of } \mathrm{pH} \\
\text { dependence } \\
\text { Acidic residues in the pore } \\
\text { entry for pore block of } \\
\text { ASIC1a }\end{array}$ & $\begin{array}{l}\text { Babini et al., 2002; Immke } \\
\text { and McCleskey, 2003; } \\
\text { Paukert et al., } 2004\end{array}$ \\
\hline & $\mathrm{Zn}^{2+}$ & $\begin{array}{l}\text { Inhibits ASIC1a, ASIC1b, } \\
\text { and ASIC3 }\end{array}$ & $\begin{array}{l}\text { Inhibitory site on the finger } \\
\text { domain of ASIC1a }\end{array}$ & Chu et al., 2004 \\
\hline & & $\begin{array}{l}\text { Potentiates ASIC2-containing } \\
\text { channels }\end{array}$ & $\begin{array}{l}\text { Potentiating sites in thumb } \\
\text { and finger of ASIC } 2 \mathrm{a}\end{array}$ & Baron et al., 2001 \\
\hline \multirow[t]{2}{*}{ Polyamines } & Spermine & $\begin{array}{l}\text { Acidic shift of } \mathrm{pH} \text { dependence } \\
\text { of } \mathrm{SSD} \text {, leading to a } \\
\text { current increase }\end{array}$ & Extracellular & $\begin{array}{l}\text { Babini et al., } 2002 ; \\
\text { Duan et al., } 2011\end{array}$ \\
\hline & Agmatine & Activates ASIC3 & Involvement of palm ${ }^{a}$ & Li et al., 2010c \\
\hline $\begin{array}{l}\text { Redox reagents } \\
\text { and free radicals }\end{array}$ & $\begin{array}{l}\mathrm{H}_{2} \mathrm{O}_{2} \text {, dithiothreitol, } \\
\text { nitric oxide }\end{array}$ & $\begin{array}{l}\text { Peak current increase by } \\
\text { reducing agents and nitric } \\
\text { oxide, inhibition by } \\
\text { oxidizing agents }\end{array}$ & $\begin{array}{l}\text { Nitric oxide acts } \\
\text { extracellularly }\end{array}$ & $\begin{array}{l}\text { Andrey et al., 2005; Chu et al., } \\
\text { 2006; Cadiou et al., 2007; } \\
\text { Cho and Askwith, } 2007\end{array}$ \\
\hline Neuropeptides & $\begin{array}{l}\text { FMRFamide, } \\
\text { dynorphin }\end{array}$ & $\begin{array}{l}\text { Shift the pH dependence of } \\
\text { SSD to more acidic values } \\
\text { Slow the kinetics of } \\
\text { desensitization and may } \\
\text { induce a sustained current } \\
\text { These effects are observed } \\
\text { with ASIC1 and ASIC3 } \\
\text { but not ASIC2a }\end{array}$ & Extracellular & $\begin{array}{l}\text { Askwith et al., 2000; } \\
\text { Sherwood and Askwith, } \\
2009\end{array}$ \\
\hline GPCR activators & $\begin{array}{l}\text { Serotonin, cannabinoid } \\
\text { receptor agonists }\end{array}$ & $\begin{array}{l}\text { Depending on the compound, } \\
\text { potentiation or Inhibition }\end{array}$ & $\begin{array}{l}\text { Effects via GPCR or directly } \\
\text { on ASICs }\end{array}$ & $\begin{array}{l}\text { Qiu et al., 2012; } \\
\text { Wang et al., } 2013\end{array}$ \\
\hline Proteases & $\begin{array}{l}\text { Trypsin, tissue } \\
\text { kallikrein }\end{array}$ & $\begin{array}{l}\text { Acidic shift the } \mathrm{pH} \\
\text { dependence of activation } \\
\text { and SSD of ASIC1a }\end{array}$ & $\begin{array}{l}\text { Trypsin cleaves ASIC1a in } \\
\text { the finger domain }\end{array}$ & $\begin{array}{l}\text { Poirot et al., 2004; Vukicevic } \\
\quad \text { et al., 2006; Su et al., } 2011\end{array}$ \\
\hline Protein kinases & PKA, PKC & $\begin{array}{l}\text { Affecting expression and } \\
\text { function of ASICs }\end{array}$ & $\begin{array}{l}\text { Intracellular } \\
\text { phosphorylation sites }\end{array}$ & $\begin{array}{l}\text { Baron et al., 2002; Leonard } \\
\text { et al., 2003; Deval et al., } \\
\text { 2004; Gao et al., } 2005\end{array}$ \\
\hline \multirow[t]{3}{*}{ Other } & Arachidonic acid & $\begin{array}{l}\text { Increases the peak currents } \\
\text { and induces in some ASIC } \\
\text { types a sustained current }\end{array}$ & Not known & $\begin{array}{l}\text { Allen and Attwell, } 2002 \text {; } \\
\text { Smith et al., } 2007\end{array}$ \\
\hline & Lactic acid & $\begin{array}{l}\text { Increases ASIC currents, } \\
\text { most likely by chelating } \\
\text { extracellular divalent cations }\end{array}$ & $\begin{array}{l}\text { Probably not acting directly } \\
\text { on ASICs }\end{array}$ & Immke and McCleskey, 2001 \\
\hline & ATP & $\begin{array}{l}\text { Increases pH sensitivity } \\
\text { of ASIC3 }\end{array}$ & $\begin{array}{l}\text { Probably through } \mathrm{P} 2 \mathrm{X} \\
\text { receptors }\end{array}$ & Birdsong et al., 2010 \\
\hline
\end{tabular}

GPCR, G protein-coupled receptor; PKC, protein kinase C

${ }^{a}$ One study concluded that the related GMQ binds to the palm of ASIC3, whereas another study showed that mutation of a putative binding site residue affected only one aspect of GMQ function (section VI.A.1.b).

a current increase (up to $\sim 3$-fold) by reducing reagents and an inhibition by oxidizing reagents (Andrey et al., 2005; Chu et al., 2006; Cho and Askwith, 2007). Depending on the conditions, the effects of reducing agents were in some cases only slowly reversible. The peak current increase by reducing agents was due to an alkaline shift of the $\mathrm{pH}$ dependence of activation in recombinant ASIC1a and in ASICs of mouse cortical neurons (Chu et al., 2006; Cho and Askwith, 2007). In recombinant ASIC1a and ASICs from trigeminal neurons, reducing agents also slowed the desensitization kinetics (Andrey et al., 2005; Cho and Askwith, 2007). There remains a controversy about the subunit specificity of ASIC redox modulation and about the involvement of heavy metal chelation in the effects of reducing agents. One study showed that only ASIC1a is redox-modulated and that chelation of $\mathrm{Zn}^{2+}$ is not involved (Chu et al., 2006), whereas another study provided evidence of redox modulation of all homomeric ASIC currents and showed that dithiothreitol had no additional effect after application of a heavy metal chelator (Cho and Askwith, 2007).

The inflammatory mediator nitric oxide (NO) regulates protein function either by an indirect mechanism involving the production of cGMP or directly by $S$-nitrosylation of Cys residues, which can lead to disulfide bond formation. NO donors increased peak current amplitudes of all homomeric ASICs by up to $\sim 2.5$-fold. 
For ASIC1a, it was shown that this was due to an alkaline shift in the $\mathrm{pH}$ dependence of activation. $\mathrm{NO}$ acted directly on the ASIC ectodomain; however, the site of action is not known. Topical application of the NO donor glyceryl trinitrate increased acid-induced pain in human volunteers (Cadiou et al., 2007).

$v$. Arachidonic Acid. AA is a metabolite of membrane phospholipids produced by phospholipase $\mathrm{A}_{2}$. Its concentration is increased in ischemia and inflammation and it has been shown to modulate the function of several channel types (Chu et al., 2011). AA potentiated ASIC currents by up to $\sim 2.5$-fold in neurons of the CNS and the PNS and of recombinant ASIC1a and ASIC3 and in many cases increased the sustained current fraction (Allen and Attwell, 2002; Smith et al., 2007). It was shown that the AA-induced current increase of ASIC3 is due to an alkaline shift of the $\mathrm{pH}$ dependence of activation (Deval et al., 2008).

vi. $G$ Protein-Coupled Receptors. Serotonin and other inflammatory mediators, such as nerve growth factor, increase ASIC mRNA levels (Mamet et al., 2002). Serotonin or subtype-specific 5-HT receptor agonists also potentiated ASIC currents in sensory neurons (Deval et al., 2004), either through a direct action on ASIC3 (Wang et al., 2013) or via activation of 5- $\mathrm{HT}_{2}$ receptors (Qiu et al., 2012). Both serotonin and the 5 - $\mathrm{HT}_{2}$ agonist $\alpha$-methyl-5-HT increased acid-induced nociceptive responses.

The cannabinoid receptor agonist WIN55,212-2 $[(R)$ (+)-[2,3-dihydro-5-methyl-3-(4-morpholinylmethyl)pyrrolo [1,2,3-de]-1,4-benzoxazin-6-yl]-1-naphthalenylmethanone] inhibited ASIC currents of DRG neurons by up to $\sim 50 \%$ with an $\mathrm{IC}_{50}$ of $\sim 10 \mathrm{nM}$, without shifting the ASIC pH dependence (Liu et al., 2012). This inhibition was mediated by cannabinoid receptor type 1 .

vii. Proteases. Stroke, brain injury, and other pathologic conditions can compromise the integrity of the blood-brain barrier and allow blood-derived proteases to access the CNS (Gingrich and Traynelis, 2000). Serine proteases modulate the function of various ion channels, including the ASICs (Poirot et al., 2004) and ENaC (see section V.B.2). Trypsin and other serine proteases shift the $\mathrm{pH}$ dependence of SSD and activation of ASIC1a to more acidic values. This decreases ASIC currents under physiologic $\mathrm{pH}$ conditions but increases the current amplitudes in situations of constitutively lowered $\mathrm{pH}$ such as ischemia. The current modulation is due to cleavage of the ASIC1a protein in the finger, at Arg146 (Fig. 5B) (Vukicevic et al., 2006), in the same subdomain as the cleavage of $\alpha$ and $\gamma \mathrm{ENaC}$. Exposure of ASIC1a to trypsin reduced the relative $\mathrm{Ca}^{2+}$ permeability (Neaga et al., 2005), which may reduce the cellular toxicity of prolonged ASIC activity. Tissue kallikrein that was shown to cleave ASIC1a, but not ASIC2a, protected ASIC1a-expressing cells from acidosis-induced injury (Su et al., 2011). This study did not test whether cleavage changed the functional properties of ASIC1a; however, the protective effect is likely due to a changed function of ASIC1a.

viii. Kinases. The protein kinase $\mathrm{C}(\mathrm{PKC})$ activator 1-oleyl-2-acetyl-sn-glycerol potentiates ASIC2a currents only in the presence of protein interacting with C kinase 1 (PICK1) (Baron et al., 2002). PICK1 interaction sites were found on ASIC1a, -2a, and $2 \mathrm{~b}$ (Baron et al., 2002; Duggan et al., 2002; HruskaHageman et al., 2002; Deval et al., 2004). The PKC modulation of ASIC2a currents requires the presence of the PDZ domain of PICK1 and the PDZ binding domain on the $\mathrm{C}$ terminus of ASIC2a and involves phosphorylation of residue T39 in the cytoplasmic N terminus. A phorbol ester activating PKC enhances ASIC2b/3 currents by inducing an alkaline shift in their $\mathrm{pH}$ dependence of activation (Deval et al., 2004). The presence of PICK1 and its binding site on the ASIC2b C terminus are required for this effect, which involves phosphorylation of ASIC3 residues. The basal ASIC3 expression in sensory neurons depends on the activation of neurotrophic tyrosine kinase receptor type 1 by nerve growth factor, which in turn leads to activation of the phospholipase C/PKC pathway (Mamet et al., 2003). In contrast to ASIC2, ASIC1a is not phosphorylated by PKC, but by protein kinase A (Leonard et al., 2003). Protein kinase A phosphorylates residue S479 of the $\mathrm{C}$ terminus and disrupts the binding of PICK1, thereby affecting the localization of ASIC1a.

In global ischemia, intracellular $\mathrm{Ca}^{2+}$ concentrations are increased because of, among other mechanisms, the activity of NMDA receptors, leading to activation of the calcium/calmodulin-dependent protein kinase II that phosphorylates the C-terminal residues S478 and S479 of ASIC1a (Gao et al., 2005). This sensitizes the channel to protons and thus potentiates its currents.

\section{B. Epithelial $\mathrm{Na}^{+}$Channel}

$\mathrm{ENaC}$ is constitutively active at the cell surface and transits between open and closed conformations with an average open probability of $\sim 0.5$ (Palmer and Frindt, 1996) (Fig. 4, D and E). During its short lifetime at the cell surface, the channel evolves between different gating modes of high and low open probability before its internalization (Garty and Palmer, 1997; Shimkets et al., 1997; Kleyman et al., 2001; Palmer et al., 2012).

1. Intrinsic Regulation. $\mathrm{Na}^{+}$ions constitute one of the different factors that directly modulate $\mathrm{ENaC}$ at the cell surface and affect ENaC activity by two mechanisms. The so-called $\mathrm{Na}^{+}$feedback inhibition is a decrease in $\mathrm{ENaC}$ activity upon an increase in cytosolic $\mathrm{Na}^{+}$concentration due to the rapid entry of $\mathrm{Na}^{+}$ ions into the cell. This inhibition develops over a time course of minutes and is due to a decrease in both the number of $\mathrm{ENaC}$ channels at the cell surface and to a reduction of their open probability (Frindt et al., 1993, 1995; Anantharam et al., 2006). $\mathrm{Na}^{+}$self-inhibition refers to a rapid decrease in $\mathrm{ENaC}$ activity after an 
increase in extracellular $\mathrm{Na}^{+}$concentration (Fuchs et al., 1977; Horisberger and Chraibi, 2004; Bize and Horisberger, 2007). These regulatory processes tend to limit the $\mathrm{Na}^{+}$entry into a single cell to optimize $\mathrm{Na}^{+}$ absorption along the aldosterone-sensitive distal nephron.

In addition, intracellular perfusion of $\mathrm{SH}$-oxidizing agents or a decrease in intracellular $\mathrm{pH}$ also reduces $\mathrm{ENaC}$ activity (Chalfant et al., 1999; Kellenberger et al., 2005), but the physiologic relevance of these processes is less clear. The cytosolic $\mathrm{N}$ terminus of $\mathrm{ENaC}$ subunits contains a conserved $\mathrm{HG}$ motif and Cys residues that modulate channel gating (Grunder et al., 1997; Kellenberger et al., 2005). The importance of the cytosolic amino terminus as regulatory domain of $\mathrm{ENaC}$ was first evidenced by a mutation in the HG motif of ENaC associated PHA-1 (Chang et al., 1996). The ENaC channels carrying mutations in the HG motif show altered gating properties characterized by abnormally long closures and short channel openings corresponding to a loss of function mutation.

2. Serine Proteases. The extracellular domain between the two transmembrane helices represents more than half of the mass of ENaC/DEG proteins. A similar feature is found in the P2X channel family (Gonzales et al., 2009). Serine proteases regulate ENaC function by proteolytic cleavage. In vitro studies showed that soluble proteases, such as trypsin or chymotrypsin, potentiate $\mathrm{ENaC}$ activity, and functional cloning approaches allowed the identification of membranebound serine proteases as $\mathrm{ENaC}$ partners involved in channel activation (Vallet et al., 1997; Vuagniaux et al., 2000). Extracellular serine proteases stimulate $\mathrm{ENaC}$ directly by increasing the open probability independently of a $\mathrm{G}$ protein-coupled receptor (Chraibi et al., 1998). Among these proteases, the first identified was the mouse CAP-1 (channel activating protease-1), an ortholog of the human prostasin (Vallet et al., 1997). Subsequently, mouse CAP-2, an ortholog of the human transmembrane protease serine 4 (TRPMSS4), and mouse CAP-3 (ortholog of the human matriptase or epithin) were shown to stimulate $\mathrm{ENaC}$ to a similar extent (Vuagniaux et al., 2002; Andreasen et al., 2006). Later, the identification of a cleavage sequence for the furin-like proprotein convertase in the extracellular domain of the $\alpha$ and $\gamma \mathrm{ENaC}$ subunits suggested a possible role of furin in $\mathrm{ENaC}$ cleavage, $\mathrm{ENaC}$ sorting, and the control of $\mathrm{ENaC}$ activity at the cell surface (Hughey et al., 2004; Bruns et al., 2007). However, ENaC regulation by serine proteases appears quite complex, because cleavage of $\gamma$ $\mathrm{ENaC}$ by furin is not absolutely required for channel activation (Harris et al., 2008), suggesting a redundancy of serine proteases in $\mathrm{ENaC}$ activation. Proteases cleave $\alpha$ and $\gamma \mathrm{ENaC}$ at defined sites in the finger domain (Hughey et al., 2003; Carattino et al., 2008) (Fig. 5C). It has been proposed that a double cleavage in the $\alpha$ and $\gamma$ subunits removes an inhibitory peptide (26 residues in $\alpha$ and 43 residues in $\gamma \mathrm{ENaC}$ ), resulting in the activation of $\mathrm{ENaC}$ (Sheng et al., 2006; Bruns et al., 2007).

3. Hormonal Regulation. The activity of the channel at the cell surface is tightly regulated by hormones. They control the expression of active $\mathrm{ENaC}$ at the cell surface by interfering at different steps of the biosynthetic pathway such as transcription, translation, or membrane trafficking. Ultimately, these hormones are essential for the maintenance of $\mathrm{Na}^{+}$homeostasis and the control of blood pressure.

Aldosterone is the major regulator of $\mathrm{ENaC}$ in the ASDN. Aldosterone increases the synthesis of $\alpha \mathrm{ENaC}$ but not of $\beta$ or $\gamma \mathrm{ENaC}$ in the kidney, in contrast to the colon where aldosterone or dexamethasone increase the synthesis of $\beta$ and $\gamma$ only (Masilamani et al., 1999; Epple et al., 2000; Fuller et al., 2000; Loffing et al., $2000 \mathrm{~b}$ ). This increase in the synthesis of $\alpha \mathrm{ENaC}$ is accompanied by the redistribution of the $\mathrm{ENaC}$ subunits from an intracellular pool to the apical membrane of principal cells. Interestingly this also correlates with the presence of cleaved $\alpha$ and $\gamma \mathrm{ENaC}$ subunits at the cell surface (Frindt and Palmer, 2009b). The increase in the abundance of $\alpha \mathrm{ENaC}$ contributes to, but is not sufficient for, the increase in aldosterone-induced net $\mathrm{Na}^{+}$transport (Frindt et al., 2008), suggesting the contribution of other processes essential for the upregulation of $\mathrm{ENaC}$ by aldosterone.

Binding of aldosterone to the mineralocorticoid receptor allows the dimerization of the receptor, its migration to the nucleus, and the binding to hormoneresponsive elements on the DNA for the induction of transcriptional responses. Aldosterone-induced proteins likely play a role in the redistribution of $\mathrm{ENaC}$ to the cell surface by controlling the exocytic pathway. These proteins include SGK1 (serum- and glucocorticoidregulated kinase 1), the deubiquitylation enzyme USP245 and GILZ (glucocorticoid-induced leucine zipper) (Soundararajan et al., 2007). These proteins likely work in concert with the ubiquitin ligase Nedd4-2 that is involved in the endocytic pathway. No evidence supports a limiting role of these proteins for the aldosterone effect on $\mathrm{ENaC}$, because mouse models with complete knockout of the genes encoding these proteins (Nedd4-2, SGK, USP2-45, GILZ) failed to suppress the response of ENaC-mediated renal $\mathrm{Na}^{+}$absorption to aldosterone (Fejes-Toth et al., 2008; Suarez et al., 2012; Pouly et al., 2013; Ronzaud et al., 2013). The complete picture of the aldosterone signaling pathway that controls ENaCmediated $\mathrm{Na}^{+}$absorption remains therefore largely unknown.

Dexamethasone upregulates the abundance of different $\mathrm{Na}^{+}$transporters in the kidney and stimulates ENaC-mediated current in the principal cells of the CCD. Dexamethasone has additive effects on the abundance of $\alpha \mathrm{ENaC}$ when coadministered with aldosterone in rats, indicating that dexamethasone regulates $\mathrm{ENaC}$ synthesis by occupying the glucocorticoid receptors 
(Frindt and Palmer, 2012). This glucocorticoiddependent increase in $\alpha \mathrm{ENaC}$ synthesis is not associated with an increase in ENaC activity at the cell surface, further suggesting that still unidentified regulatory proteins, and not as previously thought the intracellular abundance of $\mathrm{ENaC}$ proteins, are rate-limiting for addressing $\mathrm{ENaC}$ channels to the apical membrane of principal cells, (Frindt and Palmer, 2012).

A recent report showed that $\mathrm{ENaC}$ activity in the late distal convoluted tubule and the connecting tubule is independent of aldosterone, suggesting the presence of other hormones involved in $\mathrm{ENaC}$ regulation (Nesterov et al., 2012). Angiotensin II upregulated the activity of the $\mathrm{Na}^{+} / \mathrm{Cl}^{-}$cotransporter at the apical membrane of the distal tubule (San-Cristobal et al., 2009) and also of $\mathrm{ENaC}$ in the distal nephron ex vivo (Mamenko et al., 2012; Sun et al., 2012). Endothelin-1 (ET-1) is a potent vasoconstrictor that regulates systemic blood pressure. In CCD perfused ex vivo, ET-1 significantly inhibited $\mathrm{Na}^{+}$absorption; the ENaC-mediated $\mathrm{Na}^{+}$absorption was restored by an $\mathrm{ET}_{\mathrm{A}}$ receptor inhibitor, suggesting that ET-1 downregulates ENaC (Lynch et al., 2013). However, deletion of the ET-1 receptor $\mathrm{ET}_{\mathrm{A}}$ in the kidney of mice did not affect blood pressure and resulted in a modest volume expansion (Stuart et al., 2012), indicating that $\mathrm{ET}_{\mathrm{A}}$ receptors in the nephron have little effect on $\mathrm{Na}^{+}$absorption by the kidney and on blood pressure. In several cellular models, vasopressin or cAMP agonists stimulated ENaC activity (Schafer and Troutman, 1990; Kleyman et al., 1994; Auberson et al., 2003; Snyder et al., 2004). Vasopressin and aldosterone have synergistic effects on ENaC-mediated $\mathrm{Na}^{+}$absorption in the collecting duct. The vasopressin-induced upregulation of $\mathrm{ENaC}$ is mediated by vasopressin receptor type 2 (V2R). In humans, vasopressin induced an increase in urine osmolality and a reduced $\mathrm{Na}^{+}$excretion, which is likely due to an increased ENaC-dependent $\mathrm{Na}^{+}$absorption mediated by stimulation of V2R (Bankir et al., 2005).

\section{Structure-Function Relationship of Acid-Sensing Ion Channels and Epithelial $\mathrm{Na}^{+}$Channel}

Initial information on structure-function aspects of degenerin and $\mathrm{ENaC}$ was obtained from mutagenesis screens on C. elegans, and the identification of human disease mutations on $\mathrm{ENaC}$.

$\mathrm{ENaC}$ and ASIC activity is temperature-dependent (Askwith et al., 2001; Chraibi and Horisberger, 2002; Neelands et al., 2010; Blanchard and Kellenberger, 2011). This suggests that conformational changes are part of the mechanisms that control $\mathrm{ENaC}$ and ASIC activity and likely transmit binding events in the ectodomain to the channel gate. Fluorescence studies have indeed shown evidence for rapid conformational changes in ASIC1a (Passero et al., 2009; Bonifacio et al., 2014). For detailed discussions of ASIC structurefunction aspects, see also Grunder and Chen (2010) and Sherwood et al. (2012). An insightful overview of degenerin structure-function aspects is given by Eastwood and Goodman (2012).

1. The Acidic Pocket and Other Proton-Sensing Sites of Acid-Sensing Ion Channels. The acidic pocket, located between the thumb, the finger, and the $\beta$-ball is highly negatively charged and contains several pairs of acidic side chains (Jasti et al., 2007) (Fig. 5A). Because mutation of such acidic residues led to acidic shifts in the $\mathrm{pH}$ dependence of activation, it was proposed that the acidic pocket forms the $\mathrm{pH}$ sensor that controls ASIC activity (Jasti et al., 2007; Li et al., 2009; Sherwood et al., 2009). It was suggested that, in the closed conformation, the acidic residues are more distant from each other than in the crystal structures that likely represent the open or desensitized conformation. Protonation would allow the thumb to approach the finger and $\beta$-ball, and this movement would induce activation and possibly desensitization. Mutations in the acidic pocket that decreased the interaction energy between the thumb and the finger or the $\beta$-ball tended to shift the $\mathrm{pH}$ dependence of activation to more acidic values, suggesting that channel gating is facilitated by attractive forces between these subdomains (Yang et al., 2009). The mutagenesis and functional analysis of conserved charged residues of ASIC1a identified acidic residues and His residues outside the acidic pocket in the finger and the extracellular vestibule, whose mutation affected the $\mathrm{pH}$ dependence of activation (Paukert et al., 2008). This analysis emphasized the role of residues in the extracellular vestibule and pore entry for ASIC function. Another study calculated the $\mathrm{p} K_{\mathrm{a}}$ values of Asp, Glu, and His residues in ASIC1a based on the crystal structure, and functionally analyzed the role of residues with $\mathrm{p} K_{\mathrm{a}}$ values in the gating range of ASIC1a (Liechti et al., 2010). This approach identified putative $\mathrm{pH}$-sensing residues for activation or desensitization in the acidic pocket and the palm. The role of palm residues in activation was recently confirmed (Krauson et al., 2013).

2. The Finger-A Determinant of Subfamily-Specific Activation Mechanisms? Residue Asp108 of the $\alpha 1$ finger helix is critical for activation of ASIC1a and ASIC3, possibly by building a salt bridge with basic finger residues (Paukert et al., 2008; Yang et al., 2012), and protease cleavage next to Arg146 of the $\alpha 2$ helix shifts the ASIC1a pH dependence to more acidic values (Vukicevic et al., 2006) (Fig. 5B). Note that we use throughout this review the amino acid numbering of cASIC1 for ASIC1a and ASIC1 to facilitate comparison between different orthologs. Residues involved in ASIC1a and $-1 b$ inhibition and ASIC2a potentiation by $\mathrm{Zn}^{2+}$ are located at different positions within the finger. The finger is covalently linked to the $\beta$-ball and the palm at a site containing residues Asn97, His164, and Gln226. This interaction site is highly conserved, sensitive to mutations, and undergoes conformational changes during ASIC activity (Bargeton and Kellenberger, 2010) 

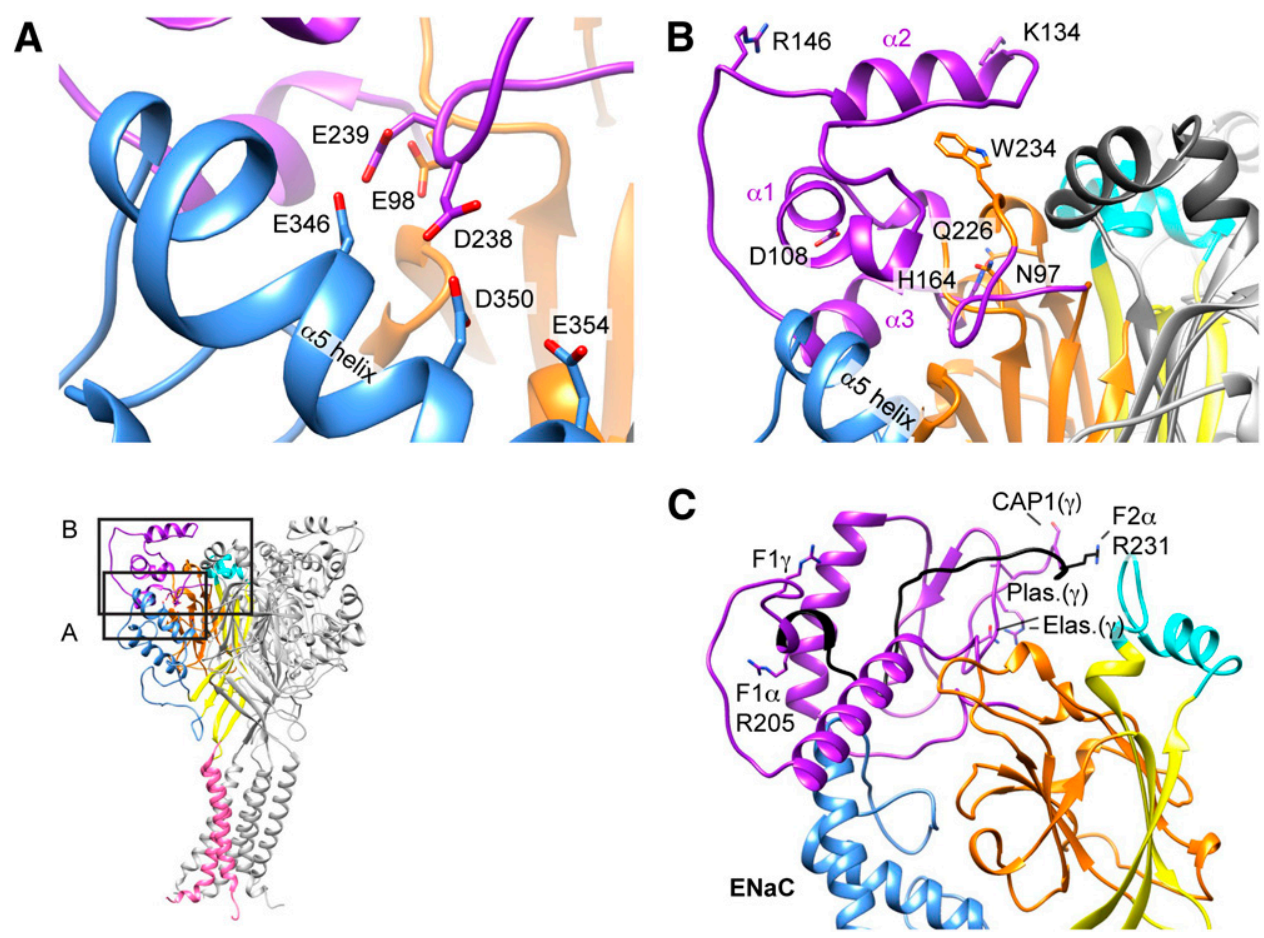

Fig. 5. Acidic pocket and finger. The color code for subdomains is the same as in Fig. 3. (A) Acidic pocket, showing acidic side chains of the thumb, finger, loop and $\beta$-ball. (B) The three $\alpha$ helices of a finger domain are indicated. The knuckle of a neighboring subunit is highlighted in dark gray. D108, involved in pH-dependent activation of ASIC1a and ASIC3; K134, important for $\mathrm{Zn}^{2+}$ inhibition of ASIC1a; H164, a residue involved in the enhancement of ASIC2a currents by $\mathrm{Zn}^{2+}$, localized with N97 and Q226 in the interaction domain between the finger, the $\beta$-ball, and the palm. ASIC1bC149, important for $\mathrm{Zn}^{2+}$ inhibition of ASIC1b, is located at the position homologous to G163 (not shown); R146, ASIC1a cleavage site by trypsin. (A and B) Based on the 2QTS structure; (C) $\alpha$ ENaC structural model, indicating the location of furin cleavage sites (F1 $\alpha$ and F2 $\alpha$ ) and homologous position of cleavage sites in $\gamma \mathrm{ENaC}$ by furin (F1 $\gamma$ ), CAP-1, plasmin (Plas.), and elastase (Elas.). The peptide of $\alpha$ ENaC located between the two furin sites and therefore cleaved by furin is highlighted in black.

(Fig. 5B). Experiments with fluorophore-quencher pairing and voltage-clamp fluorometry suggest that the upper finger helix $\alpha 2$ and the $\beta$-ball move away from each other upon channel activation, because acidification induced a fluorescence signal increase of fluorophores placed in the $\alpha 2$ finger helix and depended on the quenching by the $\beta$-ball residue Trp234 (Fig. 5B) (Bonifacio et al., 2014).

$\mathrm{ENaC}$ is activated by diverse cleaving events in the $\alpha$ and $\gamma$ subunits (see section V.B.2) (Kleyman et al., 2009; Rossier and Stutts, 2009). Two cleavage sites for furin are present in the finger domain of $\alpha \mathrm{ENaC}$ and one in the finger of $\gamma \mathrm{ENaC}$ (Fig. 5C). Elastase, plasmin, and prostasin can cleave $\gamma \mathrm{ENaC} \mathrm{C}$ terminus to the furin cleavage site.

3. The Palm. The palm forms a $\beta$ strand-rich scaffold at the central part of the channel, reaching from the transmembrane segments up to the knuckle (Fig. 3, A and B). The lower part of the palm, formed by the two short $\beta$ strands 1 and 12 connected to the TM segments and by the two long $\beta$ strands 9 and 10 , encloses the central vestibule (Figs. $3 \mathrm{~A}$ and $6 \mathrm{~A}$ ). The $\beta 1-\beta 2$ loop, connecting the lower palm to the $\beta$-ball, is critical for the kinetics of ASIC1 desensitization from the open state (Coric et al., 2003). This study showed that the desensitization kinetics are 25 -fold faster in toadfish compared with rat ASIC1a and that this difference is due to three residues in the $\beta 1-\beta 2$ loop, Ser-Gln-Leu in rat ASIC1a, located just at the beginning of a stretch of residues that are highly conserved in the ENaC/DEG family. The crystal structure indicated that the $\beta 1-\beta 2$ loop is located close to the $\beta 11-\beta 12$ loop. Several studies have shown that these loops interact with each other and codetermine the current kinetics and that mutations in this region can induce sustained opening (Li et al., 2010a,b; Springauf et al., 2011; Roy et al., 2013). Comparison of the open and desensitized crystal structures indicated a $180^{\circ}$ rotation of the peptide bond between Ser84 and Gln85 and a swapping of two critical side chains in the $\beta 11-\beta 12$ loop, Leu414 and Asn415 (Baconguis and Gouaux, 2012). Every second residue of the lower palm $\beta$ sheet surrounding the central vestibule points into the central cavity. Glu417 is a proton-sensing residue for activation (Fig. 6A) (Liechti et al., 2010; Krauson et al., 2013). Several residues of the lower palm are important for ASIC3 activation by GMQ (see section VI.A.1.b) (Yu et al., 2010; Alijevic and Kellenberger, 2012).

The Glu80 side chain is oriented toward the central cavity (Fig. 6A). When mutated to Cys, this residue of ASIC3 was better accessible to small hydrophilic sulfhydryl reagents in the closed compared with the desensitized state, consistent with a conformational change of the palm upon desensitization (Cushman 

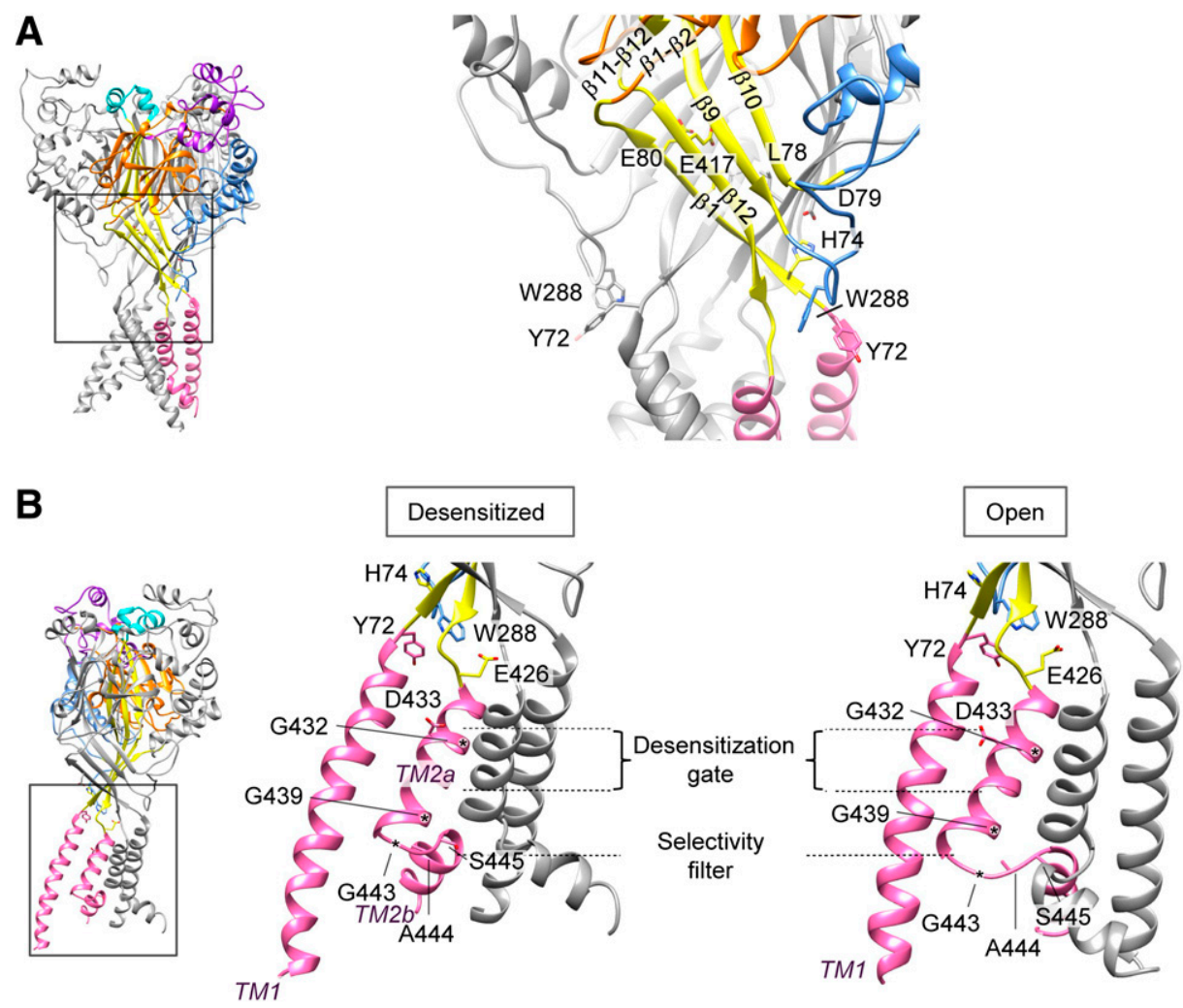

C
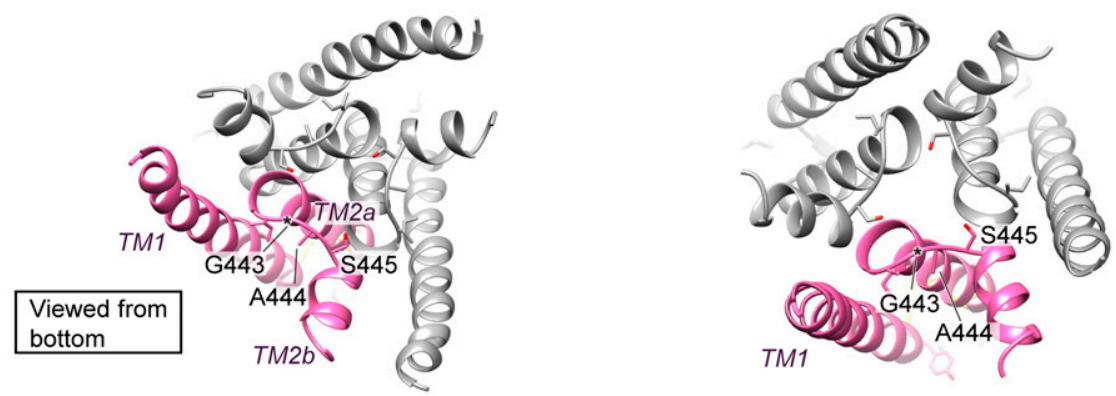

Fig. 6. Palm and transmembrane domain. (A) The lower palm region encloses the central vestibule. Its $\beta$-strands 1 and 12 are connected to the transmembrane segments, whereas the lower ends of $\beta$-strands 9 and 10 are connected via linker regions to the thumb. One of these linkers contains the $\beta$-turn (W288) interacting with Y72 of TM1. Based on 4NYK structure. (B and C) View of the pore in side view (B) and seen from the bottom (C) in the desensitized channel (left, PDB ID 4NYK) and the MitTx-bound open channel (right, PDB ID 4NTW). Only two subunits are shown in (B). The calcium binding site residues in ASIC1a (E426, D433), the DEG site (G432), the amiloride binding site (G439), and the "GAS" residues G443, A444, and S445 of the selectivity filter are indicated. *, Gly residue.

et al., 2007). In line with these observations, functional studies on ASIC1a provided evidence for a closing of the lower palm domain around the central vestibule during desensitization (Liechti et al., 2010; Della Vecchia et al., 2013; Roy et al., 2013). As mentioned above, a closing of the palm during the open desensitized transition was also evident from the comparison of putative desensitized and open crystal structures of chicken ASIC1 (Baconguis and Gouaux, 2012). Molecular dynamics simulations showed that desensitizationimpairing mutations changed the palm conformation and prevented its closing movement (Roy et al., 2013). Together, this demonstrates the important role of the lower palm and adjacent loops for desensitization. The constriction below the central cavity at the level of Leu78 is not changed between the open and the desensitized structure. Leu78 forms a contact point between the three subunits and may serve as a pivotal point that allows transmission of palm movements to the pore. The closing movement of the palm may lead through a rotation around residues Leu78 to pore closing.

4. The $\beta$-Turn and the Extracellular Vestibule-at the Interface between the Extracellular and Transmembrane Domains. The $\beta$-turn is located in the loop connecting the palm $\beta$ strand 9 with the thumb helix $\alpha 5$ and points down toward the upper end of the TM1. Trp288 of the $\beta$-turn interacts with Tyr72 of TM1 (Jasti et al., 2007) (Fig. 6, A and B). It had been suggested that this interaction may transmit conformational changes of the acidic pocket toward the channel gates. Consistent with this hypothesis, mutations that disrupted this hydrophobic interaction led to nonfunctional channels $(\mathrm{Li}$ 
et al., 2009). Mutations of the interacting residue in either the $\beta$-turn or the TM1 lowered the expression of the channels at the cell surface and rendered the plasma membrane-resident mutants nonfunctional (Jing et al., 2011). Normal mode analysis suggested the movements of $\beta$-turn residues to be highly correlated with movements of the upper TM1 (Yang et al., 2009).

The extracellular vestibule is surrounded by the flexible wrist that connects the palm to the transmembrane pore region and is located at the same level as the $\beta$-turn. It contains three large fenestrations that most likely form the extracellular access route for cations to the channel pore. Functional studies identified two His residues in the extracellular vestibule, His73 and His74, as well as Asp79 as critical for pH-dependent ASIC1a activity (Paukert et al., 2008). Mutations of these residues did not affect the $\mathrm{Ca}^{2+}$ dependence of gating, suggesting that they are not $\mathrm{Ca}^{2+}$ binding sites. His74 is oriented toward Asp79 of the neighboring subunit (Fig. 6A). This intersubunit interaction likely stabilizes protonation of one of the two residues.

\section{The Transmembrane Domain.}

a. Components of the channel pore. Studies examining the accessibility of specific residues in the transmembrane helices of ENaC indicated that the TM2 lines the channel pore and identified residues oriented toward the pore lumen (Schild et al., 1997; Snyder et al., 1999; Sheng et al., 2001, 2005). Crystal structures of cASIC1 in complex with PcTx1 or MitTx confirmed that the TM2 segments line the pore. The cASIC1 construct used for cocrystallization with PcTx1 showed in the presence of high concentrations of PcTx 1 a nonselective, amiloride-resistant conductance at $\mathrm{pH} 7.25$ and a $\mathrm{Na}^{+}$-selective, amiloride-sensitive current at $\mathrm{pH} 5.5$ (Baconguis and Gouaux, 2012). Accordingly, the structure obtained at $\mathrm{pH} 7.25$ showed a very wide pore and that obtained at $\mathrm{pH} 5.5$, a narrower open pore. These structures contained continuous TM1 and TM2 $\alpha$ helices. In contrast, the TM2 of the cASIC1-MitTx structure is split in two parts (TM2a and -b) by the GlyAla-Ser (GAS) selectivity filter motif, which forms a horizontal extended structure (Fig. 6, B and C). The GAS site corresponds to the G/S-x-S selectivity filter identified in $\mathrm{ENaC}$ (see section V.C.5.d). The horizontal GAS segment places the lower TM2 $\alpha$ helix (TM2b) in the continuation of the upper TM2 helix (TM2a) of a neighboring subunit. The narrowest part of the nonselective cASIC1-PcTx1 pore was $\sim 10 \AA$ wide. The $\mathrm{Na}^{+}$-selective cASIC1-PcTx1 pore was asymmetric, its section showing an elliptical shape, and was narrowest in its lower half, with dimensions of 4-5 × 7-10. . In the cASIC1-MitTx structure the transmembrane channel part is symmetrical and has similar dimensions as the pH 5.5 cASIC1-PcTx1 structure, except for wider intraand extracellular openings (Baconguis et al., 2014).

b. The desensitization and closing gate. The desensitized structure identified the "desensitization gate," an $\sim 8 \AA$-thick constriction in the upper part of the pore at the level of residues Asp433-Gly436 (Gonzales et al., 2009). A functional study used measurements of reaction rates of sulfhydryl reagents to engineered Cys residues to locate the closing gate ( $\mathrm{Li}$ et al., 2011a). These experiments were carried out in the lamprey ASIC1, which does not desensitize. They identified a constriction in the closed ASIC between Gly432 and Gln437, corresponding likely to the closing gate, which therefore appears to be at the same location as the desensitization gate (Fig. 6B). The open channel was not accessible to the sulfhydryl reagents between residues Leu440 and Ile446, consistent with the presence of the selectivity filter.

c. The degenerin residue and the amiloride binding site. Gly432 constitutes the DEG site, a conserved small residue in all $\mathrm{ENaC/DEG}$ channels, whose replacement by larger residues induces constitutive activity in most family members, leading to degeneration of sensory neurons in C. elegans (Eastwood and Goodman, 2012). Substitution of the DEG residue induced in ASIC2a, besides a constitutive current, a slowing of desensitization and an altered $\mathrm{pH}$ dependence of the $\mathrm{H}^{+}$-induced current (Adams et al., 1998; Champigny et al., 1998). The DEG site of ASIC2a is solvent accessible only in open channels (Adams et al., 1998). Its replacement by large residues may keep the pore open. Mutation to large residues or introduction of large adducts to engineered Cys residues at the DEG position of $\alpha, \beta$ or $\gamma \mathrm{ENaC}$ subunits locked the channel in an open conformation (Snyder et al., 2000; Kellenberger et al., 2002). In the crystal structure, the DEG site is on the side of the TM2 helix that faces the pore lumen.

A recent study connected ASIC1a subunits via modification of engineered Cys residues at position 430-hence one helical turn higher up than the DEG site-with a photosensitive linker whose conformation could be switched by light from cis to trans. The cis-to-trans isomerization pushed the upper ends of the TM2 $\alpha$ helix apart, thereby opening the channel (Browne et al., 2014). This likely mimics the movement of the TM2 helices needed for channel opening that is normally induced by complex conformational changes of the ectodomain.

The amiloride binding site of $\mathrm{ENaC}$ is at the position corresponding to Gly439 (Schild et al., 1997), which has been confirmed as functional amiloride binding site in ASICs (Adams et al., 1999; Alijevic and Kellenberger, 2012). The G439 backbone carbonyls point into the pore lumen in the cASIC1-MitTx structure.

d. The selectivity filter. As mentioned, $\mathrm{ENaC}$ conducts $\mathrm{Na}^{+}$ions at rates 100 - to 1000 -fold higher than $\mathrm{K}^{+}$. Substitution of the C-terminal Ser residue of the conserved G/S-x-S motif in the lower part of the TM2 (Ser589 in $\alpha \mathrm{ENaC}$ ) with large residues reduced the high selectivity of $\mathrm{ENaC}$ for $\mathrm{Na}^{+}$ions considerably (Kellenberger et al., 1999a). The likely explanation for this observation is that the mutations of $\alpha$ ENaC-S589 
enlarge the pore diameter, allowing large cations, such as $\mathrm{K}^{+}$or ammonium, to permeate the $\mathrm{ENaC}$ pore (Kellenberger et al., 2001; Takeda et al., 2007). These and related studies identified the ion selectivity filter as the narrowest part of the $\mathrm{ENaC}$ channel pore, allowing almost exclusively monovalent cations of the size of $\mathrm{Na}^{+}$to pass through the channel pore (Kellenberger et al., 1999b; Snyder et al., 1999; Sheng et al., 2000). The ENaC selectivity filter corresponds to the GAS motif in ASIC1. In ASIC1, this stretch is part of the narrowest region in the open pore (Baconguis and Gouaux, 2012; Baconguis et al., 2014). In the cASIC1MitTx structure the GAS motifs of the three subunits split the TM2 $\alpha$ helices in two and form a horizontal belt. The carbonyl oxygens of Gly443 point into the pore lumen and form a binding site for permeant ions. At this level, the pore radius is $3.6 \AA$, close to the radius of a hydrated $\mathrm{Na}^{+}$ion (3.8 $\AA$ ) (Baconguis et al., 2014; Mahler and Persson, 2012). The authors suggest therefore that the selectivity filter functions as a barrier, achieving selectivity by discrimination of hydrated ions. The side chain of Ser445 interacts with residues of the TM2a helix of a neighboring subunit, stabilizing the continuity of the separated TM2 helix (Fig. 6, B and C). In the cASIC1PcTx1 structures in contrast, the GAS motif is part of the continuous TM2 $\alpha$ helix, with the side chain of Ser445 pointing to the adjacent TM1 (Baconguis and Gouaux, 2012).

In the cASIC1-PcTx1 structures a single cation binding site in the pore was shown at the extracellular pore entry close to Asp433. The cASIC1-MitTx structure showed cations at the same level and, in addition, one cation in the center of the selectivity filter. Functional studies demonstrated that the GAS segment of ASICs is important for ion selectivity and permeation. Mutation of Gly443 of one single subunit within the trimer decreased the unitary conductance and affected ion selectivity (Li et al., 2011a). Mutation of either Leu440 or Ala444 changed the $\mathrm{Na}^{+} / \mathrm{K}^{+}$ permeability ratio (Yang et al., 2009). Together this suggests that the location of the selectivity filter is conserved between ENaC and ASICs. The TM2 is the best-conserved domain between ASICs and $\mathrm{ENaC}$, and several residues involved in ion selectivity are conserved between ENaC and ASICs. Functional studies indicated, however, that $\mathrm{ENaC}$ has a 10 - to 100 -fold higher $\mathrm{Na}^{+} / \mathrm{K}^{+}$selectivity than ASICs and needs to transport completely dehydrated ions to ensure its high selectivity. This functional difference may be due to the small differences in primary structure of the selectivity filter between $\mathrm{ENaC}$ and ASICs or to a different relative positioning of the TM2 domains.

6. Cytoplasmic $N$ and $C$ Termini. It was shown that the cytoplasmic $\mathrm{N}$ terminus codetermines the selectivity between monovalent cations in ASIC2 and ASIC3 (Coscoy et al., 1999), whereas the analogous domain in ASIC1 contributes to the $\mathrm{Ca}^{2+}$ permeability (Bassler et al., 2001). Accessibility studies have shown that residues of the ASIC1a $\mathrm{N}$ terminus likely contribute to the intracellular pore vestibule (Pfister et al., 2006). The conserved HG motif, whose mutations in $\mathrm{ENaC}$ are at the origin of PHA-1 in humans by decreasing $\mathrm{ENaC}$ open probability and cell surface expression (see section V.B.1), is located directly downstream of the residues involved in ASIC selectivity.

The cytoplasmic $\mathrm{C}$ termini of $\mathrm{ENaC}$ and ASIC contain phosphorylation and protein-protein interaction sites. The motifs of $\mathrm{ENaC} \beta$ and $\gamma$ subunits, which bind Nedd4-2 and are mutated or deleted in Liddle syndrome (see section III.B.2) are located at a distance of 15 residues from the $\mathrm{C}$ terminus. ASIC subunits contain PDZ binding domains formed by the last four residues, which are involved in protein-protein interactions (Wemmie et al., 2006) (Table 3).

7. A Model of Acid-Sensing Ion Channel Gating. The crystal structures, together with state-dependent accessibility, mutagenesis, and voltage-clamp fluorometry studies, suggest the following steps leading to opening and desensitization, illustrated in Fig. 7. Upon acidification, which protonates residues in different domains, such as the finger, the acidic pocket, the
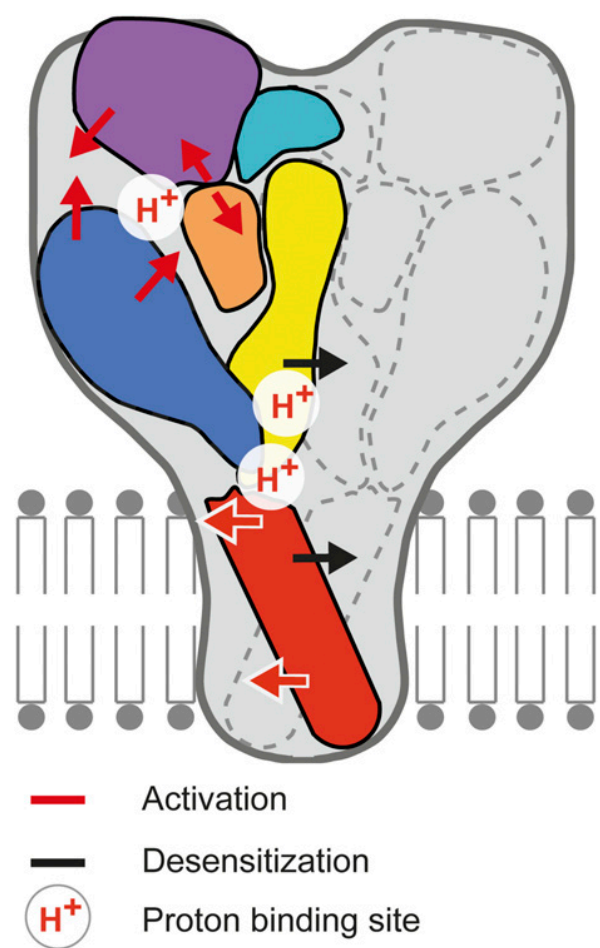

Fig. 7. A model of ASIC gating. Schematic view of an ASIC trimer, showing the domains of one subunit in color. The contours of the domains of a second subunit are shown as dashed lines, whereas the third subunit is omitted for clarity. Proposed protonation sites and conformational changes are only shown in the colored subunit. The main protonation sites are shown as " $\mathrm{H}^{+}$." Red arrows indicate the direction of proposed conformational changes associated with ASIC activation. Black arrows indicate the direction of proposed conformational changes associated with ASIC desensitization. Proposed conformational changes in the wrist are not shown, because their direction is not known. The domains are colored as follows: finger (purple), thumb (blue), knuckle (turquoise), $\beta$-ball (orange), palm (yellow), transmembrane segments (red). 
palm, and the wrist (Paukert et al., 2008; Liechti et al., 2010; Krauson et al., 2013), rapid movements are observed in the finger and the extracellular vestibule, with the finger $\alpha 2$ helix and the $\beta$-ball moving away from each other (Passero et al., 2009; Bonifacio et al., 2014) and likely the thumb helices approaching the $\beta$-ball and the finger (Jasti et al., 2007). It is currently not clear whether the finger movements are transmitted to the pore via the outer structures (thumb and palm-thumb loops) or more centrally via the palm to the extracellular vestibule. These conformational changes lead together with contributions of the palm and the wrist to the opening of the closing gate ( $\mathrm{Li}$ et al., 2011a), which is located between Gly432 and Gln437. Slower movements in the palm (Bonifacio et al., 2014), detected as closing movement of the lower palm around the central vestibule in accessibility studies in the closed-to-desensitized transition (Cushman et al., 2007; Liechti et al., 2010; Della Vecchia et al., 2013; Roy et al., 2013) and documented as a narrower central vestibule in the desensitized compared with the open ASIC structure (Baconguis and Gouaux, 2012; Baconguis et al., 2014), are associated with desensitization. The closing movement of the palm leads to the closing of the desensitization gate, preventing ion conduction (Baconguis and Gouaux, 2012).

\section{Pharmacology}

\section{A. Acid-Sensing Ion Channels}

\section{Small molecules.}

a. Acid-sensing ion channel inhibitors.

i. Amiloride. Amiloride (Fig. 8) inhibits the transient ASIC currents with $\mathrm{IC}_{50}$ values of the order of $10-100 \mu \mathrm{M}$, thus with a 100 - to 1000 -fold lower potency than its potency for ENaC block (Table 2) (Kellenberger and Schild, 2002). The sustained component of the ASIC3 current is only partially inhibited or even increased by amiloride (de Weille et al., 1998; Babinski et al., 1999; Yagi et al., 2006; Li et al., 2011b). Amiloride induces a conformational change in ASIC2a that exposes the "DEG site" (located in the pore entry; Fig. 6B) to the extracellular solution, in addition to blocking the pore (Adams et al., 1999). Together these observations suggest that amiloride binds to two different sites in ASICs. The homologous residue to the ENaC blocking site (Schild et al., 1997) is also necessary for inhibition of ASIC1a, ASIC2a, and ASIC3 (Adams et al., 1999; Alijevic and Kellenberger, 2012) (Fig. 6B). The location of the modulatory amiloride binding site is not known; however, it was shown that residues of the palm are necessary for the amilorideinduced current increase in ASIC3 (Li et al., 2011b). In the open MitTx-cASIC1 structure, amiloride was found in the acidic pocket when the crystallization was carried out in the presence of the drug, suggesting that the modulatory site may be in the acidic pocket (Baconguis et al., 2014). Although amiloride is far from being an ideal ASIC inhibitor, because at the micromolar concentrations needed to inhibit ASICs it also inhibits ENaC, T-type calcium channels, and the sodium-proton exchanger (Kleyman and Cragoe, 1988), it has been successfully used in several studies targeting ASIC functions. Cortical spreading depression, occurring during migraine aura, is associated with failure of brain ion homeostasis and the release of various agents, as e.g., protons and $\mathrm{AA}$, which activate or enhance ASIC function. Amiloride blocked cortical spreading depression in rodents and reduced aura and headache symptoms in human patients (Holland et al., 2012). Furthermore, a recent study suggested that amiloride has a neuroprotective action on MS patients (Arun et al., 2013). A search for amiloride derivatives with increased potency on ASIC3 resulted in the identification of several substitutions of the NH2 group at position 5 of the pyrazine ring that increased the potency by 10 -fold (Kuduk et al., 2009b).

ii. Nonsteroidal Anti-Inflammatory Drugs. Inflammation induces a large increase in ASIC mRNA levels in DRGs, which is prevented by administration of the nonsteroidal anti-inflammatory drugs (NSAIDs)<smiles>CC(C)C1c2cc(C3CC3c3ccc4cc(C(=N)N)ccc4c3)ccc2CCN1C</smiles><smiles>N=C(N)NC(=O)c1nc(Cl)c(N)nc1N</smiles><smiles>Cc1nc(NC(=N)N)nc2ccccc12</smiles><smiles>N=C(NCc1ccccc1)NC(=O)c1nc(Cl)c(N)nc1N</smiles>

GMQ

Benzamil (benzyl amiloride)

Fig. 8. ENaC/DEG channel modulators and inhibitors. The chemical structures of GMQ, A-317567, amiloride, and benzamil are shown. 
aspirin, diclofenac, and ibuprofen at therapeutic doses (Voilley et al., 2001). In addition, ASIC currents are inhibited by NSAIDs with $\mathrm{IC}_{50}$ values in the order of hundreds of micromolars to several millimolars (Voilley et al., 2001; Dorofeeva et al., 2008), thus with 100- to 1000 -fold lower potency than the inhibition of cyclooxygenases by these drugs (Warner et al., 1999). It is therefore likely that the inhibition of ASIC expression, but not the experimentally observed inhibition of ASIC currents, may contribute to the clinical effects of NSAIDs.

iii. Other Small-Molecule Inhibitors. A-317567 is structurally unrelated to amiloride (Fig. 8) and inhibits ASIC currents in DRG neurons with $\mathrm{IC}_{50}$ values of 2$30 \mu \mathrm{M}$ (Dube et al., 2005). In contrast to amiloride, A-317567 inhibits transient and sustained ASIC currents with similar potency. In animal pain models, A-317567 was more potent than amiloride. Subsequently, a series of indol amidines was tested for inhibition of ASIC3, identifying compounds inhibiting ASIC3 with an $\mathrm{IC}_{50}$ $<1 \mu \mathrm{M}$ that partially reversed mechanical hypersensitivity after paw inflammation (Kuduk et al., 2009a). Different anti-protozoal diarylamidines inhibited ASICs with $\mathrm{IC}_{50}$ of $0.3-38 \mu \mathrm{M}$ (Chen et al., 2010). Nafomastat, a clinically used serine protease inhibitor (Fujii and Hitomi, 1981), inhibits ASIC currents, including the sustained component of the ASIC3 current, with an $\mathrm{IC}_{50}$ of $\sim 2-70 \mu \mathrm{M}$ (Ugawa et al., 2007). More recently, the screening of a fragment library and subsequent optimization yielded 2-aminopyridine derivatives inhibiting ASIC3, with an $\mathrm{IC}_{50}$ of $\sim 3 \mu \mathrm{M}$ (Wolkenberg et al., 2011). ASIC currents are inhibited by the local anesthetics tetracaine and lidocaine with $\mathrm{IC}_{50}$ values of $\sim 10 \mathrm{mM}$ and by the $\mathrm{K}^{+}$channel inhibitor 4-aminopyridine with $\mathrm{IC}_{50}$ values $\geq 1 \mathrm{mM}$ (Lin et al., 2011; Boiko et al., 2013; Leng et al., 2013).

$b$. The acid-sensing ion channel modulator 2-guanidine4-methylquinazoline. GMQ induces persistent ASIC3 currents when applied at $\mathrm{pH} 7.4$ and induces painrelated behavior in wild-type but not $\mathrm{ASIC}^{-1-}$ mice (Yu et al., 2010). GMQ, which shares some structural similarity with amiloride (Fig. 8), was the first discovered ASIC activator other than protons. It was shown that mild acidosis and reduction of extracellular $\mathrm{Ca}^{2+}$ concentration enhance the GMQ-induced currents. Several residues in the palm domain are critical for the effects of GMQ (Yu et al., 2011). Covalent modification of one of these residues, Glu79, is sufficient for ASIC3 activation, suggesting that GMQ may bind to the central cavity formed by the lower palm domains (Yu et al., 2010). The potency of GMQ for ASIC3 activation is low with an $\mathrm{EC}_{50}$ of $\sim 1 \mathrm{mM}$ at physiologic $\mathrm{Ca}^{2+}$ concentrations. It was later shown that, in addition to the synthetic GMQ, the arginine metabolites agmatine and arcaine have qualitatively similar effects on ASIC3 (Li et al., 2010c). Agmatine levels are increased during trauma, infection, and cancer. In concert with other endogenous ASIC modulators, such as AA, agmatine may affect ASIC function under physiologic or pathologic conditions. Agmatine injection induced pain-related behaviors in mice. A recent study addressed the mechanisms of action of GMQ and showed that this compound induces an acidic shift of the $\mathrm{pH}$ dependence of SSD and an alkaline shift of the $\mathrm{pH}$ dependence of activation of ASIC3, creating a window current at physiologic $\mathrm{pH}$ (Alijevic and Kellenberger, 2012). Intriguingly, mutation of Glu79, previously shown to be critical for ASIC3 activation by GMQ at physiologic $\mathrm{pH}$, prevented the shift of the $\mathrm{SSD}$, but not of the activation $\mathrm{pH}$ dependence, suggesting that this residue may rather be involved in the effect of GMQ than being part of the GMQ binding site (Alijevic and Kellenberger, 2012). Deletion of a residue in the lower palm-thus in the same domainof $\beta \mathrm{ENaC}$ suppressed the effect of the $\mathrm{ENaC}$ activator S3969 [ $N$-(2-hydroxyethyl)-4-methyl-2-(4-methyl- $1 H$ indol-3-ylthio)pentanamide] (Lu et al., 2008). GMQ also affected the $\mathrm{pH}$ dependence of ASIC subtypes other than ASIC3-mostly by shifts to more acidic $\mathrm{pH}$ - which, however, did not induce currents at physiologic $\mathrm{pH}$ (Alijevic and Kellenberger, 2012). At higher concentrations GMQ inhibited ASIC currents by a pore block.

2. Toxins. Venom toxins acting on ASICs have importantly contributed to the understanding of physiologic and pathologic functions of ASICs (Baron et al., 2013). The most important ASIC-targeting toxins are the spider toxin Psalmotoxin1 (PcTx1) (Escoubas et al., 2000), the sea anemone toxin APETx2 (Diochot et al., 2004), and the snake toxins Mambalgin-1-3 (Diochot et al., 2012) and MitTx (Bohlen et al., 2011). APETx2 and Mambalgins are inhibitors, MitTx is an activator of ASICs, and PcTx1 acts depending on the ASIC subtype and the $\mathrm{pH}$ conditions either as an inhibitor or an activator. PcTx1 and Mambalgin, the two toxins for which the mechanism of action has been elucidated, are gating modifiers. The properties of these toxins are summarized in Table 5. Other ASICtargeting toxins with lower potency or incomplete inhibition are known, such as the sea anemone toxins Ugr 9-1 that inhibit ASIC3 currents with an $\mathrm{IC}_{50}$ of $\sim 10 \mu \mathrm{M}$ (Osmakov et al., 2013) and PhcrTx1, whose inhibition of DRG neuron ASIC currents is incomplete $(\sim 40 \%)$ with an $\mathrm{IC}_{50}$ of $\sim 100 \mathrm{nM}$ (Rodriguez et al., 2014). These two toxins will not be further discussed here. All of these ASIC-targeting toxins are minor venom components, and their use for the organism producing them is not clear, except for MitTx that induces pain.

a. Psalmotoxin1. PcTx1 of the spider Psalmopoeus cambridgei inhibits homomeric ASIC1a and heteromeric ASIC1a/2b with nanomolar potency (Escoubas et al., 2000; Sherwood et al., 2011). The structure of PcTx1 was solved by NMR (Escoubas et al., 2003; Saez et al., 2011) and later by X-ray crystallography as part of the cASIC1-PcTx1 complex (Baconguis and Gouaux, 2012; Dawson et al., 2012). Composed of a three-stranded antiparallel $\beta$ sheet, it is folded 
TABLE 5

Properties of ASIC-targeting toxins

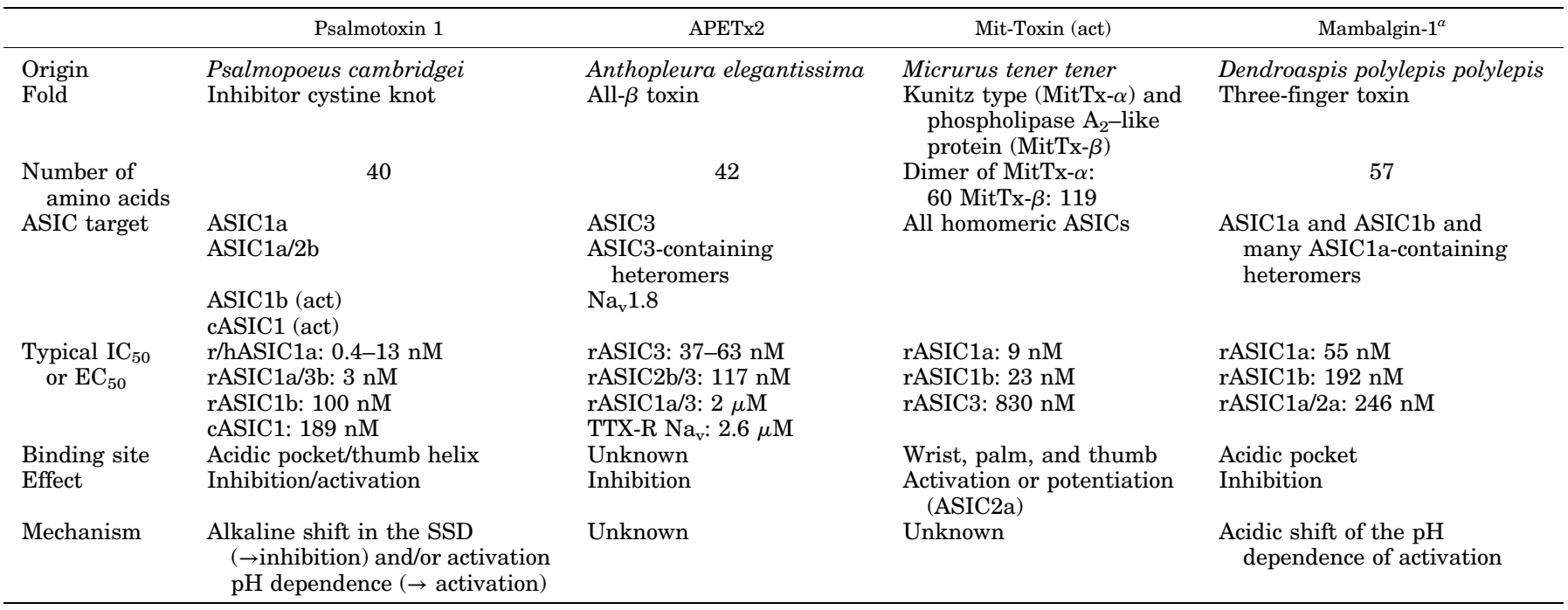

act, activation.

${ }^{a}$ Mambalgin-2 from Dendroaspis polylepis polylepis and Mambalgin-3 from Dendroaspis angusticeps differ each in a single residue from Mambalgin-1 (Baron et al., 2013). For references, see text.

according to the inhibitor cystine knot motif. The charge distribution of PcTx1 shows an electrostatic anisotropy that can be represented by a dipole moment. PcTx1 binds to the acidic pockets of ASIC in a stoichiometry of three PcTx1 molecules per channel trimer (Fig. 9A). A hydrophobic patch of PcTx1 (pink in Fig. 9A) binds to the $\alpha 5$ thumb helix, and a basic cluster (Arg27, Arg28, light green) extends deeply into the acidic pocket (Baconguis and Gouaux, 2012; Dawson et al., 2012). The functional importance of several of the interacting residues on the toxin and the channel had previously been demonstrated by site-directed mutagenesis (Salinas et al., 2006; Saez et al., 2011). PcTx1 shifts the ASIC1a pH dependence of SSD and to a smaller extent that of activation to more alkaline values and thereby desensitizes the channel at pH 7.4 (Chen et al., 2005). At higher concentrations, PcTx1 also binds to ASIC1b, on which it also induces alkaline shifts in $\mathrm{pH}$ dependence. Because SSD occurs at more acidic $\mathrm{pH}$ in ASIC1b compared with ASIC1a and the shift induced by PcTx1 is small in ASIC1b, PcTx1 does not inhibit ASIC1b under physiologic $\mathrm{pH}$ conditions but in contrast enhances ASIC1b currents at mildly acidic $\mathrm{pH}$ (Chen et al., 2006). Chicken ASIC1 is activated by PcTx 1 at $\mathrm{pH} 7.4$ (Samways et al., 2009; Baconguis and Gouaux, 2012), suggesting that PcTx1 induces an alkaline shift of the cASIC1 activation $\mathrm{pH}$ dependence. This has not, however, been shown so far.

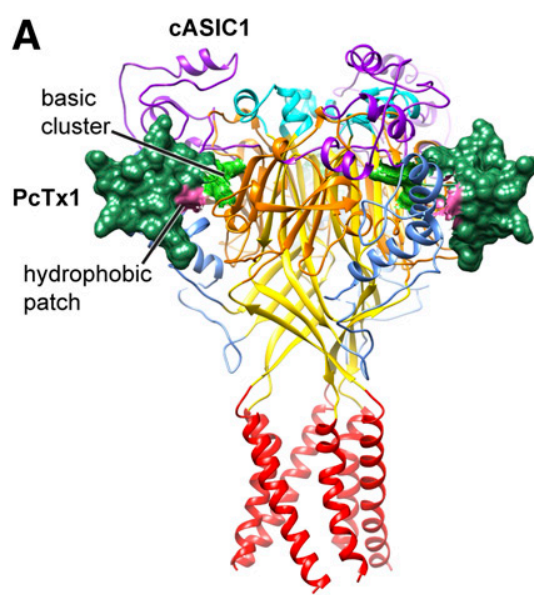

cASIC1-Psalmotoxin

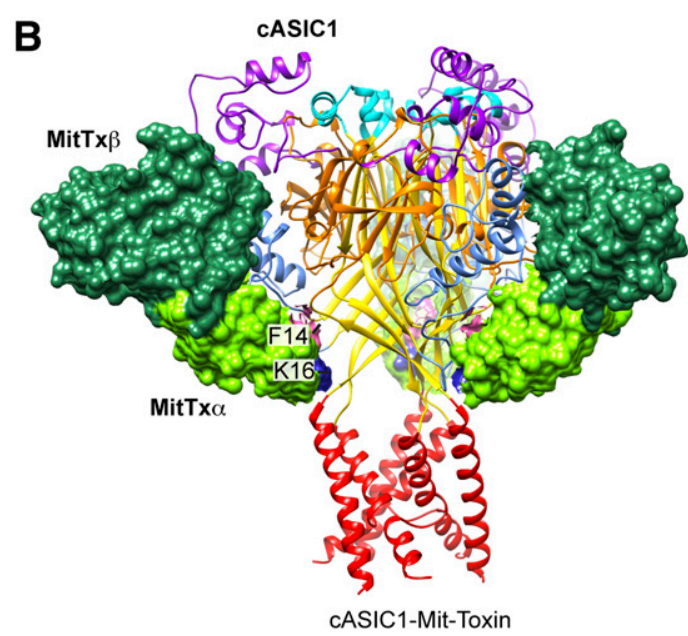

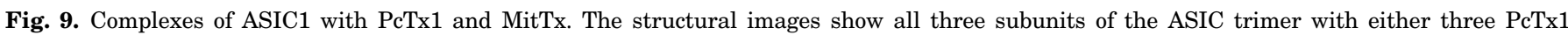

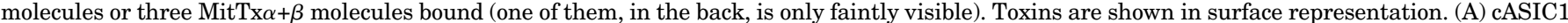

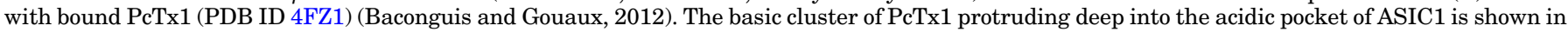

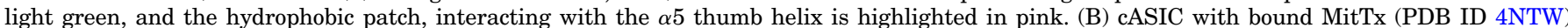

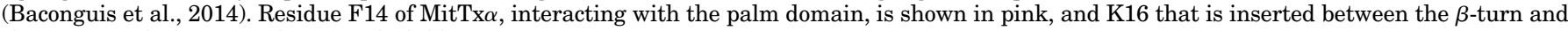
the upper end of TM1 is shown in dark blue. 
b. APETx2. This toxin of the sea anemone Anthopleura elegantissima inhibits ASIC3 and ASIC3-containing heteromers with $\mathrm{IC}_{50}$ values ranging from $63 \mathrm{nM}$ to $2 \mu \mathrm{M}$ (Diochot et al., 2004). APETx2 shares 64\% sequence identity with the HERG channel inhibitor APETx1 and 25-35\% identity with several $\mathrm{K}_{\mathrm{v}^{-}}$and $\mathrm{Na}_{\mathrm{v}}$-targeting toxins (Diochot et al., 2004). On the basis of the solution structure of the native APETx2 peptide and on comparison with related toxins, it was suggested that the channel-interacting surface may be constituted by basic and aromatic residues (Chagot et al., 2005). One of these aromatic residues, Phe15, was recently shown to be important for ASIC3 inhibition (Anangi et al., 2012). The site of action of APETx2 is not known. On the basis of the presence of the basic-aromatic toxin surface patch it has been suggested that APETx2 may bind as PcTx1 to the acidic pocket (Baron et al., 2013). APETx2 is not selective for ASICs and inhibits voltage-gated $\mathrm{Na}^{+}$ currents in DRG neurons with an $\mathrm{IC}_{50}$ of $2.6 \mu \mathrm{M}$, recombinant $\mathrm{Na}_{\mathrm{v}} 1.8\left(\mathrm{IC}_{50}\right.$ of $55 \mathrm{nM}$ or $19 \mu \mathrm{M}$, depending on the study), and $\mathrm{Na}_{\mathrm{v}} 1.2\left(\mathrm{IC}_{50}\right.$ of $114 \mathrm{nM}$ ) (Blanchard et al., 2012; Peigneur et al., 2012).

c. Mambalgins. Mambalgin-1 and -2 from black mamba and Mambalgin-3 from green mamba differ only in one amino acid from each other and inhibit ASIC1a, ASIC1b, and ASIC1a-containing heteromers with $\mathrm{IC}_{50}$ values ranging from 11 to $250 \mathrm{nM}$ (Diochot et al., 2012; Baron et al., 2013). Modeling of the threedimensional structure of Mambalgins and its determination by NMR (Schroeder et al., 2014) showed that they form a new subfamily of three-finger toxins. The peptide surface contains a hydrophobic patch and several clusters of basic or acidic residues. Combination of mutagenesis and functional analysis showed that Mambalgin- 2 binds in the acidic pocket to the thumb $\alpha 5$ helix, the $\beta$-ball, and to the palm of an adjacent subunit (Salinas et al., 2014; Schroeder et al., 2014). This is very close to the PcTx1 binding site, and it is surprising that PcTx1 and Mambalgin-1 appear not to interact with each other on ASIC1a (Diochot et al., 2012). Mambalgin-1 shifts the activation curve strongly to more acid values, thereby preventing channel opening.

d. Mit-toxin. MitTx of the Texas coral snake is formed by noncovalent interaction between the two peptides MitTx $\alpha$, a Kunitz type peptide, and $\operatorname{MitTx} \beta$, a phospholipase $\mathrm{A}_{2}$-like protein (Bohlen et al., 2011). This complex resembles the $\beta$-bungarotoxins, in which a Kunitz type peptide and a phospholipase $\mathrm{A}_{2}$ domain are covalently linked by a disulfide bond (Doley and Kini, 2009). MitTx induces a slow activation of ASIC1a, ASIC1b, and ASIC3 with $\mathrm{EC}_{50}$ values of 9, 23, and 830 $\mathrm{nM}$, respectively. It only poorly activates ASIC2a, but potentiates ASIC2a currents with an $\mathrm{EC}_{50}$ of $75 \mathrm{nM}$ by inducing a strong alkaline shift of the activation curve. The mechanism of action of MitTx is currently not known. However, the most recent ASIC structure was obtained from a cASIC1-MitTx complex, revealing the structure and binding site of MitTx (Baconguis et al., 2014). Three molecules of MitTx bind to one channel trimer (Fig. 9B). Seen from the top, the toxin heterodimers protrude from the edges of the cASIC1 trimer. The toxin heterodimer is held together by extensive interactions between the two subunits. It interacts mainly with the wrist, palm, and thumb domains of cASIC1 but does not reach into the acidic pocket as does PcTx1 (Fig. 9). The arrangement and possible effect of MitTx is compared with that of a church key bottle opener, with $\operatorname{MitTx} \beta$ forming the upper part, interacting with residues of the two thumb $\alpha$ helices, and MitTx $\alpha$ reaching down to the membrane plane, interacting with residues of the two palm-thumb loops. MitTx $\alpha$ inserts its residue Phe14 (pink in Fig. 9B) between the bottom of the palm domains of two adjacent subunits where it interacts with the $\beta 1-\beta 2$ linker, and Lys16 (dark blue) is placed in the wrist between the $\beta$ turn and the upper end of the TM1. These interactions may open the palm and change the pore conformation to open the channel pore.

\section{B. Epithelial $\mathrm{Na}^{+}$Channel}

\section{Direct Epithelial $\mathrm{Na}^{+}$Channel Antagonists.}

a. Properties. Amiloride is the prototypical ENaC blocker. Developed by Cragoe in the early 1960s, it has been widely used as an adjunctive therapy with loop diuretics or thiazides to minimize hypokalemia (Cragoe et al., 1967). Amiloride is a pyrazinoylguanidine bearing amino groups in positions 3 and 5 and a chloro group at position 6 of the pyrazine ring (Fig. 8). Amiloride was found to be a potent reversible inhibitor of the epithelial $\mathrm{Na}^{+}$selective conductance in tight epithelia such as the toad urinary bladder, with an $\mathrm{IC}_{50}$ of $0.1-0.3 \mu \mathrm{M}$ (Lindemann and Van Driessche, 1977). Pharmacodynamic experiments on tight amphibian epithelial models provided the first clues on the mechanism of block of the epithelial $\mathrm{Na}^{+}$channels by amiloride. An important observation was that amiloride inhibition depended on the transmembrane voltage that, if negative, would tend to drive the positively charged amiloride in the membrane channel, and that amiloride interacts competitively with permeant cations (Palmer and Andersen, 1989; Schild et al., 1997). These observations were interpreted as amiloride binding within the transmembrane part of the channel pore, thereby inhibiting the flux of permeant ions. Patch-clamp experiments on renal CCD cells provided evidence that amiloride directly interacts with a highly selective $\mathrm{Na}^{+}$channel at the apical membrane, resulting in a concentration-dependent decrease in the open-channel probability, by promoting a nonconducting state of the channel (Palmer and Frindt, 1986).

A large number of amiloride analogs were synthesized (Kleyman and Cragoe, 1988). Among these analogs, the most specific inhibitors of ENaC, such as benzamil, bear hydrophobic substituents on the terminal nitrogen atom of the guanidinium moiety (Fig. 8) (Kleyman and Cragoe, 1988). The positively charged guanidinium is needed for 
ENaC block (Palmer, 1984). Amiloride and its analogs were found to be rather poorly specific and inhibit other $\mathrm{Na}^{+}$transporters, such as $\mathrm{Na}^{+} / \mathrm{H}^{+}$or $\mathrm{Na}^{+} / \mathrm{Ca}^{2+}$ exchangers. A higher specificity of amiloride analogs for the $\mathrm{Na}^{+} / \mathrm{H}^{+}$ exchanger is conferred by addition of hydrophobic substituents on the 5-amino group of the pyrazine ring (Kleyman and Cragoe, 1988).

The identification of the primary structure of $\mathrm{ENaC}$ made experiments possible that provided a more precise picture of the ENaC block by amiloride. Site-directed mutagenesis coupled to functional expression of $\mathrm{ENaC}$ mutants identified specific residues in the TM2 that when mutated considerably decreased the affinity of the channel for amiloride. In the center of TM2, a SerGly-Gly ring in the $\alpha, \beta$, and $\gamma$ subunits (corresponding to cASIC1-G439; Fig. 6B) was found to contain the most critical structural determinants of the high amiloride affinity of $\mathrm{ENaC}$ (Schild et al., 1997). Substitution of $\alpha \mathrm{S} 583$ with residues such as Ala, Gly, or Cys increased the $\mathrm{IC}_{50}$ for amiloride by 6 - to 25 -fold depending on the type of mutation. Similar substitutions in the $\beta$ or $\gamma$ subunits increased the $\mathrm{IC}_{50}$ by more than 1000 -fold and 100- to 1000-fold, respectively. Analysis of the kinetics of $\mathrm{ENaC}$ block by amiloride revealed that the decrease of the amiloride affinity in $\mathrm{ENaC}$ mutants by 1-3 orders of magnitude was essentially due to an increase in the dissociation rate constant of amiloride from its receptor site (Kellenberger et al., 2003). In other words, mutations of the G/S ring in the pore of $\mathrm{ENaC}$ destabilize the binding interaction of amiloride with its binding site. These experiments identified the amiloride binding site in the channel pore of $\mathrm{ENaC}$ and confirmed observations from early experiments that amiloride acts on $\mathrm{ENaC}$ as a pore blocker (Palmer and Andersen, 1989). The mutations in the $\mathrm{ENaC}$ pore that affect the amiloride potency decreased to a similar extend the affinity of other $\mathrm{ENaC}$ channel blockers such as triamterene or the amiloride analog benzamil, indicating a common pore blocking mechanism (Kellenberger et al., 2003).

Currently no allosteric inhibitors other than the pore blockers such as amiloride and its derivatives are known to block ENaC activity. However, functional domains important for ENaC activity and its modulation could represent potential target sites for allosteric antagonists. An interesting candidate among them is the N-terminal intracellular domain with highly conserved Cys residues that lead to efficient inhibition of $\mathrm{ENaC}$ when modified by sulfhydryl reagents or oxidizing agents (Kellenberger et al., 2005).

b. Renal effects. The renal effects of amiloride are directly related to $\mathrm{ENaC}$ inhibition. Amiloride reaches its target in the lumen of the CCD by filtration and secretion in the proximal tubule by an organic cation transporter. The $\mathrm{ENaC}$ inhibition results in an increase in urinary $\mathrm{Na}^{+}$excretion and a decrease in $\mathrm{K}^{+}$secretion. The effect on $\mathrm{K}^{+}$secretion is due to the decrease in the apical $\mathrm{Na}^{+}$conductance, which hyperpolarizes the apical membrane and decreases the driving force for $\mathrm{K}^{+}$ secretion from the tubular cell into the lumen of the $\mathrm{CCD}$. Interestingly, $\mathrm{K}^{+}$secretion in the distal nephron depends under normal $\mathrm{K}^{+}$diet entirely on $\mathrm{ENaC}$ mediated $\mathrm{Na}^{+}$absorption. In contrast, a part of the $\mathrm{K}^{+}$ secretion is independent of $\mathrm{ENaC}$ activity under high $\mathrm{K}^{+}$ diet (Frindt and Palmer, 2009a).

Because of the limited contribution of $\mathrm{ENaC}$ to the overall reabsorption of the filtered $\mathrm{Na}^{+}$along the nephron, its effect on $\mathrm{Na}^{+}$excretion is smaller than that of loop diuretics or thiazides. Because the $\mathrm{K}^{+}$secretion coupled to ENaC-mediated $\mathrm{Na}^{+}$absorption is the main secretory pathway for $\mathrm{K}^{+}$secretion under standard $\mathrm{K}^{+}$ diet, the effect of amiloride on $\mathrm{K}^{+}$secretion is larger than its effect on $\mathrm{Na}^{+}$absorption.

In a randomized, crossover trial involving young healthy volunteers under a standardized diet, amiloride was not different from placebo regarding a shortterm 24-hour blood pressure or a $\mathrm{Na}^{+}$or $\mathrm{K}^{+}$excretion, consistent with the presence of compensatory mechanisms to maintain $\mathrm{Na}^{+}$and $\mathrm{K}^{+}$homeostasis in healthy subjects exposed to amiloride (Matthesen et al., 2013).

c. Pulmonary effects. As mentioned previously, $\mathrm{ENaC}$ is expressed in airway epithelial cells and is crucial for the maintenance of an appropriate ASL level and mucociliary clearance. These processes represent the primary innate defense mechanism against respiratory tract infections. Because cystic fibrosis $(\mathrm{CF})$ pathogenesis involves defective mucus clearance, amiloride was tested as an inhalation therapy for rehydrating ASL, enhancing mucus clearance in the respiratory tract of $\mathrm{CF}$ patients. Amiloride failed as an inhalation therapy (Graham et al., 1993; Grasemann et al., 2007). Among the possible reasons that were evoked to explain this failure were first a restricted drug delivery associated with conventional inhalation therapy due to the limited solubility of amiloride, second a limited potency and a rapid dissociation from the receptor, and third a rapid absorption by the airway epithelia. The amiloride derivative benzamil is a more potent inhibitor of $\mathrm{ENaC}$ but was not more efficient than amiloride in the treatment of CF. These observations led to an optimization strategy of the amiloride structure-activity relationship. Interestingly, amiloride shows a high structural tolerance for substitutions, allowing the generation of a variety of ENaC blockers (Hirsh et al., 2006). For instance, modifications of the distal guanidinium group to introduce a permanent positive charge reproduced features that resemble quaternary amines with a high potency for ENaC inhibition. This permanent positive charge introduces an increased polarity of the blocking molecule that results in an increased solubility and a restricted permeability across cell membranes. Other amiloride derivatives were obtained by longchain substitutions at the guanidine nitrogen. One of the compounds, 552-02, was shown to be more potent 
and more selective than amiloride, less epitheliumpermeant, and able to increase mucus clearance in vivo and ASL volume in CF bronchial epithelial cells (Hirsh et al., 2008; Schoenberger and Althaus, 2013).

2. Indirect Antagonists. Other $\mathrm{ENaC}$ antagonists indirectly modulate $\mathrm{ENaC}$ activity at the cell surface. The best-known examples are the antagonists of the mineralocorticoid receptor such as spironolactone or eplerenone. The effects on urinary $\mathrm{Na}^{+}$or $\mathrm{K}^{+}$excretion are very similar to those of amiloride, but these drugs do not require access to the tubule lumen. Endothelin and aldosterone have opposing effects on ENaC-mediated $\mathrm{Na}^{+}$ absorption in the distal nephron and the collecting duct. Endothelin antagonists are expected to relieve ENaC from inhibition by endothelin, but the physiologic/ pharmacological relevance of this phenomenon is unknown.

3. Agonists. As already pointed out, the liquid homeostasis in the adult lung depends on the passive flow of cations via $\mathrm{ENaC}$ and cyclic nucleotide-gated ion channels (Berthiaume and Matthay, 2007). A proof of principle for the development of $\mathrm{ENaC}$ agonists is provided by the covalent modification of Cys residues introduced at specific sites in the external vestibule of the channel pore, e.g., at the DEG site (section V.C). The compound S3969 was recently reported to reversibly stimulate the human $\mathrm{ENaC}$ in heterologous cell expression systems ( $\mathrm{Lu}$ et al., 2008). This compound acts on $\mathrm{ENaC}$ by increasing the channel open probability with an apparent affinity $\left(\mathrm{EC}_{50}\right)$ of $1 \mu \mathrm{M}$. In addition, a cyclic peptide was shown to activate ENaC by increasing its open probability in heterologous expression systems (Shabbir et al., 2013).

The antinatriuretic effect of vasopressin mediated by the V2R has been attributed to a stimulation of ENaCdependent $\mathrm{Na}^{+}$absorption in the ASDN. In normal healthy volunteers under a high $\mathrm{Na}^{+}$diet to suppress aldosterone secretion, the potent V2R agonist desmopressin decreased $\mathrm{Na}^{+}$excretion. A 7-day treatment with amiloride prevented the vasopressin-induced natriuresis, consistent with an ENaC-mediated $\mathrm{Na}^{+}$absorption (Bankir et al., 2005).

\section{Bile Acid-Sensitive Ion Channel}

Many of the chemical compounds that inhibit ASICs have also been applied to the related BASIC. Amiloride inhibits the constitutive mouse BASIC current and the bile-activated rat BASIC current with $\mathrm{IC}_{50}$ values of 7 and $9 \mu \mathrm{M}$, respectively (Wiemuth and Grunder, 2010; Wiemuth et al., 2012). The diarylamidines diminazene and nafamostat, previously shown to inhibit ASICs, also block BASIC currents with IC $_{50}$ values of $2-6 \mu \mathrm{M}$ in a voltagedependent way, suggesting a pore block (Wiemuth and Grunder, 2011; Lefevre et al., 2014). Fenamates such as flufenamic acid are NSAIDs that inhibit the cyclooxygenase in their clinical use and have been known to modulate the function of a large number of ion channels
(Wiemuth and Grunder, 2011). Flufenamic acid and to a lesser extent related drugs, such as diclofenac, activate BASIC at millimolar concentrations, thus at concentrations that are not reached in clinical use of these drugs (Wiemuth and Grunder, 2011). It is interesting to note in this context that diclofenac is known to inhibit ASIC3 with an $\mathrm{IC}_{50}$ of $\sim 100 \mu \mathrm{M}$ (Voilley et al., 2001).

\section{Conclusions and Perspectives}

The cloning of ENaC and ASICs boosted the research on these channels and made possible the investigation of molecular aspects of their function and cellular roles. The physiologic and pathologic roles of both $\mathrm{ENaC}$ and ASICs have been addressed extensively in genetic mouse models. More recently, tissue-specific knockout approaches provided more detailed information on the $\mathrm{ENaC}$ physiology. Newly discovered ASIC toxins contributed importantly to the understanding of the involvement of ASICs in pain sensation and neurodegeneration after ischemic stroke. There are still many open questions remaining, and further studies are needed to find answers to questions such as the molecular mechanisms of $\mathrm{ENaC}$ regulation by aldosterone or of the involvement of ASICs in pain sensation, synaptic plasticity, and the expression of fear. Studies addressing these questions may identify new drug targets for $\mathrm{ENaC}$ regulation and will likely provide more precise information on ASIC physiology and confirm ASICs as promising drug targets.

The recent publication of crystal structures of an ASIC channel has stimulated the structure-function investigation of ASICs. Together, newly available structural and functional information allowed elucidating molecular mechanisms of ASIC and $\mathrm{ENaC}$ function. By continuing these investigations, it will be possible to describe the molecular mechanisms by which extra- and intracellular factors control $\mathrm{ENaC}$ and ASIC activity and to identify specific sites within the channel proteins that can be targeted by novel drugs.

\section{Acknowledgments}

The authors thank Miguel van Bemmelen, Olivier Staub, Edith Hummler, Karolina Gwiazda, Gaetano Bonifacio, and Omar Alijevic for comments on a previous version of the manuscript.

\section{Authorship Contributions}

Wrote or contributed to the writing of the manuscript: Kellenberger, Schild.

\section{References}

Adams CM, Snyder PM, Price MP, and Welsh MJ (1998) Protons activate brain $\mathrm{Na}^{+}$ channel 1 by inducing a conformational change that exposes a residue associated with neurodegeneration. J Biol Chem 273:30204-30207.

Adams CM, Snyder PM, and Welsh MJ (1999) Paradoxical stimulation of a DEG/ENaC channel by amiloride. J Biol Chem 274:15500-15504.

Alexander SP, Benson HE, Faccenda E, Pawson AJ, Sharman JL, Catterall WA, Spedding M, Peters JA, and Harmar AJ; CGTP Collaborators (2013) The Concise Guide to PHARMACOLOGY 2013/14: ion channels. Br J Pharmacol 170:1607-1651. Ali A, Pillai KP, Ahmad FJ, Dua Y, and Vohora D(2006) Anticonvulsant effect of amiloride in pentetrazole-induced status epilepticus in mice. Pharmacol Rep 58:242-245. 
Alijevic O and Kellenberger S (2012) Subtype-specific modulation of acid-sensing ion channel (ASIC) function by 2-guanidine-4-methylquinazoline. J Biol Chem 287: 36059-36070.

Allen NJ and Attwell D (2002) Modulation of ASIC channels in rat cerebellar Purkinje neurons by ischaemia-related signals. J Physiol 543:521-529.

Alvarez de la Rosa D, Krueger SR, Kolar A, Shao D, Fitzsimonds RM, and Canessa CM (2003) Distribution, subcellular localization and ontogeny of ASIC1 in the mammalian central nervous system. J Physiol 546:77-87.

Anangi R, Rash LD, Mobli M, and King GF (2012) Functional expression in Escherichia coli of the disulfide-rich sea anemone peptide APETx2, a potent blocker of acid-sensing ion channel 3. Mar Drugs 10:1605-1618.

Anantharam A and Palmer LG (2007) Determination of epithelial $\mathrm{Na}^{+}$channel subunit stoichiometry from single-channel conductances. J Gen Physiol 130 $55-70$.

Anantharam A, Tian Y, and Palmer LG (2006) Open probability of the epithelial sodium channel is regulated by intracellular sodium. J Physiol 574:333-347.

Andreasen D, Vuagniaux G, Fowler-Jaeger N, Hummler E, and Rossier BC (2006) Activation of epithelial sodium channels by mouse channel activating proteases (mCAP) expressed in Xenopus oocytes requires catalytic activity of mCAP3 and mCAP2 but not mCAP1. J Am Soc Nephrol 17:968-976.

Andrey F, Tsintsadze T, Volkova T, Lozovaya N, and Krishtal O (2005) Acid sensing ionic channels: modulation by redox reagents. Biochim Biophys Acta 1745:1-6.

Anzai N, Deval E, Schaefer L, Friend V, Lazdunski M, and Lingueglia E (2002) The multivalent PDZ domain-containing protein CIPP is a partner of acid-sensing ion channel 3 in sensory neurons. J Biol Chem 277:16655-16661.

Arun T, Tomassini V, Sbardella E, de Ruiter MB, Matthews L, Leite MI, GelineauMorel R, Cavey A, Vergo S, and Craner M, et al. (2013) Targeting ASIC1 in primary progressive multiple sclerosis: evidence of neuroprotection with amiloride. Brain 136:106-115

Askwith CC, Benson CJ, Welsh MJ, and Snyder PM (2001) DEG/ENaC ion channels involved in sensory transduction are modulated by cold temperature. Proc Nat Acad Sci USA 98:6459-6463.

Askwith CC, Cheng C, Ikuma M, Benson C, Price MP, and Welsh MJ (2000) Neuropeptide FF and FMRFamide potentiate acid-evoked currents from sensory neurons and proton-gated DEG/ENaC channels. Neuron 26:133-141.

Auberson M, Hoffmann-Pochon N, Vandewalle A, Kellenberger S, and Schild L (2003) Epithelial $\mathrm{Na}^{+}$channel mutants causing Liddle's syndrome retain ability to respond to aldosterone and vasopressin. Am J Physiol Renal Physiol 285:F459-F471.

Babini E, Paukert M, Geisler HS, and Grunder S (2002) Alternative splicing and interaction with di- and polyvalent cations control the dynamic range of acidsensing ion channel 1 (ASIC1). J Biol Chem 277:41597-41603.

Babinski K, Lê KT, and Séguéla P (1999) Molecular cloning and regional distribution of a human proton receptor subunit with biphasic functional properties. J Neurochem 72:51-57.

Baconguis I, Bohlen CJ, Goehring A, Julius D, and Gouaux E (2014) X-ray structure of acid-sensing ion channel 1-snake toxin complex reveals open state of a $\mathrm{Na}$ $\left.{ }^{+}\right)$-selective channel. Cell 156:717-729.

Baconguis I and Gouaux E (2012) Structural plasticity and dynamic selectivity of acid-sensing ion channel-spider toxin complexes. Nature 489:400-405.

Bankir L, Fernandes S, Bardoux P, Bouby N, and Bichet DG (2005) Vasopressin-V2 receptor stimulation reduces sodium excretion in healthy humans. J Am Soc Nephrol 16:1920-1928.

Bargeton B and Kellenberger S (2010) The contact region between three domains of the extracellular loop of ASIC1a is critical for channel function. J Biol Chem $\mathbf{2 8 5}$ 13816-13826.

Baron A, Deval E, Salinas M, Lingueglia E, Voilley N, and Lazdunski M (2002) Protein kinase $\mathrm{C}$ stimulates the acid-sensing ion channel ASIC2a via the PDZ domain-containing protein PICK1. J Biol Chem 277:50463-50468.

Baron A, Diochot S, Salinas M, Deval E, Noël J, and Lingueglia E (2013) Venom toxins in the exploration of molecular, physiological and pathophysiological functions of acid-sensing ion channels. Toxicon 75:187-204.

Baron A, Schaefer L, Lingueglia E, Champigny G, and Lazdunski M (2001) $\mathrm{Zn}^{2+}$ and $\mathrm{H}^{+}$are coactivators of acid-sensing ion channels. J Biol Chem 276:35361-35367.

Baron A, Voilley N, Lazdunski M, and Lingueglia E (2008) Acid sensing ion channels in dorsal spinal cord neurons. J Neurosci 28:1498-1508.

Bartoi T, Augustinowski K, Polleichtner G, Gründer S, and Ulbrich MH (2014) Acidsensing ion channel (ASIC) 1a/2a heteromers have a flexible 2:1/1:2 stoichiometry. Proc Natl Acad Sci USA 111:8281-8286.

Bässler EL, Ngo-Anh TJ, Geisler HS, Ruppersberg JP, and Gründer S (2001) Molecular and functional characterization of acid-sensing ion channel (ASIC) $1 \mathrm{~b} . J$ Biol Chem 276:33782-33787.

Benson CJ, Xie J, Wemmie JA, Price MP, Henss JM, Welsh MJ, and Snyder PM (2002) Heteromultimers of DEG/ENaC subunits form $\mathrm{H}^{+}$-gated channels in mouse sensory neurons. Proc Natl Acad Sci USA 99:2338-2343.

Bernardinelli L, Murgia SB, Bitti PP, Foco L, Ferrai R, Musu L, Prokopenko I, Pastorino R, Saddi V, and Ticca A, et al. (2007) Association between the ACCN1 gene and multiple sclerosis in Central East Sardinia. PLoS ONE 2:e480.

Berthiaume Y and Matthay MA (2007) Alveolar edema fluid clearance and acute lung injury. Respir Physiol Neurobiol 159:350-359.

Birdsong WT, Fierro L, Williams FG, Spelta V, Naves LA, Knowles M, Marsh-Haffner J, Adelman JP, Almers W, and Elde RP, et al. (2010) Sensing muscle ischemia: coincident detection of acid and ATP via interplay of two ion channels. Neuron 68:739-749.

Bize V and Horisberger JD (2007) Sodium self-inhibition of human epithelial sodium channel: selectivity and affinity of the extracellular sodium sensing site. Am J Physiol Renal Physiol 293:F1137-F1146.

Blanchard MG and Kellenberger S (2011) Effect of a temperature increase in the nonnoxious range on proton-evoked ASIC and TRPV1 activity. Pflugers Arch 461:123-139.

Blanchard MG, Rash LD, and Kellenberger S (2012) Inhibition of voltage-gated $\mathrm{Na}^{+}{ }^{+}$ currents in sensory neurones by the sea anemone toxin APETx2. Br J Pharmacol 165:2167-2177.
Bohlen CJ, Chesler AT, Sharif-Naeini R, Medzihradszky KF, Zhou S, King D, Sánchez EE, Burlingame AL, Basbaum AI, and Julius D (2011) A heteromeric Texas coral snake toxin targets acid-sensing ion channels to produce pain. Nature 479:410-414.

Boiko N, Kucher V, Eaton BA, and Stockand JD (2013) Inhibition of neuronal degenerin/epithelial $\mathrm{Na}+$ channels by the multiple sclerosis drug 4-aminopyridine. J Biol Chem 288:9418-9427.

Boiko N, Kucher V, Wang B, and Stockand JD (2014) Restrictive expression of acidsensing ion channel 5 (asic5) in unipolar brush cells of the vestibulocerebellum. PLoS ONE 9:e91326.

Bonifacio G, Lelli CI, and Kellenberger S (2014) Protonation controls ASIC1a activity via coordinated movements in multiple domains. $J$ Gen Physiol 143: $105-118$

Browne LE, Nunes JP, Sim JA, Chudasama V, Bragg L, Caddick S, and North RA (2014) Optical control of trimeric P2X receptors and acid-sensing ion channels. Proc Natl Acad Sci USA 111:521-526.

Bruns JB, Carattino MD, Sheng S, Maarouf AB, Weisz OA, Pilewski JM, Hughey RP, and Kleyman TR (2007) Epithelial $\mathrm{Na}^{+}$channels are fully activated by furin- and prostasin-dependent release of an inhibitory peptide from the gamma-subunit. $J$ Biol Chem 282:6153-6160.

Burch LH, Talbot CR, Knowles MR, Canessa CM, Rossier BC, and Boucher RC (1995) Relative expression of the human epithelial $\mathrm{Na}^{+}$channel subunits in normal and cystic fibrosis airways. Am J Physiol 269:C511-C518.

Cadiou H, Studer M, Jones NG, Smith ES, Ballard A, McMahon SB, and McNaughton PA (2007) Modulation of acid-sensing ion channel activity by nitric oxide. J Neurosci 27:13251-13260.

Canessa CM, Horisberger J-D, and Rossier BC (1993) Epithelial sodium channel related to proteins involved in neurodegeneration. Nature 361:467-470.

Canessa CM, Merillat AM, and Rossier BC (1994a) Membrane topology of the epithelial sodium channel in intact cells. Am J Physiol 267:C1682-C1690.

Canessa CM, Schild L, Buell G, Thorens B, Gautschi I, Horisberger JD, and Rossier BC (1994b) Amiloride-sensitive epithelial $\mathrm{Na}+$ channel is made of three homologous subunits. Nature 367:463-467.

Carattino MD, Hughey RP, and Kleyman TR (2008) Proteolytic processing of the epithelial sodium channel gamma subunit has a dominant role in channel activation. J Biol Chem 283:25290-25295.

Carnally SM, Dev HS, Stewart AP, Barrera NP, Van Bemmelen MX, Schild L, Henderson RM, and Edwardson JM (2008) Direct visualization of the trimeric structure of the ASIC1a channel, using AFM imaging. Biochem Biophys Res Commun 372:752-755.

Chagot B, Escoubas P, Diochot S, Bernard C, Lazdunski M, and Darbon H (2005) Solution structure of APETx2, a specific peptide inhibitor of ASIC3 proton-gated channels. Protein Sci 14:2003-2010.

Chai S, Li M, Lan J, Xiong ZG, Saugstad JA, and Simon RP (2007) A kinaseanchoring protein 150 and calcineurin are involved in regulation of acid-sensing ion channels ASIC1a and ASIC2a. J Biol Chem 282:22668-22677.

Chalfant ML, Denton JS, Berdiev BK, Ismailov II, Benos DJ, and Stanton BA (1999) Intracellular $\mathrm{H}^{+}$regulates the alpha-subunit of $\mathrm{ENaC}$, the epithelial $\mathrm{Na}^{+}$channel. Am J Physiol 276:C477-C486.

Champigny G, Voilley N, Waldmann R, and Lazdunski M (1998) Mutations causing neurodegeneration in Caenorhabditis elegans drastically alter the $\mathrm{pH}$ sensitivity and inactivation of the mammalian $\mathrm{H}^{+}$-gated $\mathrm{Na}^{+}$channel MDEG1. J Biol Chem 273:15418-15422.

Chandrashekar J, Kuhn C, Oka Y, Yarmolinsky DA, Hummler E, Ryba NJ, and Zuker CS (2010) The cells and peripheral representation of sodium taste in mice. Nature 464:297-301.

Chang SS, Grunder S, Hanukoglu A, Rösler A, Mathew PM, Hanukoglu I, Schild L, Lu Y, Shimkets RA, and Nelson-Williams C, et al. (1996) Mutations in subunits of the epithelial sodium channel cause salt wasting with hyperkalaemic acidosis, pseudohypoaldosteronism type 1. Nat Genet 12:248-253.

Chen CC and Wong CW (2013) Neurosensory mechanotransduction through acidsensing ion channels. J Cell Mol Med 17:337-349.

Chen X and Gründer S (2007) Permeating protons contribute to tachyphylaxis of the acid-sensing ion channel (ASIC) 1a. J Physiol 579:657-670.

Chen X, Kalbacher H, and Gründer S (2005) The tarantula toxin psalmotoxin 1 inhibits acid-sensing ion channel (ASIC) 1a by increasing its apparent $\mathrm{H}^{+}$affinity. $J$ Gen Physiol 126:71-79.

Chen X, Kalbacher H, and Gründer S (2006) Interaction of acid-sensing ion channel (ASIC) 1 with the tarantula toxin psalmotoxin 1 is state dependent. J Gen Physiol 127:267-276

Chen X, Qiu L, Li M, Dürrnagel S, Orser BA, Xiong ZG, and MacDonald JF (2010) Diarylamidines: high potency inhibitors of acid-sensing ion channels. Neuropharmacology 58:1045-1053.

Cho JH and Askwith CC (2007) Potentiation of acid-sensing ion channels by sulfhydryl compounds. Am J Physiol Cell Physiol 292:C2161-C2174.

Chraïbi A and Horisberger JD (2002) Na self inhibition of human epithelial Na channel: temperature dependence and effect of extracellular proteases. $J$ Gen Physiol 120:133-145.

Chraïbi A, Vallet V, Firsov D, Hess SK, and Horisberger JD (1998) Protease modulation of the activity of the epithelial sodium channel expressed in Xenopus oocytes. $J$ Gen Physiol 111:127-138.

Christensen BM, Perrier R, Wang Q, Zuber AM, Maillard M, Mordasini D, Malsure S, Ronzaud C, Stehle JC, and Rossier BC, et al. (2010) Sodium and potassium balance depends on $\alpha \mathrm{ENaC}$ expression in connecting tubule. J Am Soc Nephrol 21:1942-1951.

Chu XP, Close N, Saugstad JA, and Xiong ZG (2006) ASIC1a-specific modulation of acid-sensing ion channels in mouse cortical neurons by redox reagents. J Neurosci $\mathbf{2 6}$ $5329-5339$

Chu XP, Papasian CJ, Wang JQ, and Xiong ZG (2011) Modulation of acid-sensing ion channels: molecular mechanisms and therapeutic potential. Int J Physiol Pathophysiol Pharmacol 3:288-309. 
Chu XP, Wemmie JA, Wang WZ, Zhu XM, Saugstad JA, Price MP, Simon RP, and Xiong ZG (2004) Subunit-dependent high-affinity zinc inhibition of acidsensing ion channels. J Neurosci 24:8678-8689.

Cobbe SM and Poole-Wilson PA (1980) Tissue acidosis in myocardial hypoxia. J Mol Cell Cardiol 12:761-770.

Coric T, Zhang P, Todorovic N, and Canessa CM (2003) The extracellular domain determines the kinetics of desensitization in acid-sensitive ion channel 1. J Biol Chem 278:45240-45247.

Coryell MW, Wunsch AM, Haenfler JM, Allen JE, Schnizler M, Ziemann AE, Cook MN, Dunning JP, Price MP, and Rainier JD, et al. (2009) Acid-sensing ion channel$1 \mathrm{a}$ in the amygdala, a novel therapeutic target in depression-related behavior. $J$ Neurosci 29:5381-5388.

Coryell MW, Ziemann AE, Westmoreland PJ, Haenfler JM, Kurjakovic Z, Zha XM, Price M, Schnizler MK, and Wemmie JA (2007) Targeting ASIC1a reduces innate fear and alters neuronal activity in the fear circuit. Biol Psychiatry 62 : $1140-1148$.

Coscoy S, de Weille JR, Lingueglia E, and Lazdunski M (1999) The pretransmembrane 1 domain of acid-sensing ion channels participates in the ion pore. J Biol Chem 274:10129-10132.

Cragoe EJ Jr, Woltersdorf OW Jr, Bicking JB, Kwong SF, and Jones JH (1967) Pyrazine diuretics. II. N-amidino-3-amino-5-substituted 6-halopyrazinecarboxamides. $J$ Med Chem 10:66-75.

Cushman KA, Marsh-Haffner J, Adelman JP, and McCleskey EW (2007) A conformation change in the extracellular domain that accompanies desensitization of acid-sensing ion channel (ASIC) 3. J Gen Physiol 129:345-350.

Dawson RJ, Benz J, Stohler P, Tetaz T, Joseph C, Huber S, Schmid G, Hügin D, Pflimlin P, and Trube G, et al. (2012) Structure of the acid-sensing ion channel 1 in complex with the gating modifier Psalmotoxin 1. Nat Commun 3:936.

Debonneville C, Flores SY, Kamynina E, Plant PJ, Tauxe C, Thomas MA, Münster C, Chraïbi A, Pratt JH, and Horisberger JD, et al. (2001) Phosphorylation of Nedd4-2 by $\mathrm{Sgk} 1$ regulates epithelial $\mathrm{Na}(+)$ channel cell surface expression. EMBO $J \mathbf{2 0}$ : $7052-7059$

Delaunay A, Gasull X, Salinas M, Noël J, Friend V, Lingueglia E, and Deval E (2012) Human ASIC3 channel dynamically adapts its activity to sense the extracellular $\mathrm{pH}$ in both acidic and alkaline directions. Proc Natl Acad Sci USA 109:13124-13129.

Della Vecchia MC, Rued AC, and Carattino MD (2013) Gating transitions in the palm domain of ASIC1a. J Biol Chem 288:5487-5495.

Deval E, Baron A, Lingueglia E, Mazarguil H, Zajac JM, and Lazdunski M (2003) Effects of neuropeptide SF and related peptides on acid sensing ion channel 3 and sensory neuron excitability. Neuropharmacology 44:662-671.

Deval E, Friend V, Thirant C, Salinas M, Jodar M, Lazdunski M, and Lingueglia E (2006) Regulation of sensory neuron-specific acid-sensing ion channel 3 by the adaptor protein $\mathrm{Na}^{+} / \mathrm{H}^{+}$exchanger regulatory factor-1. J Biol Chem 281:1796-1807.

Deval E, Noël J, Lay N, Alloui A, Diochot S, Friend V, Jodar M, Lazdunski M, and Lingueglia E (2008) ASIC3, a sensor of acidic and primary inflammatory pain. EMBO J 27:3047-3055.

Deval E, Salinas M, Baron A, Lingueglia E, and Lazdunski M (2004) ASIC2bdependent regulation of ASIC3, an essential acid-sensing ion channel subunit in sensory neurons via the partner protein PICK-1. J Biol Chem 279:19531-19539.

de Weille J and Bassilana F (2001) Dependence of the acid-sensitive ion channel, ASIC1a, on extracellular $\left.\mathrm{Ca}^{(2+}\right)$ ions. Brain Res 900:277-281.

de Weille JR, Bassilana F, Lazdunski M, and Waldmann R (1998) Identification, functional expression and chromosomal localisation of a sustained human protongated cation channel. FEBS Lett 433:257-260.

Dijkink L, Hartog A, van Os CH, and Bindels RJ (2002) The epithelial sodium channel $(\mathrm{ENaC})$ is intracellularly located as a tetramer. Pflugers Arch 444:549-555.

Diochot S, Baron A, Rash LD, Deval E, Escoubas P, Scarzello S, Salinas M, and Lazdunski M (2004) A new sea anemone peptide, APETx2, inhibits ASIC3, a major acid-sensitive channel in sensory neurons. EMBO $J$ 23:1516-1525.

Diochot S, Baron A, Salinas M, Douguet D, Scarzello S, Dabert-Gay AS, Debayle D, Friend V, Alloui A, and Lazdunski M, et al. (2012) Black mamba venom peptides target acid-sensing ion channels to abolish pain. Nature 490:552-555.

Doley R and Kini RM (2009) Protein complexes in snake venom. Cell Mol Life Sci 66 2851-2871.

Donier E, Rugiero F, Okuse K, and Wood JN (2005) Annexin II light chain p11 promotes functional expression of acid-sensing ion channel ASIC1a. J Biol Chem 280:38666-38672.

Dorofeeva NA, Barygin OI, Staruschenko A, Bolshakov KV, and Magazanik LG (2008) Mechanisms of non-steroid anti-inflammatory drugs action on ASICs expressed in hippocampal interneurons. J Neurochem 106:429-441.

Drew LJ, Rohrer DK, Price MP, Blaver KE, Cockayne DA, Cesare P, and Wood JN (2004) Acid-sensing ion channels ASIC2 and ASIC3 do not contribute to mechanically activated currents in mammalian sensory neurones. $J$ Physiol 556:691-710.

Drummond HA, Gebremedhin D, and Harder DR (2004) Degenerin/epithelial $\mathrm{Na}^{+}$ channel proteins: components of a vascular mechanosensor. Hypertension 44: 643-648.

Du J, Reznikov LR, Price MP, Zha XM, Lu Y, Moninger TO, Wemmie JA, and Welsh MJ (2014) Protons are a neurotransmitter that regulates synaptic plasticity in the lateral amygdala. Proc Natl Acad Sci USA 111:8961-8966.

Duan B, Liu DS, Huang Y, Zeng WZ, Wang X, Yu H, Zhu MX, Chen ZY, and Xu TL (2012) PI3-kinase/Akt pathway-regulated membrane insertion of acid-sensing ion channel 1a underlies BDNF-induced pain hypersensitivity. J Neurosci 32:6351-6363.

Duan B, Wang YZ, Yang T, Chu XP, Yu Y, Huang Y, Cao H, Hansen J, Simon RP, and Zhu MX, et al. (2011) Extracellular spermine exacerbates ischemic neuronal injury through sensitization of ASIC1a channels to extracellular acidosis. J Neurosci 31:2101-2112.

Duan B, Wu LJ, Yu YQ, Ding Y, Jing L, Xu L, Chen J, and Xu TL (2007) Upregulation of acid-sensing ion channel ASIC1a in spinal dorsal horn neurons contributes to inflammatory pain hypersensitivity. $J$ Neurosci 27:11139-11148.
Dubé GR, Lehto SG, Breese NM, Baker SJ, Wang X, Matulenko MA, Honoré P, Stewart AO, Moreland RB, and Brioni JD (2005) Electrophysiological and in vivo characterization of A-317567, a novel blocker of acid sensing ion channels. Pain 117:88-96.

Duggan A, Garcia-Anoveros J, and Corey DP (2002) The PDZ domain protein PICK1 and the sodium channel $\mathrm{BNaC} 1$ interact and localize at mechanosensory terminals of dorsal root ganglion neurons and dendrites of central neurons. $J$ Biol Chem 277: $5203-5208$

Eastwood AL and Goodman MB (2012) Insight into DEG/ENaC channel gating from genetics and structure. Physiology (Bethesda) 27:282-290.

Epple HJ, Amasheh S, Mankertz J, Goltz M, Schulzke JD, and Fromm M (2000) Early aldosterone effect in distal colon by transcriptional regulation of $\mathrm{ENaC}$ subunits. Am J Physiol Gastrointest Liver Physiol 278:G718-G724.

Escoubas P, Bernard C, Lambeau G, Lazdunski M, and Darbon H (2003) Recombinant production and solution structure of PcTx1, the specific peptide inhibitor of ASIC1a proton-gated cation channels. Protein Sci 12:1332-1343.

Escoubas P, De Weille JR, Lecoq A, Diochot S, Waldmann R, Champigny G, Moinier D, Ménez A, and Lazdunski M (2000) Isolation of a tarantula toxin specific for a class of proton-gated $\mathrm{Na}^{+}$channels. J Biol Chem 275:25116-25121.

Eshcol JO, Harding AM, Hattori T, Costa V, Welsh MJ, and Benson CJ (2008) Acidsensing ion channel 3 (ASIC3) cell surface expression is modulated by PSD-95 within lipid rafts. Am J Physiol Cell Physiol 295:C732-739.

Eskandari S, Snyder PM, Kreman M, Zampighi GA, Welsh MJ, and Wright EM (1999) Number of subunits comprising the epithelial sodium channel. J Biol Chem 274:27281-27286.

Fejes-Tóth G, Frindt G, Náray-Fejes-Tóth A, and Palmer LG (2008) Epithelial $\mathrm{Na}^{+}$ channel activation and processing in mice lacking SGK1. Am $J$ Physiol Renal Physiol 294:F1298-F1305.

Firsov D, Gautschi I, Merillat AM, Rossier BC, and Schild L (1998) The heterotetrameric architecture of the epithelial sodium channel (ENaC). EMBO $J$ 17: 344-352.

Firsov D, Schild L, Gautschi I, Mérillat AM, Schneeberger E, and Rossier BC (1996) Cell surface expression of the epithelial Na channel and a mutant causing Liddle syndrome: a quantitative approach. Proc Natl Acad Sci USA 93:15370-15375.

Friese MA, Craner MJ, Etzensperger R, Vergo S, Wemmie JA, Welsh MJ, Vincent A and Fugger L (2007) Acid-sensing ion channel-1 contributes to axonal degeneration in autoimmune inflammation of the central nervous system. Nat Med $\mathbf{1 3}$ 1483-1489.

Frindt G, Ergonul Z, and Palmer LG (2008) Surface expression of epithelial Na channel protein in rat kidney. J Gen Physiol 131:617-627.

Frindt G and Palmer LG (2004) Na channels in the rat connecting tubule. Am $J$ Physiol Renal Physiol 286:F669-F674.

Frindt G and Palmer LG (2009a) $\mathrm{K}^{+}$secretion in the rat kidney: $\mathrm{Na}^{+}$channeldependent and -independent mechanisms. Am J Physiol Renal Physiol 297: F389-F396.

Frindt G and Palmer LG (2009b) Surface expression of sodium channels and transporters in rat kidney: effects of dietary sodium. Am J Physiol Renal Physiol 297 F1249-F1255.

Frindt G and Palmer LG (2012) Regulation of epithelial $\mathrm{Na}^{+}$channels by adrenal steroids: mineralocorticoid and glucocorticoid effects. Am J Physiol Renal Physiol 302:F20-F26.

Frindt G, Silver RB, Windhager EE, and Palmer LG (1993) Feedback regulation of $\mathrm{Na}$ channels in rat CCT. II. Effects of inhibition of Na entry. Am J Physiol 264: F565-F574.

Frindt G, Silver RB, Windhager EE, and Palmer LG (1995) Feedback regulation of Na channels in rat CCT. III. Response to cAMP. Am J Physiol 268:F480-F489.

Fuchs W, Larsen EH, and Lindemann B (1977) Current-voltage curve of sodium channels and concentration dependence of sodium permeability in frog skin. $J$ Physiol 267:137-166.

Fujii S and Hitomi Y (1981) New synthetic inhibitors of C1r, C1 esterase, thrombin plasmin, kallikrein and trypsin. Biochim Biophys Acta 661:342-345.

Fuller PJ, Brennan FE, and Burgess JS (2000) Acute differential regulation by corticosteroids of epithelial sodium channel subunit and Nedd4 mRNA levels in the distal colon. Pflugers Arch 441:94-101.

Gao J, Duan B, Wang DG, Deng XH, Zhang GY, Xu L, and Xu TL (2005) Coupling between NMDA receptor and acid-sensing ion channel contributes to ischemic neuronal death. Neuron 48:635-646.

Garty H and Palmer LG (1997) Epithelial sodium channels: function, structure, and regulation. Physiol Rev 77:359-396.

Geller DS, Rodriguez-Soriano J, Vallo Boado A, Schifter S, Bayer M, Chang SS, and Lifton RP (1998) Mutations in the mineralocorticoid receptor gene cause autosomal dominant pseudohypoaldosteronism type I. Nat Genet 19:279-281.

Gingrich MB and Traynelis SF (2000) Serine proteases and brain damage - is there a link? Trends Neurosci 23:399-407.

Gonzales EB, Kawate T, and Gouaux E (2009) Pore architecture and ion sites in acidsensing ion channels and P2X receptors. Nature 460:599-604

Goralski JL, Boucher RC, and Button B (2010) Osmolytes and ion transport modulators: new strategies for airway surface rehydration. Curr Opin Pharmacol 10 294-299.

Graham A, Hasani A, Alton EW, Martin GP, Marriott C, Hodson ME, Clarke SW, and Geddes DM (1993) No added benefit from nebulized amiloride in patients with cystic fibrosis. Eur Respir J 6:1243-1248.

Grasemann H, Stehling F, Brunar H, Widmann R, Laliberte TW, Molina L, Döring G, and Ratjen F (2007) Inhalation of Moli1901 in patients with cystic fibrosis. Chest 131:1461-1466.

Gründer S and Augustinowski K (2012) Toxin binding reveals two open state structures for one acid-sensing ion channel. Channels (Austin) 6:409-413.

Gründer S and Chen X (2010) Structure, function, and pharmacology of acid-sensing ion channels (ASICs): focus on ASIC1a. Int J Physiol Pathophysiol Pharmacol 2: 73-94. 
Gründer S, Firsov D, Chang SS, Jaeger NF, Gautschi I, Schild L, Lifton RP, and Rossier BC (1997) A mutation causing pseudohypoaldosteronism type 1 identifies a conserved glycine that is involved in the gating of the epithelial sodium channel. EMBO J 16:899-907.

Halpern BP (1998) Amiloride and vertebrate gustatory responses to $\mathrm{NaCl}$. Neurosci Biobehav Rev 23:5-47.

Harris M, Garcia-Caballero A, Stutts MJ, Firsov D, and Rossier BC (2008) Preferential assembly of epithelial sodium channel (ENaC) subunits in Xenopus oocytes: role of furin-mediated endogenous proteolysis. J Biol Chem 283:7455-7463.

Hesselager M, Timmermann DB, and Ahring PK (2004) pH Dependency and desensitization kinetics of heterologously expressed combinations of acid-sensing ion channel subunits. J Biol Chem 279:11006-11015.

Hirsh AJ, Molino BF, Zhang J, Astakhova N, Geiss WB, Sargent BJ, Swenson BD, Usyatinsky A, Wyle MJ, and Boucher RC, et al. (2006) Design, synthesis, and structure-activity relationships of novel 2-substituted pyrazinoylguanidine epithelial sodium channel blockers: drugs for cystic fibrosis and chronic bronchitis. J Med Chem 49:4098-4115.

Hirsh AJ, Zhang J, Zamurs A, Fleegle J, Thelin WR, Caldwell RA, Sabater JR, Abraham WM, Donowitz M, and Cha B, et al. (2008) Pharmacological properties of N-(3,5-diamino-6-chloropyrazine-2-carbonyl)-N'-4-[4-(2,3-dihydroxypropoxy) phenyl]butyl-guanidine methanesulfonate (552-02), a novel epithelial sodium channel blocker with potential clinical efficacy for cystic fibrosis lung disease. $J$ Pharmacol Exp Ther 325:77-88.

Hobbs CA, Da Tan C, and Tarran R (2013) Does epithelial sodium channel hyperactivity contribute to cystic fibrosis lung disease? J Physiol 591:4377-4387.

Holland PR, Akerman S, Andreou AP, Karsan N, Wemmie JA, and Goadsby PJ (2012) Acid-sensing ion channel 1: a novel therapeutic target for migraine with aura. Ann Neurol 72:559-563.

Horisberger JD and Chraïbi A (2004) Epithelial sodium channel: a ligand-gated channel? Nephron, Physiol 96:37-41.

Hruska-Hageman AM, Benson CJ, Leonard AS, Price MP, and Welsh MJ (2004) PSD-95 and Lin-7b interact with acid-sensing ion channel-3 and have opposite effects on $\mathrm{H}^{+}$- gated current. J Biol Chem 279:46962-46968

Hruska-Hageman AM, Wemmie JA, Price MP, and Welsh MJ (2002) Interaction of the synaptic protein PICK1 (protein interacting with C kinase 1) with the nonvoltage gated sodium channels BNC1 (brain Na+ channel 1) and ASIC (acidsensing ion channel). Biochem $J$ 361:443-450.

Hughey RP, Bruns JB, Kinlough CL, Harkleroad KL, Tong Q, Carattino MD, Johnson JP, Stockand JD, and Kleyman TR (2004) Epithelial sodium channels are activated by furin-dependent proteolysis. J Biol Chem 279:18111-18114.

Hughey RP, Mueller GM, Bruns JB, Kinlough CL, Poland PA, Harkleroad KL, Carattino MD, and Kleyman TR (2003) Maturation of the epithelial $\mathrm{Na}^{+}$channel involves proteolytic processing of the alpha- and gamma-subunits. J Biol Chem 278:37073-37082.

Hummler E, Barker P, Gatzy J, Beermann F, Verdumo C, Schmidt A, Boucher R, and Rossier BC (1996) Early death due to defective neonatal lung liquid clearance in alpha-ENaC-deficient mice. Nat Genet 12:325-328.

Hummler E, Barker P, Talbot C, Wang Q, Verdumo C, Grubb B, Gatzy J, Burnier M, Horisberger JD, and Beermann F, et al. (1997) A mouse model for the renal saltwasting syndrome pseudohypoaldosteronism. Proc Natl Acad Sci USA 94: $11710-11715$.

Immke DC and McCleskey EW (2001) Lactate enhances the acid-sensing $\mathrm{Na}^{+}$ channel on ischemia-sensing neurons. Nat Neurosci 4:869-870.

Immke DC and McCleskey EW (2003) Protons open acid-sensing ion channels by catalyzing relief of $\mathrm{Ca}^{2+}$ blockade. Neuron 37:75-84

Jasti J, Furukawa H, Gonzales EB, and Gouaux E (2007) Structure of acid-sensing ion channel 1 at 1.9 A resolution and low $\mathrm{pH}$. Nature 449:316-323.

Jiang Q, Inoue K, Wu X, Papasian CJ, Wang JQ, Xiong ZG, and Chu XP (2011) Cysteine 149 in the extracellular finger domain of acid-sensing ion channel $1 \mathrm{~b}$ subunit is critical for zinc-mediated inhibition. Neuroscience 193:89-99.

Jiang Q, Papasian CJ, Wang JQ, Xiong ZG, and Chu XP (2010) Inhibitory regulation of acid-sensing ion channel 3 by zinc. Neuroscience 169:574-583.

Jing L, Jiang YQ, Jiang Q, Wang B, Chu XP, and Zha XM (2011) The interaction between the first transmembrane domain and the thumb of ASIC1a is critical for its N-glycosylation and trafficking. PLoS ONE 6:e26909.

Jones NG, Slater R, Cadiou H, McNaughton P, and McMahon SB (2004) Acid-induced pain and its modulation in humans. $J$ Neurosci 24:10974-10979.

Jones RC 3rd, Xu L, and Gebhart GF (2005) The mechanosensitivity of mouse colon afferent fibers and their sensitization by inflammatory mediators require transient receptor potential vanilloid 1 and acid-sensing ion channel 3. J Neurosci 25 10981-10989.

Kang S, Jang JH, Price MP, Gautam M, Benson CJ, Gong H, Welsh MJ, and Brennan TJ (2012) Simultaneous disruption of mouse ASIC1a, ASIC2 and ASIC3 genes enhances cutaneous mechanosensitivity. PLoS ONE 7:e35225.

Kashlan OB, Adelman JL, Okumura S, Blobner BM, Zuzek Z, Hughey RP, Kleyman TR, and Grabe M (2011) Constraint-based, homology model of the extracellular domain of the epithelial $\mathrm{Na}+$ channel $\alpha$ subunit reveals a mechanism of channel activation by proteases. $J$ Biol Chem 286:649-660.

Kashlan OB and Kleyman TR (2011) ENaC structure and function in the wake of a resolved structure of a family member. Am J Physiol Renal Physiol 301: F684-F696.

Kellenberger S, Auberson M, Gautschi I, Schneeberger E, and Schild L (2001) Permeability properties of ENaC selectivity filter mutants. $J$ Gen Physiol 118: 679-692.

Kellenberger S, Gautschi I, Pfister Y, and Schild L (2005) Intracellular thiolmediated modulation of epithelial sodium channel activity. J Biol Chem 280: $7739-7747$

Kellenberger S, Gautschi I, and Schild L (1999a) A single point mutation in the pore region of the epithelial $\mathrm{Na}+$ channel changes ion selectivity by modifying molecular sieving. Proc Natl Acad Sci USA 96:4170-4175.
Kellenberger S, Gautschi I, and Schild L (2002) An external site controls closing of the epithelial $\mathrm{Na}^{+}$channel ENaC. J Physiol 543:413-424.

Kellenberger S, Gautschi I, and Schild L (2003) Mutations in the epithelial $\mathrm{Na}^{+}$ channel ENaC outer pore disrupt amiloride block by increasing its dissociation rate. Mol Pharmacol 64:848-856.

Kellenberger S, Hoffmann-Pochon N, Gautschi I, Schneeberger E, and Schild L (1999b) On the molecular basis of ion permeation in the epithelial $\mathrm{Na}^{+}$channel. $J$ Gen Physiol 114:13-30.

Kellenberger S and Schild L (2002) Epithelial sodium channel/degenerin family of ion channels: a variety of functions for a shared structure. Physiol Rev 82:735-767.

Kleyman TR, Carattino MD, and Hughey RP (2009) ENaC at the cutting edge: regulation of epithelial sodium channels by proteases. J Biol Chem 284:20447-20451.

Kleyman TR and Cragoe EJ Jr (1988) Amiloride and its analogs as tools in the study of ion transport. $J$ Membr Biol 105:1-21.

Kleyman TR, Ernst SA, and Coupaye-Gerard B (1994) Arginine vasopressin and forskolin regulate apical cell surface expression of epithelial $\mathrm{Na}+$ channels in $\mathrm{A} 6$ cells. Am J Physiol 266:F506-F511.

Kleyman TR, Zuckerman JB, Middleton P, McNulty KA, Hu B, Su X, An B, Eaton DC, and Smith PR (2001) Cell surface expression and turnover of the alpha-subunit of the epithelial sodium channel. Am J Physiol Renal Physiol 281:F213-F221.

Koefoed-Johnsen V and Ussing HH (1958) The nature of the frog skin potential. Acta Physiol Scand 42:298-308.

Kosari F, Sheng S, Li J, Mak DO, Foskett JK, and Kleyman TR (1998) Subunit stoichiometry of the epithelial sodium channel. J Biol Chem 273:13469-13474.

Kozlenkov A, Lapatsina L, Lewin GR, and Smith ES (2014) Subunit-specific inhibition of acid sensing ion channels by stomatin-like protein 1. J Physiol 592:557-569.

Krauson AJ, Rued AC, and Carattino MD (2013) Independent contribution of extracellular proton binding sites to ASIC1a activation. J Biol Chem 288:34375-34383.

Kreple CJ, Lu Y, Taugher RJ, Schwager-Gutman AL, Du J, Stump M, Wang Y, Ghobbeh A, Fan R, and Cosme CV, et al. (2014) Acid-sensing ion channels contribute to synaptic transmission and inhibit cocaine-evoked plasticity. Nat Neurosci 17:1083-1091.

Krueger B, Schlötzer-Schrehardt U, Haerteis S, Zenkel M, Chankiewitz VE, Amann KU, Kruse FE, and Korbmacher C (2012) Four subunits $(\alpha \beta \gamma \delta)$ of the epithelial sodium channel $(\mathrm{ENaC})$ are expressed in the human eye in various locations. Invest Ophthalmol Vis Sci 53:596-604.

Kuduk SD, Chang RK, Wai JM, Di Marco CN, Cofre V, DiPardo RM, Cook SP, Cato MJ, Jovanovska A, and Urban MO, et al. (2009a) Amidine derived inhibitors of acid-sensing ion channel-3 (ASIC3). Bioorg Med Chem Lett 19:4059-4063.

Kuduk SD, Di Marco CN, Chang RK, Dipardo RM, Cook SP, Cato MJ, Jovanovska A, Urban MO, Leitl M, and Spencer RH, et al. (2009b) Amiloride derived inhibitors of acid-sensing ion channel-3 (ASIC3). Bioorg Med Chem Lett 19:2514-2518.

Lapatsina L, Jira JA, Smith ES, Poole K, Kozlenkov A, Bilbao D, Lewin GR, and Heppenstall PA (2012) Regulation of ASIC channels by a stomatin/STOML3 complex located in a mobile vesicle pool in sensory neurons. Open Biol 2:120096.

Lefêvre CM, Diakov A, Haerteis S, Korbmacher C, Gründer S, and Wiemuth D (2014) Pharmacological and electrophysiological characterization of the human bile acidsensitive ion channel (hBASIC). Pflugers Arch 466:253-263.

Leng T, Lin J, Cottrell JE, and Xiong ZG (2013) Subunit and frequency-dependent inhibition of acid sensing ion channels by local anesthetic tetracaine. Mol Pain 9:27. Leonard AS, Yermolaieva O, Hruska-Hageman A, Askwith CC, Price MP, Wemmie JA, and Welsh MJ (2003) cAMP-dependent protein kinase phosphorylation of the acid-sensing ion channel-1 regulates its binding to the protein interacting with C-kinase-1. Proc Natl Acad Sci USA 100:2029-2034.

$\mathrm{Li}$ T, Yang Y, and Canessa CM (2009) Interaction of the aromatics Tyr-72/Trp-288 in the interface of the extracellular and transmembrane domains is essential for proton gating of acid-sensing ion channels. J Biol Chem 284:4689-4694.

Li T, Yang Y, and Canessa CM (2010a) Asn415 in the beta11-beta12 linker decreases proton-dependent desensitization of ASIC1. J Biol Chem 285:31285-31291.

Li T, Yang Y, and Canessa CM (2010b) Leu85 in the beta1-beta2 linker of ASIC1 slows activation and decreases the apparent proton affinity by stabilizing a closed conformation. J Biol Chem 285:22706-22712.

Li T, Yang Y, and Canessa CM (2011a) Outlines of the pore in open and closed conformations describe the gating mechanism of ASIC1. Nat Commun 2:399.

Li WG, Yu Y, Huang C, Cao H, and Xu TL (2011b) The nonproton ligand sensing domain is required for paradoxical stimulation of ASIC3 channels by amiloride. $J$ Biol Chem 286:42635-42646.

Li WG, Yu Y, Zhang ZD, Cao H, and Xu TL (2010c) ASIC3 channels integrate agmatine and multiple inflammatory signals through the nonproton ligand sensing domain. Mol Pain 6:88.

Liddle GWBT and Coppage WS (1963) A familial renal disorder simulating primary aldosteronism but with negligible aldosterone secretion. Trans Assoc Am Physicians 76:199-213.

Liechti LA, Bernèche $\mathrm{S}$, Bargeton $\mathrm{B}$, Iwaszkiewicz J, Roy $\mathrm{S}$, Michielin $\mathrm{O}$, and Kellenberger S (2010) A combined computational and functional approach identifies new residues involved in $\mathrm{pH}$-dependent gating of ASIC1a. J Biol Chem 285:16315-16329.

Lin J, Chu X, Maysami S, Li M, Si H, Cottrell JE, Simon RP, and Xiong Z (2011) Inhibition of acid sensing ion channel currents by lidocaine in cultured mouse cortical neurons. Anesth Analg 112:977-981.

Lindemann B and Van Driessche W (1977) Sodium-specific membrane channels of frog skin are pores: current fluctuations reveal high turnover. Science 195:292-294 Lingueglia E, Champigny G, Lazdunski M, and Barbry P (1995) Cloning of the amiloride-sensitive FMRFamide peptide-gated sodium channel. Nature 378:730-733.

Lingueglia E, Deval E, and Lazdunski M (2006) FMRFamide-gated sodium channel and ASIC channels: a new class of ionotropic receptors for FMRFamide and related peptides. Peptides 27:1138-1152.

Lingueglia E, de Weille JR, Bassilana F, Heurteaux C, Sakai H, Waldmann R, and Lazdunski M (1997) A modulatory subunit of acid sensing ion channels in brain and dorsal root ganglion cells. J Biol Chem 272:29778-29783. 
Liu YQ, Qiu F, Qiu CY, Cai Q, Zou P, Wu H, and Hu WP (2012) Cannabinoids inhibit acid-sensing ion channel currents in rat dorsal root ganglion neurons. PLoS ONE 7:e45531.

Loffing J, Loffing-Cueni D, Macher A, Hebert SC, Olson B, Knepper MA, Rossier BC, and Kaissling B (2000a) Localization of epithelial sodium channel and aquaporin-2 in rabbit kidney cortex. Am J Physiol Renal Physiol 278:F530-F539.

Loffing J, Pietri L, Aregger F, Bloch-Faure M, Ziegler U, Meneton P, Rossier BC, and Kaissling B (2000b) Differential subcellular localization of ENaC subunits in mouse kidney in response to high- and low-Na diets. Am J Physiol Renal Physiol 279:F252-F258.

Lu M, Echeverri F, Kalabat D, Laita B, Dahan DS, Smith RD, Xu H, Staszewski L, Yamamoto J, and Ling J, et al. (2008) Small molecule activator of the human epithelial sodium channel. J Biol Chem 283:11981-11994.

Lu Y, Ma X, Sabharwal R, Snitsarev V, Morgan D, Rahmouni K, Drummond HA Whiteis CA, Costa V, and Price M, et al. (2009) The ion channel ASIC2 is required for baroreceptor and autonomic control of the circulation. Neuron 64:885-897.

Luszczki JJ, Sawicka KM, Kozinska J, Dudra-Jastrzebska M, and Czuczwar SJ (2009) Amiloride enhances the anticonvulsant action of various antiepileptic drugs in the mouse maximal electroshock seizure model. J Neural Transm 116:57-66.

Lv RJ, He JS, Fu YH, Zhang YQ, Shao XQ, Wu LW, Lu Q, Jin LR, and Liu H (2011) ASIC1a polymorphism is associated with temporal lobe epilepsy. Epilepsy Res $\mathbf{9 6}$ : 74-80.

Lynch IJ, Welch AK, Kohan DE, Cain BD, and Wingo CS (2013) Endothelin-1 inhibits sodium reabsorption by ET(A) and ET(B) receptors in the mouse cortical collecting duct. Am J Physiol Renal Physiol 305:F568-F573.

Mähler J and Persson I (2012) A study of the hydration of the alkali metal ions in aqueous solution. Inorg Chem 51:425-438.

Mall MA, Button B, Johannesson B, Zhou Z, Livraghi A, Caldwell RA, Schubert SC, Schultz C, O'Neal WK, and Pradervand S, et al. (2010) Airway surface liquid volume regulation determines different airway phenotypes in liddle compared with betaENaC-overexpressing mice. J Biol Chem 285:26945-26955.

Malsure S, Wang Q, Charles RP, Sergi C, Perrier R, Christensen BM, Maillard M, Rossier BC, and Hummler E (2014) Colon-specific deletion of epithelial sodium channel causes sodium loss and aldosterone resistance. J Am Soc Nephrol 25:1453-1464.

Mamenko M, Zaika O, Ilatovskaya DV, Staruschenko A, and Pochynyuk O (2012) Angiotensin II increases activity of the epithelial $\mathrm{Na}^{+}$channel $(\mathrm{ENaC})$ in distal nephron additively to aldosterone. $J$ Biol Chem 287:660-671.

Mamet J, Baron A, Lazdunski M, and Voilley N (2002) Proinflammatory mediators, stimulators of sensory neuron excitability via the expression of acid-sensing ion channels. J Neurosci 22:10662-10670.

Mamet J, Lazdunski M, and Voilley N (2003) How nerve growth factor drives physiological and inflammatory expressions of acid-sensing ion channel 3 in sensory neurons. J Biol Chem 278:48907-48913.

Masilamani S, Kim GH, Mitchell C, Wade JB, and Knepper MA (1999) Aldosteronemediated regulation of $\mathrm{ENaC}$ alpha, beta, and gamma subunit proteins in rat kidney. J Clin Invest 104:R19-R23.

Matthesen SK, Larsen T, Vase H, Lauridsen TG, Jensen JM, and Pedersen EB (2013) Effect of amiloride and spironolactone on renal tubular function and central blood pressure in patients with arterial hypertension during baseline conditions and after furosemide: a double-blinded, randomized, placebo-controlled crossover trial. Clin Exp Hypertens 35:313-324.

Mauro T, Guitard M, Behne M, Oda Y, Crumrine D, Komuves L, Rassner U, Elias $\mathrm{PM}$, and Hummler E (2002) The ENaC channel is required for normal epidermal differentiation. J Invest Dermatol 118:589-594.

Mazzuca M, Heurteaux C, Alloui A, Diochot S, Baron A, Voilley N, Blondeau N, Escoubas P, Gélot A, and Cupo A, et al. (2007) A tarantula peptide against pain via ASIC1a channels and opioid mechanisms. Nat Neurosci 10:943-945.

Mogil JS, Breese NM, Witty M-F, Ritchie J, Rainville M-L, Ase A, Abbadi N, Stucky CL, and Séguéla P (2005) Transgenic expression of a dominant-negative ASIC3 subunit leads to increased sensitivity to mechanical and inflammatory stimuli. $J$ Neurosci 25:9893-9901.

Neaga E, Amuzescu B, Dinu C, Macri B, Pena F, and Flonta M-L (2005) Extracellular trypsin increases ASIC1a selectivity for monovalent versus divalent cations. $J$ Neurosci Methods 144:241-248.

Neelands TR, Zhang XF, McDonald H, and Puttfarcken P (2010) Differential effects of temperature on acid-activated currents mediated by TRPV1 and ASIC channels in rat dorsal root ganglion neurons. Brain Res 1329:55-66.

Nesterov V, Dahlmann A, Krueger B, Bertog M, Loffing J, and Korbmacher C (2012) Aldosterone-dependent and -independent regulation of the epithelial sodium channel $(\mathrm{ENaC})$ in mouse distal nephron. Am J Physiol Renal Physiol 303:F1289-F1299.

N'Gouemo P (2008) Amiloride delays the onset of pilocarpine-induced seizures in rats. Brain Res 1222:230-232.

Osmakov DI, Kozlov SA, Andreev YA, Koshelev SG, Sanamyan NP, Sanamyan KE, Dyachenko IA, Bondarenko DA, Murashev AN, and Mineev KS, et al. (2013) Sea anemone peptide with uncommon $\beta$-hairpin structure inhibits acid-sensing ion channel 3 (ASIC3) and reveals analgesic activity. J Biol Chem 288:23116-23127.

Page AJ, Brierley SM, Martin CM, Price MP, Symonds E, Butler R, Wemmie JA, and Blackshaw LA (2005) Different contributions of ASIC channels 1a, 2, and 3 in gastrointestinal mechanosensory function. Gut 54:1408-1415.

Palmer LG (1984) Voltage-dependent block by amiloride and other monovalent cations of apical Na channels in the toad urinary bladder. J Membr Biol 80:153-165.

Palmer LG and Andersen OS (1989) Interactions of amiloride and small monovalent cations with the epithelial sodium channel. Inferences about the nature of the channel pore. Biophys J 55:779-787.

Palmer LG and Andersen OS (2008) The two-membrane model of epithelial transport: Koefoed-Johnsen and Ussing (1958). J Gen Physiol 132:607-612.

Palmer LG and Frindt G (1986) Amiloride-sensitive Na channels from the apical membrane of the rat cortical collecting tubule. Proc Natl Acad Sci USA 83:2767-2770.

Palmer LG and Frindt G (1996) Gating of Na channels in the rat cortical collecting tubule: effects of voltage and membrane stretch. J Gen Physiol 107:35-45.
Palmer LG and Frindt G (2007) $\mathrm{Na}^{+}$and $\mathrm{K}^{+}$transport by the renal connecting tubule. Curr Opin Nephrol Hypertens 16:477-483.

Palmer LG, Patel A, and Frindt G (2012) Regulation and dysregulation of epithelial $\mathrm{Na}^{+}$channels. Clin Exp Nephrol 16:35-43.

Passero CJ, Okumura S, and Carattino MD (2009) Conformational changes associated with proton-dependent gating of ASIC1a. J Biol Chem 284:36473-36481.

Paukert M, Babini E, Pusch M, and Gründer S (2004) Identification of the $\mathrm{Ca}^{2+}$ blocking site of acid-sensing ion channel (ASIC) 1: implications for channel gating. $J$ Gen Physiol 124:383-394.

Paukert M, Chen X, Polleichtner G, Schindelin H, and Gründer S (2008) Candidate amino acids involved in $\mathrm{H}^{+}$gating of acid-sensing ion channel 1a. $J$ Biol Chem 283.572-581.

Peigneur S, Béress L, Möller C, Marí F, Forssmann WG, and Tytgat J (2012) A natural point mutation changes both target selectivity and mechanism of action of sea anemone toxins. FASEB J 26:5141-5151.

Petroff E, Snitsarev V, Gong H, and Abboud FM (2012) Acid sensing ion channels regulate neuronal excitability by inhibiting BK potassium channels. Biochem Biophys Res Commun 426:511-515.

Petroff EY, Price MP, Snitsarev V, Gong H, Korovkina V, Abboud FM, and Welsh MJ (2008) Acid-sensing ion channels interact with and inhibit BK $\mathrm{K}^{+}$channels. Proc Natl Acad Sci USA 105:3140-3144.

Pettersen EF, Goddard TD, Huang CC, Couch GS, Greenblatt DM, Meng EC, and Ferrin TE (2004) UCSF Chimera-a visualization system for exploratory research and analysis. J Comput Chem 25:1605-1612.

Pfister Y, Gautschi I, Takeda AN, van Bemmelen M, Kellenberger S, and Schild L (2006) A gating mutation in the internal pore of ASIC1a. J Biol Chem 281:11787-11791.

Pidoplichko VI, Aroniadou-Anderjaska V, Prager EM, Figueiredo TH, AlmeidaSuhett CP, Miller SL, and Braga MF (2014) ASIC1a activation enhances inhibition in the basolateral amygdala and reduces anxiety. $J$ Neurosci 34:3130-3141.

Pignataro G, Simon RP, and Xiong ZG (2007) Prolonged activation of ASIC1a and the time window for neuroprotection in cerebral ischaemia. Brain 130:151-158.

Poirot O, Berta T, Decosterd I, and Kellenberger S (2006) Distinct ASIC currents are expressed in rat putative nociceptors and are modulated by nerve injury. J Physiol 576:215-234.

Poirot O, Vukicevic M, Boesch A, and Kellenberger S (2004) Selective regulation of acid-sensing ion channel 1 by serine proteases. J Biol Chem 279:38448-38457.

Pouly D, Debonneville A, Ruffieux-Daidié D, Maillard M, Abriel H, Loffing J, and Staub $\mathrm{O}$ (2013) Mice carrying ubiquitin-specific protease 2 (Usp2) gene inactivation maintain normal sodium balance and blood pressure. Am J Physiol Renal Physiol 305:F21-F30. Pradervand S, Vandewalle A, Bens M, Gautschi I, Loffing J, Hummler E, Schild L, and Rossier BC (2003) Dysfunction of the epithelial sodium channel expressed in the kidney of a mouse model for Liddle syndrome. $J$ Am Soc Nephrol 14:2219-2228.

Price MP, Thompson RJ, Eshcol JO, Wemmie JA, and Benson CJ (2004) Stomatin modulates gating of acid-sensing ion channels. J Biol Chem 279:53886-53891.

Qiu F, Qiu CY, Liu YQ, Wu D, Li JD, and Hu WP (2012) Potentiation of acid-sensing ion channel activity by the activation of $5-\mathrm{HT}_{2}$ receptors in rat dorsal root ganglion neurons. Neuropharmacology 63:494-500.

Reddy MM, Light MJ, and Quinton PM (1999) Activation of the epithelial $\mathrm{Na}^{+}$ channel (ENaC) requires CFTR Cl- channel function. Nature 402:301-304

Renard S, Lingueglia E, Voilley N, Lazdunski M, and Barbry P (1994) Biochemical analysis of the membrane topology of the amiloride-sensitive $\mathrm{Na}^{+}$channel. $\mathrm{J} \mathrm{Biol}$ Chem 269:12981-12986.

Riepe FG (2009) Clinical and molecular features of type 1 pseudohypoaldosteronism. Horm Res 72:1-9.

Rodríguez AA, Salceda E, Garateix AG, Zaharenko AJ, Peigneur S, López O, Pons T, Richardson M, Díaz M, and Hernández Y, et al. (2014) A novel sea anemone peptide that inhibits acid-sensing ion channels. Peptides 53:3-12.

Ronzaud C, Loffing-Cueni D, Hausel P, Debonneville A, Malsure SR, Fowler-Jaeger N, Boase NA, Perrier R, Maillard M, and Yang B, et al. (2013) Renal tubular NEDD4-2 deficiency causes NCC-mediated salt-dependent hypertension. J Clin Invest 123:657-665.

Rossier BC (2014) Epithelial sodium channel (ENaC) and the control of blood pressure. Curr Opin Pharmacol 15:33-46.

Rossier BC and Stutts MJ (2009) Activation of the epithelial sodium channel (ENaC) by serine proteases. Annu Rev Physiol 71:361-379.

Rotin D (2000) Regulation of the epithelial sodium channel (ENaC) by accessory proteins. Curr Opin Nephrol Hypertens 9:529-534.

Roy S, Boiteux C, Alijevic O, Liang C, Bernèche S, and Kellenberger S (2013) Molecular determinants of desensitization in an ENaC/degenerin channel. FASEB $J$ 27:5034-5045.

Rubera I, Loffing J, Palmer LG, Frindt G, Fowler-Jaeger N, Sauter D, Carroll T, McMahon A, Hummler E, and Rossier BC (2003) Collecting duct-specific gene in activation of alphaENaC in the mouse kidney does not impair sodium and potassium balance. J Clin Invest 112:554-565.

Saez NJ, Mobli M, Bieri M, Chassagnon IR, Malde AK, Gamsjaeger R, Mark AE, Gooley PR, Rash LD, and King GF (2011) A dynamic pharmacophore drives the interaction between Psalmotoxin-1 and the putative drug target acid-sensing ion channel 1a. Mol Pharmacol 80:796-808.

Sakai H, Lingueglia E, Champigny G, Mattei MG, and Lazdunski M (1999) Cloning and functional expression of a novel degenerin-like $\mathrm{Na}^{+}$channel gene in mammals. J Physiol 519:323-333.

Salinas M, Besson T, Delettre Q, Diochot S, Boulakirba S, Douguet D, and Lingueglia $\mathrm{E}$ (2014) Binding site and inhibitory mechanism of the mambalgin-2 pain-relieving peptide on acid-sensing ion channel 1a. J Biol Chem 289:13363-13373.

Salinas M, Rash LD, Baron A, Lambeau G, Escoubas P, and Lazdunski M (2006) The receptor site of the spider toxin PcTx1 on the proton-gated cation channel ASIC1a. J Physiol 570:339-354

Samways DS, Harkins AB, and Egan TM (2009) Native and recombinant ASIC1a receptors conduct negligible $\mathrm{Ca}^{2+}$ entry. Cell Calcium 45:319-325.

San-Cristobal P, Pacheco-Alvarez D, Richardson C, Ring AM, Vazquez N, Rafiqi FH, Chari D, Kahle KT, Leng Q, and Bobadilla NA, et al. (2009) Angiotensin II 
signaling increases activity of the renal Na-Cl cotransporter through a WNK4SPAK-dependent pathway. Proc Natl Acad Sci USA 106:4384-4389.

Saugstad JA, Roberts JA, Dong J, Zeitouni S, and Evans RJ (2004) Analysis of the membrane topology of the acid-sensing ion channel 2a. J Biol Chem 279 $55514-55519$.

Schaefer L, Sakai H, Mattei M, Lazdunski M, and Lingueglia E (2000) Molecular cloning, functional expression and chromosomal localization of an amiloridesensitive $\mathrm{Na}^{+}$) channel from human small intestine. FEBS Lett 471:205-210.

Schafer JA and Troutman SL (1990) cAMP mediates the increase in apical membrane $\mathrm{Na}^{+}$conductance produced in rat CCD by vasopressin. Am J Physiol 259: F823-F831.

Schild L, Canessa CM, Shimkets RA, Gautschi I, Lifton RP, and Rossier BC (1995) A mutation in the epithelial sodium channel causing Liddle disease increases channel activity in the Xenopus laevis oocyte expression system. Proc Natl Acad Sci USA 92:5699-5703.

Schild L, Schneeberger E, Gautschi I, and Firsov D (1997) Identification of amino acid residues in the alpha, beta, and gamma subunits of the epithelial sodium channe $(\mathrm{ENaC})$ involved in amiloride block and ion permeation. J Gen Physiol 109:15-26.

Schnizler MK, Schnizler K, Zha XM, Hall DD, Wemmie JA, Hell JW, and Welsh MJ (2009) The cytoskeletal protein alpha-actinin regulates acid-sensing ion channel 1a through a C-terminal interaction. J Biol Chem 284:2697-2705.

Schoenberger M and Althaus M (2013) Novel small molecule epithelial sodium channel inhibitors as potential therapeutics in cystic fibrosis - a patent evaluation. Expert Opin Ther Pat 23:1383-1389.

Schroeder CI, Rash LD, Vila-Farrés X, Rosengren KJ, Mobli M, King GF, Alewood PF, Craik DJ, and Durek T (2014) Chemical synthesis, 3D struc ture, and ASIC binding site of the toxin mambalgin-2. Angew Chem Int Ed Engl 53:1017-1020.

Schurr A (2002) Lactate, glucose and energy metabolism in the ischemic brain (Review). Review Int J Mol Med 10:131-136.

Shabbir W, Scherbaum-Hazemi P, Tzotzos S, Fischer B, Fischer H, Pietschmann H, Lucas R, and Lemmens-Gruber R (2013) Mechanism of action of novel lung edema therapeutic AP301 by activation of the epithelial sodium channel. Mol Pharmacol 84:899-910.

Sheng S, Carattino MD, Bruns JB, Hughey RP, and Kleyman TR (2006) Furin cleavage activates the epithelial $\mathrm{Na}+$ channel by relieving $\mathrm{Na}^{+}$self-inhibition. $\mathrm{Am}$ J Physiol Renal Physiol 290:F1488-F1496.

Sheng S, McNulty KA, Harvey JM, and Kleyman TR (2001) Second transmembrane domains of ENaC subunits contribute to ion permeation and selectivity. $J$ Biol Chem 276:44091-44098.

Sheng S, Perry CJ, Kashlan OB, and Kleyman TR (2005) Side chain orientation of residues lining the selectivity filter of epithelial $\mathrm{Na}^{+}$channels. $J$ Biol Chem 280 : $8513-8522$.

Sheng S, Li J, McNulty KA, Avery D, and Kleyman TR (2000) Characterization of the selectivity filter of the epithelial sodium channel. J Biol Chem 275:8572-8581.

Sherwood T, Franke R, Conneely S, Joyner J, Arumugan P, and Askwith C (2009) Identification of protein domains that control proton and calcium sensitivity of ASIC1a. J Biol Chem 284:27899-27907.

Sherwood TW and Askwith CC (2008) Endogenous arginine-phenylalanine-amiderelated peptides alter steady-state desensitization of ASIC1a. J Biol Chem $\mathbf{2 8 3}$ $1818-1830$.

Sherwood TW and Askwith CC (2009) Dynorphin opioid peptides enhance acidsensing ion channel $1 \mathrm{a}$ activity and acidosis-induced neuronal death. $J$ Neurosci 29:14371-14380.

Sherwood TW, Frey EN, and Askwith CC (2012) Structure and activity of the acidsensing ion channels. Am J Physiol Cell Physiol 303:C699-C710.

Sherwood TW, Lee KG, Gormley MG, and Askwith CC (2011) Heteromeric acidsensing ion channels (ASICs) composed of ASIC2b and ASIC1a display novel channel properties and contribute to acidosis-induced neuronal death. $J$ Neurosci 31:9723-9734.

Shimkets RA, Lifton RP, and Canessa CM (1997) The activity of the epithelial sodium channel is regulated by clathrin-mediated endocytosis. $J$ Biol Chem 272 25537-25541.

Shimkets RA, Warnock DG, Bositis CM, Nelson-Williams C, Hansson JH, Schambelan M, Gill JR Jr, Ulick S, Milora RV, and Findling JW, et al. (1994) Liddle's syndrome: heritable human hypertension caused by mutations in the beta subunit of the epithelial sodium channel. Cell 79:407-414.

Sluka KA, Winter OC, and Wemmie JA (2009) Acid-sensing ion channels: A new target for pain and CNS diseases. Curr Opin Drug Discov Devel 12:693-704.

Smith ES, Cadiou H, and McNaughton PA (2007) Arachidonic acid potentiates acidsensing ion channels in rat sensory neurons by a direct action. Neuroscience $\mathbf{1 4 5}$ $686-698$

Smoller JW, Gallagher PJ, Duncan LE, McGrath LM, Haddad SA, Holmes AJ, Wolf AB, Hilker S, Block SR, and Weill S, et al. (2014) The human ortholog of acidsensing ion channel gene ASIC1a is associated with panic disorder and amygdala structure and function. Biol Psychiatry DOI: 10.1016/j.biopsych.2013.12.018.

Snyder PM, Bucher DB, and Olson DR (2000) Gating induces a conformational change in the outer vestibule of ENaC. J Gen Physiol 116:781-790.

Snyder PM, McDonald FJ, Stokes JB, and Welsh MJ (1994) Membrane topology of the amiloride-sensitive epithelial sodium channel. J Biol Chem 269:24379-24383.

Snyder PM, Olson DR, and Bucher DB (1999) A pore segment in DEG/ENaC $\mathrm{Na}^{+}$) channels. J Biol Chem 274:28484-28490.

Snyder PM, Olson DR, Kabra R, Zhou R, and Steines JC (2004) cAMP and serum and glucocorticoid-inducible kinase (SGK) regulate the epithelial $\mathrm{Na}(+)$ channel through convergent phosphorylation of Nedd4-2. J Biol Chem 279:45753-45758.

Soundararajan R, Wang J, Melters D, and Pearce D (2007) Differential activities of glucocorticoid-induced leucine zipper protein isoforms. $J$ Biol Chem 282:36303-36313.

Springauf A, Bresenitz P, and Gründer S (2011) The interaction between two extracellular linker regions controls sustained opening of acid-sensing ion channel 1. $J$ Biol Chem 286:24374-24384.
Stahler F, Riedel K, Demgensky S, Neumann K, Dunkel A, Taubert A, Raab B, Behrens M, Raguse JD, and Hofmann T, et al. (2008) A role of the epithelial sodium channel in human salt taste transduction? Chemosens Percept 1:78-90.

Staub O, Abriel H, Plant P, Ishikawa T, Kanelis V, Saleki R, Horisberger JD, Schild L, and Rotin D (2000) Regulation of the epithelial $\mathrm{Na}^{+}$channel by Nedd4 and ubiquitination. Kidney Int 57:809-815.

Stuart D, Rees S, Woodward SK, Koesters R, Strait KA, and Kohan DE (2012) Disruption of the endothelin A receptor in the nephron causes mild fluid volume expansion. BMC Nephrol 13:166.

Studer RA, Person E, Robinson-Rechavi M, and Rossier BC (2011) Evolution of the epithelial sodium channel and the sodium pump as limiting factors of aldosterone action on sodium transport. Physiol Genomics 43:844-854.

Su J, Tang Y, Liu L, Zhou H, and Dong Q (2011) Regulation of acid-sensing ion channel 1a function by tissue kallikrein may be through channel cleavage. Neurosci Lett 490:46-51.

Suarez PE, Rodriguez EG, Soundararajan R, Mérillat AM, Stehle JC, Rotman S, Roger T, Voirol MJ, Wang J, and Gross O, et al. (2012) The glucocorticoid-induced leucine zipper (gilz/Tsc22d3-2) gene locus plays a crucial role in male fertility. $M o l$ Endocrinol 26:1000-1013.

Sun P, Yue P, and Wang WH (2012) Angiotensin II stimulates epithelial sodium channels in the cortical collecting duct of the rat kidney. Am J Physiol Renal Physiol 302:F679-F687.

Sutherland SP, Benson CJ, Adelman JP, and McCleskey EW (2001) Acid-sensing ion channel 3 matches the acid-gated current in cardiac ischemia-sensing neurons. Proc Natl Acad Sci USA 98:711-716.

Takeda AN, Gautschi I, van Bemmelen MX, and Schild L (2007) Cadmium trapping in an epithelial sodium channel pore mutant. J Biol Chem 282:31928-31936.

Ugawa S, Ishida Y, Ueda T, Inoue K, Nagao M, and Shimada S (2007) Nafamostat mesilate reversibly blocks acid-sensing ion channel currents. Biochem Biophys Res Commun 363:203-208.

Ugawa S, Ueda T, Ishida Y, Nishigaki M, Shibata Y, and Shimada S (2002) Amiloride-blockable acid-sensing ion channels are leading acid sensors expressed in human nociceptors. $J$ Clin Invest 110:1185-1190.

Vallet V, Chraibi A, Gaeggeler HP, Horisberger JD, and Rossier BC (1997) An epithelial serine protease activates the amiloride-sensitive sodium channel Nature 389:607-610.

Vergo S, Craner MJ, Etzensperger R, Attfield K, Friese MA, Newcombe J, Esiri M, and Fugger L (2011) Acid-sensing ion channel 1 is involved in both axonal injury and demyelination in multiple sclerosis and its animal model. Brain 134:571-584.

Voilley N, de Weille J, Mamet J, and Lazdunski M (2001) Nonsteroid antiinflammatory drugs inhibit both the activity and the inflammation-induced expression of acid-sensing ion channels in nociceptors. J Neurosci 21:8026-8033.

Vuagniaux G, Vallet V, Jaeger NF, Hummler E, and Rossier BC (2002) Synergistic activation of $\mathrm{ENaC}$ by three membrane-bound channel-activating serine proteases mCAP1, mCAP2, and mCAP3) and serum- and glucocorticoid-regulated kinase (Sgk1) in Xenopus Oocytes. J Gen Physiol 120:191-201.

Vuagniaux G, Vallet V, Jaeger NF, Pfister C, Bens M, Farman N, Courtois-Coutry N, Vandewalle A, Rossier BC, and Hummler E (2000) Activation of the amiloridesensitive epithelial sodium channel by the serine protease mCAP1 expressed in a mouse cortical collecting duct cell line. J Am Soc Nephrol 11:828-834.

Vukicevic M and Kellenberger S (2004) Modulatory effects of acid-sensing ion channels on action potential generation in hippocampal neurons. Am J Physiol Cell Physiol 287:C682-C690.

Vukicevic M, Weder G, Boillat A, Boesch A, and Kellenberger S (2006) Trypsin cleaves acid-sensing ion channel 1a in a domain that is critical for channel gating. $J$ Biol Chem 281:714-722.

Waldmann R, Bassilana F, de Weille J, Champigny G, Heurteaux C, and Lazdunski M (1997a) Molecular cloning of a non-inactivating proton-gated $\mathrm{Na}^{+}$channel specific for sensory neurons. J Biol Chem 272:20975-20978.

Waldmann R, Champigny G, Bassilana F, Heurteaux C, and Lazdunski M (1997b) A proton-gated cation channel involved in acid-sensing. Nature 386:173-177.

Waldmann R, Champigny G, Bassilana F, Voilley N, and Lazdunski M (1995) Molecular cloning and functional expression of a novel amiloride-sensitive $\mathrm{Na}^{+}$ channel. J Biol Chem 270:27411-27414.

Wang WZ, Chu XP, Li MH, Seeds J, Simon RP, and Xiong ZG (2006) Modulation of acid-sensing ion channel currents, acid-induced increase of intracellular $\mathrm{Ca}^{2+}$ and acidosis-mediated neuronal injury by intracellular pH. J Biol Chem 281 . 29369-29378.

Wang X, Li WG, Yu Y, Xiao X, Cheng J, Zeng WZ, Peng Z, Xi Zhu M, and Xu TL (2013) Serotonin facilitates peripheral pain sensitivity in a manner that depends on the nonproton ligand sensing domain of ASIC3 channel. J Neurosci 33:4265-4279.

Warner TD, Giuliano F, Vojnovic I, Bukasa A, Mitchell JA, and Vane JR (1999) Nonsteroid drug selectivities for cyclo-oxygenase-1 rather than cyclo-oxygenase-2 are associated with human gastrointestinal toxicity: a full in vitro analysis. Proc Natl Acad Sci USA 96:7563-7568.

Wemmie JA, Askwith CC, Lamani E, Cassell MD, Freeman JH Jr, and Welsh MJ (2003) Acid-sensing ion channel 1 is localized in brain regions with high synaptic density and contributes to fear conditioning. J Neurosci 23:5496-5502.

Wemmie JA, Chen J, Askwith CC, Hruska-Hageman AM, Price MP, Nolan BC, Yoder PG, Lamani E, Hoshi T, and Freeman JH Jr, et al. (2002) The acid-activated ion channel ASIC contributes to synaptic plasticity, learning, and memory. Neuron 34:463-477.

Wemmie JA, Coryell MW, Askwith CC, Lamani E, Leonard AS, Sigmund CD, and Welsh MJ (2004) Overexpression of acid-sensing ion channel 1a in transgenic mice increases acquired fear-related behavior. Proc Natl Acad Sci USA 101:3621-3626.

Wemmie JA, Price MP, and Welsh MJ (2006) Acid-sensing ion channels: advances, questions and therapeutic opportunities. Trends Neurosci 29:578-586.

Wemmie JA, Taugher RJ, and Kreple CJ (2013) Acid-sensing ion channels in pain and disease. Nat Rev Neurosci 14:461-471.

Wiemuth D and Gründer S (2010) A single amino acid tunes $\mathrm{Ca}^{2+}$ inhibition of brain liver intestine $\mathrm{Na}^{+}$channel (BLINaC). J Biol Chem 285:30404-30410. 
Wiemuth D and Gründer S (2011) The pharmacological profile of brain liver intestine $\mathrm{Na}^{+}$channel: inhibition by diarylamidines and activation by fenamates. $\mathrm{Mol}$ Pharmacol 80:911-919.

Wiemuth D, Sahin H, Falkenburger BH, Lefèvre CM, Wasmuth HE, and Gründer S (2012) BASIC - a bile acid-sensitive ion channel highly expressed in bile ducts. FASEB J 26:4122-4130.

Wolkenberg SE, Zhao Z, Mulhearn JJ, Harrison ST, Sanders JM, Cato MJ, Jovanovska A, Panigel J, Cook SP, and Henze DA, et al. (2011) High concentration electrophysiologybased fragment screen: discovery of novel acid-sensing ion channel 3 (ASIC3) inhibitors. Bioorg Med Chem Lett 21:2646-2649.

Wu LJ, Duan B, Mei YD, Gao J, Chen JG, Zhuo M, Xu L, Wu M, and Xu TL (2004) Characterization of acid-sensing ion channels in dorsal horn neurons of rat spinal cord. J Biol Chem 279:43716-43724.

Wu PY, Huang YY, Chen CC, Hsu TT, Lin YC, Weng JY, Chien TC, Cheng IH, and Lien CC (2013) Acid-sensing ion channel-1a is not required for normal hippocampal LTP and spatial memory. $J$ Neurosci 33:1828-1832.

Xiong ZG, Zhu XM, Chu XP, Minami M, Hey J, Wei WL, MacDonald JF, Wemmie JA Price MP, and Welsh MJ, et al. (2004) Neuroprotection in ischemia: blocking calcium-permeable acid-sensing ion channels. Cell 118:687-698.

Yagi J, Wenk HN, Naves LA, and McCleskey EW (2006) Sustained currents through ASIC3 ion channels at the modest $\mathrm{pH}$ changes that occur during myocardial ischemia. Circ Res 99:501-509.

Yan J and Dussor G (2014) Ion channels and migraine. Headache 54:619-639.

Yan J, Edelmayer RM, Wei X, De Felice M, Porreca F, and Dussor G (2011) Dural afferents express acid-sensing ion channels: a role for decreased meningeal $\mathrm{pH}$ in migraine headache. Pain 152:106-113.
Yang H, Yu Y, Li WG, Yu F, Cao H, Xu TL, and Jiang H (2009) Inherent dynamics of the acid-sensing ion channel 1 correlates with the gating mechanism. PLoS Biol 7:e1000151.

Yang Y, Yu Y, Cheng J, Liu Y, Liu DS, Wang J, Zhu MX, Wang R, and Xu TL (2012) Highly conserved salt bridge stabilizes rigid signal patch at extracellular loop critical for surface expression of acid-sensing ion channels. J Biol Chem 287:14443-14455.

Yu Y, Chen Z, Li WG, Cao H, Feng EG, Yu F, Liu H, Jiang H, and Xu TL (2010) A nonproton ligand sensor in the acid-sensing ion channel. Neuron 68:61-72.

Yu Y, Li WG, Chen Z, Cao H, Yang H, Jiang H, and Xu TL (2011) Atomic level characterization of the nonproton ligand-sensing domain of ASIC3 channels. J Biol Chem 286:24996-25006.

Zha XM, Costa V, Harding AM, Reznikov L, Benson CJ and Welsh MJ (2009) ASIC2 subunits target acid-sensing ion channels to the synapse via an association with PSD-95. J Neurosci 29:8438-8446.

Zha XM, Wemmie JA, Green SH, and Welsh MJ (2006) Acid-sensing ion channel 1a is a postsynaptic proton receptor that affects the density of dendritic spines. Proc Natl Acad Sci USA 103:16556-16561.

Zhang P, Sigworth FJ, and Canessa CM (2006) Gating of acid-sensitive ion channel-1: release of $\mathrm{Ca}^{2+}$ block vs. allosteric mechanism. J Gen Physiol 127: 109-117.

Ziemann AE, Allen JE, Dahdaleh NS, Drebot II, Coryell MW, Wunsch AM, Lynch CM, Faraci FM, Howard MA 3rd, and Welsh MJ, et al. (2009) The amygdala is a chemosensor that detects carbon dioxide and acidosis to elicit fear behavior. Cell 139:1012-1021.

Ziemann AE, Schnizler MK, Albert GW, Severson MA, Howard MA 3rd, Welsh MJ, and Wemmie JA (2008) Seizure termination by acidosis depends on ASIC1a. Nat Neurosci 11:816-822. 